\title{
The aporhoeadane alkaloids
}

\author{
Michael S. Leonard \\ Department of Chemistry, Washington \& Jefferson College, 60 South Lincoln Street, \\ Washington, PA 15301, USA \\ E-mail: mleonard@washjeff.edu
}

DOI: http://dx.doi.org/10.3998/ark.5550190.0014.101

\begin{abstract}
The aporhoeadane alkaloids, exemplified by the natural products chilenine and lennoxamine, have received significant attention from the synthetic community over the course of nearly 50 years. This review details the approaches to these heterocycles, as well as their major reactions.
\end{abstract}

Keywords: Isoindolobenzazepines, chilenine, lennoxamine, Schöpf's base VI, chilenamine

\section{Table of Contents}

1. Introduction

2. Late-stage Synthesis of the Isoindole

2.1. Formation of the N7-C8 bond

2.2. Formation of the N7-C8 and C8-C8a bonds

2.3. Formation of the $\mathrm{C} 12 \mathrm{a}-\mathrm{C} 13$ bond

3. Late-stage Synthesis of the Benzazepine

3.1. Formation of the $\mathrm{C} 14-\mathrm{C} 14 \mathrm{a}$ bond

3.2. Formation of the C6-N7 bond

3.3. Formation of the $\mathrm{C} 4 \mathrm{a}-\mathrm{C} 5$ bond

3.4. Formation of the $\mathrm{C} 13-\mathrm{C} 14$ bond

4. Concurrent Synthesis of the Seven/Five Ring System

4.1. Formation of the N7-C13 bond

4.2. Formation of the N7-C13 and C13-C14 bonds

4.3. Formation of the $\mathrm{N} 7-\mathrm{C} 8$ and $\mathrm{C} 13-\mathrm{C} 14$ bonds

4.4. Formation of the N7-C8, N7-C13, and C13-C14 bonds

4.5. Formation of the $\mathrm{C} 14 \mathrm{a}-\mathrm{C} 14$ bond

4.6. Formation of the $\mathrm{C} 12 \mathrm{a}-\mathrm{C} 13$ and $\mathrm{C} 14-\mathrm{C} 14 \mathrm{a}$ bonds

4.7. Formation of the N7-C13, C12a-C13, and C14-C14a bonds

5. Reactions of Aporhoeadanes 
5.1. Reactions in base

5.2. Reactions in acid

5.3. Reactions with reducing agents

5.4. Hofmann elimination

6. Conclusions

7. References

\section{Introduction}

The substituted isoindolo[2,3-c][3]benzazepine shown in Figure 1 has been termed aporhoeadane, suggesting structural similarity to the rhoeadane and papaverrubine alkaloids. ${ }^{1}$

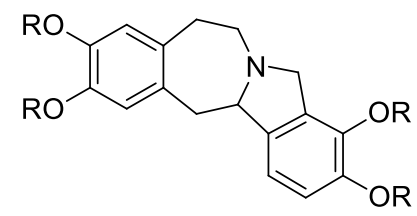

Figure 1. The aporhoeadane core.

This structural similarity is highlighted by the fact that norisorhoeadine, also known as papaverrubine A (1, Scheme 1), is converted into the isoindolobenzazepine $\mathbf{4}$ upon treatment with dilute hydrochloric acid. Fragmentation of the acetal leads to aldehyde $\mathbf{2}$, which cyclizes and dehydrates to form iminium ion $\mathbf{3}$. This iminium ion can be reduced to provide aporhoeadane 4, which oxidizes freely back to 3 upon exposure to air. ${ }^{2}$

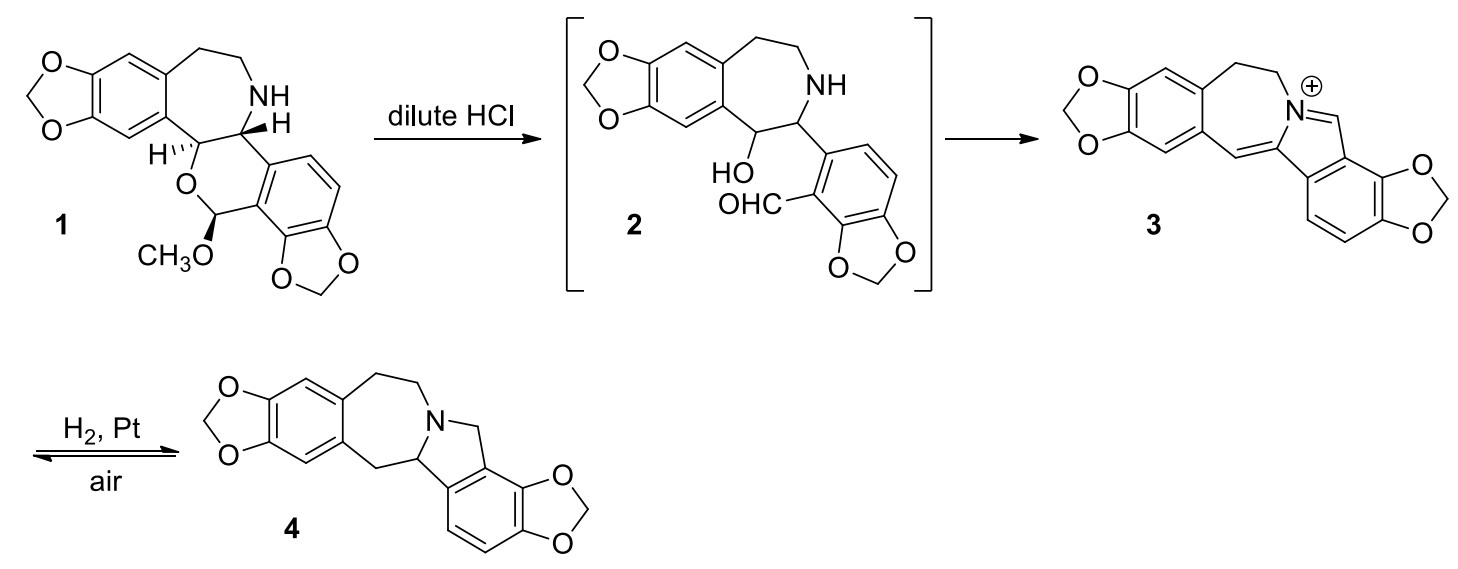

Scheme 1. Conversion of papaverrubine A to an aporhoeadane. 
Since the intermediate iminium ion is intensely red, this reaction had been used to identify opium samples, which commonly contain papaverrubines. ${ }^{1}$

$( \pm$ )-Chilenine (5, Figure 2), isolated from Chilean barberries (Berberis empetrifolia Lam), was the first example of the aporhoeadane skeleton appearing in a natural product. ${ }^{3}$ Various numbering schemes have been used for structures of this type. The numbering system designated by Shamma and co-workers, who isolated this natural product, will be used in this review.

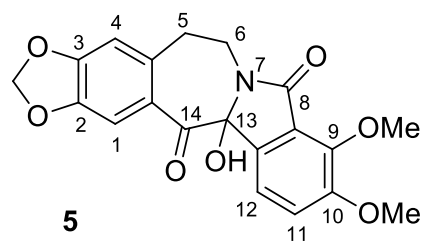

Figure 2. Chilenine.

Chilenine exhibits weak cytotoxic activity against breast, lung, colon, and prostate cancer cells, as well as epidermoid carcinoma of the nasopharynx, with $\mathrm{IC}_{50}$ values in the $\mu \mathrm{M}$ range. Chilenine also demonstrated weak antimalarial activity. ${ }^{4}$

Biosynthetically, chilenine is believed to originate from berberine (6) via oxidation to a compound that has been termed prechilenine (7) and subsequent base-catalyzed rearrangement of the six/six ring system to a seven/five system (Scheme 2$){ }^{3}$

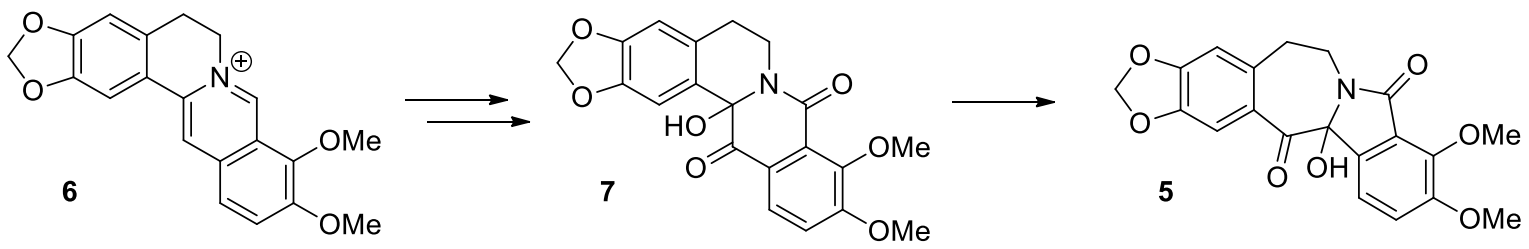

Scheme 2. Proposed biosynthesis of chilenine from berberine via prechilenine.

Prechilenine was isolated as its $O$-methyl ether from Berberis darwinii Hook. ${ }^{5}$ The $O$-methyl ether is believed to originate from prechilenine, particularly since this transformation happens readily in vitro (vide infra). ${ }^{6}$

Several analogues have been isolated from plants of the family Berberidaceae. These include analogues having different ring sizes, such as: the nor analogue $( \pm)$-nuevamine $(\mathbf{8}$, from Berberis darwinii), the first known isoindoloisoquinoline natural product, ${ }^{7}$ the homologue $( \pm)$ puntarenine (9, from Berberis empetrifolia, as well as from Xanthorhiza simplicissima Marsha.), ${ }^{8,9}$ and the isoindolobenzazocine ( \pm )-magallanesine (10, from Berberis darwinii) ${ }^{10}$ (Figure 3). 


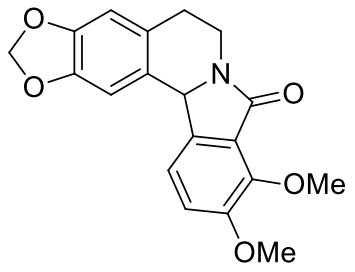

nuevamine (8)

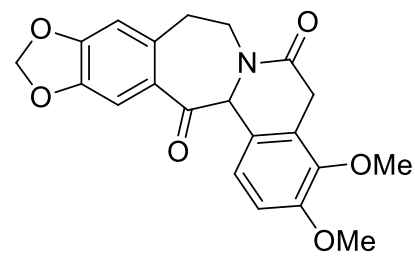

puntarenine (9)

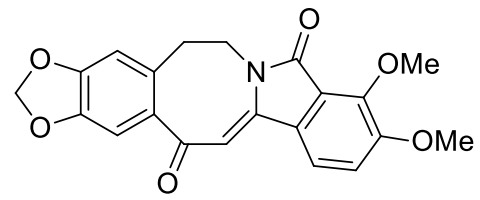

magallanesine (10)

Figure 3. Analogues of chilenine having different ring sizes.

The diversity of ring systems illustrates that "the family Berberidaceae possesses a unique propensity for expansion as well as contraction of nitrogenous rings." ${ }^{10}$ Interestingly, saulatine, a congener of puntarenine in which the methylenedioxy bridge is replaced by two methoxy groups, was isolated from Abuta bullata Moldenke (family Menispermaceae). ${ }^{11}$ A similar analogue of chilenine is described shortly.

Additionally, a number of analogues bearing the aporhoeadane core have been isolated, including: the partially reduced analogue $( \pm)$-lennoxamine $\left(\mathbf{1 1}\right.$, from Berberis darwinii). ${ }^{7}( \pm)-13-$ deoxychilenine (12, from Berberis actinacantha Mart. Ex Schult.), ${ }^{5}$ pictonamine, the methyl enol ether of deoxychilenine (13, from Berberis darwinii), ${ }^{5}$ chileninone (14, from Berberis actinacantha, Berberis darwinii, and Berberis valdiviana Phil.), ${ }^{5}$ ( \pm )-chilenamine (15), also widely known as Schöpf's base VI or Schöpf-Schweickert base VI (from Berberis darwinii), ${ }^{5}$ and ( \pm )-palmanine (16), the tetramethoxy analogue of chilenine (from Berberis actinacantha) ${ }^{5}$ (Figure 4).

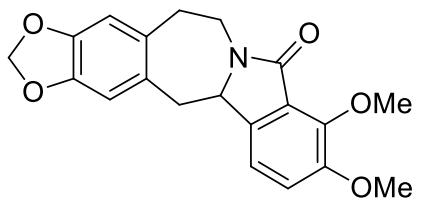

lennoxamine (11)

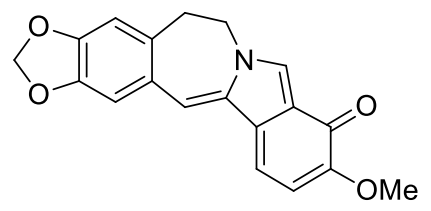

chileninone (14)

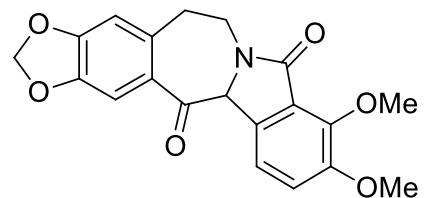

13-deoxychilenine (12)

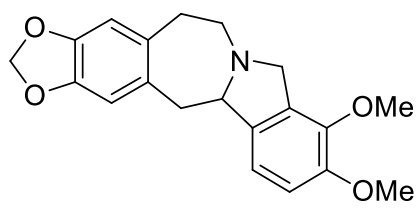

chilenamine (15)

(Schopf's base VI)<smiles>COC1=C2c3ccc(OC)c(OC)c3C(=O)N2CCc2cc3c(cc21)OCO3</smiles>

pictonamine (13)

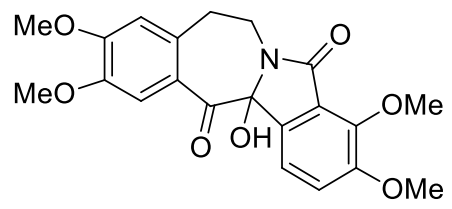

palmanine (16)

Figure 4. Uniquely functionalized analogues of chilenine. 
It is suspected that the biogenesis of lennoxamine results from a series of dehydrations and reductions of chilenine. ${ }^{7}$ Similarly, 13-deoxychilenine (12) is believed to result from chilenine (5) via loss of the hydroxyl group to form iminium ion $\mathbf{1 7}$ and subsequent reduction (Scheme 3$)^{5}$

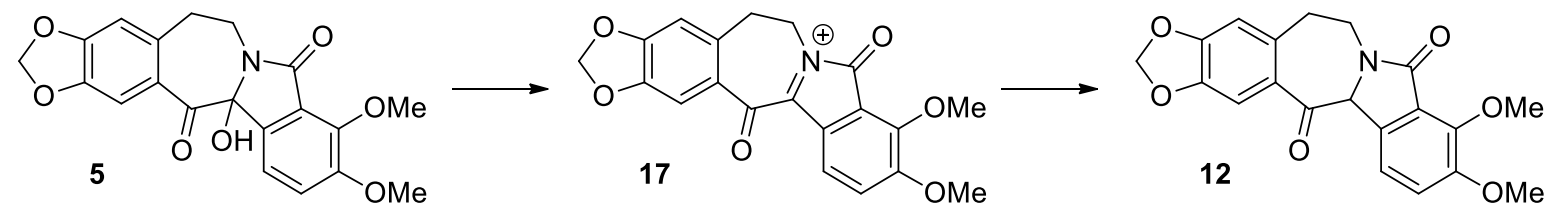

Scheme 3. Proposed biogenesis of 13-deoxychilenine.

A possible biosynthesis of chileninone (14) has been proposed to involve nucleophilic $O$ demethylation of lennoxamine, yielding a phenol (18) whose isomerization and dehydration would result in chileninone (Scheme 4).
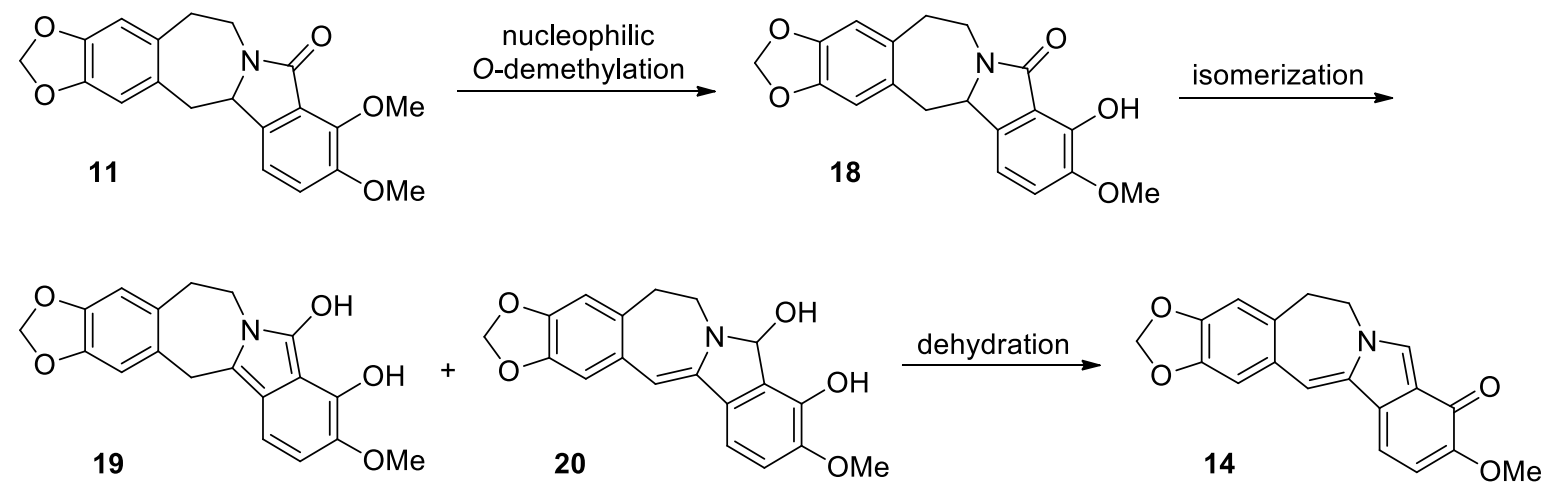

Scheme 4. Possible biosynthesis of chileninone.

While the biogenesis of chilenamine (15) is less clear, one hypothesis involves the in vivo reduction of chileninone (14) to phenol 21 followed by enzymatic $O$-methylation (Scheme 5). ${ }^{5}$

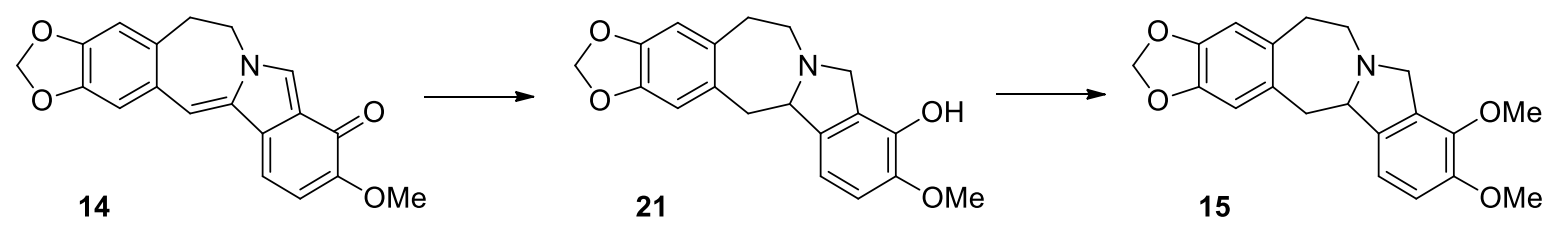

Scheme 5. Proposed biogenesis of chilenamine.

Structural similarities between the aporhoeadanes and several other classes of alkaloids (e.g. the berberines, papaverrubines, protopines, and rhoeadines) explain why the aporhoeadanes are common degradation products of other heterocycles isolated from natural sources, why they can 
be prepared from these natural products, and why the aporhoeadanes might serve as synthetic precursors to diverse heterocyclic structures.

Sections 2-4 here describe the syntheses of aporhoeadanes. The syntheses within each section are ordered chronologically, and each synthetic strategy is categorized by the bond or bonds formed during the end game of the synthesis. Section 5 details the principal reactions of aporhoeadanes.

\section{Late-stage Synthesis of the Isoindole}

\subsection{Formation of the N7-C8 bond}

Papaverrubine A (1, the $N$-desmethyl analogue of isorhoeadine) has been modified to provide the aporhoeadane skeleton (Scheme 6). ${ }^{2,12-15}$ Treatment of papaverrubine A with dilute hydrochloric acid produces the intensely red iminium salt $\mathbf{3}$. Reduction to the tertiary amine (4) is readily reversed through exposure to air. However, oxidation with mercuric acetate yields the enelactam 22.
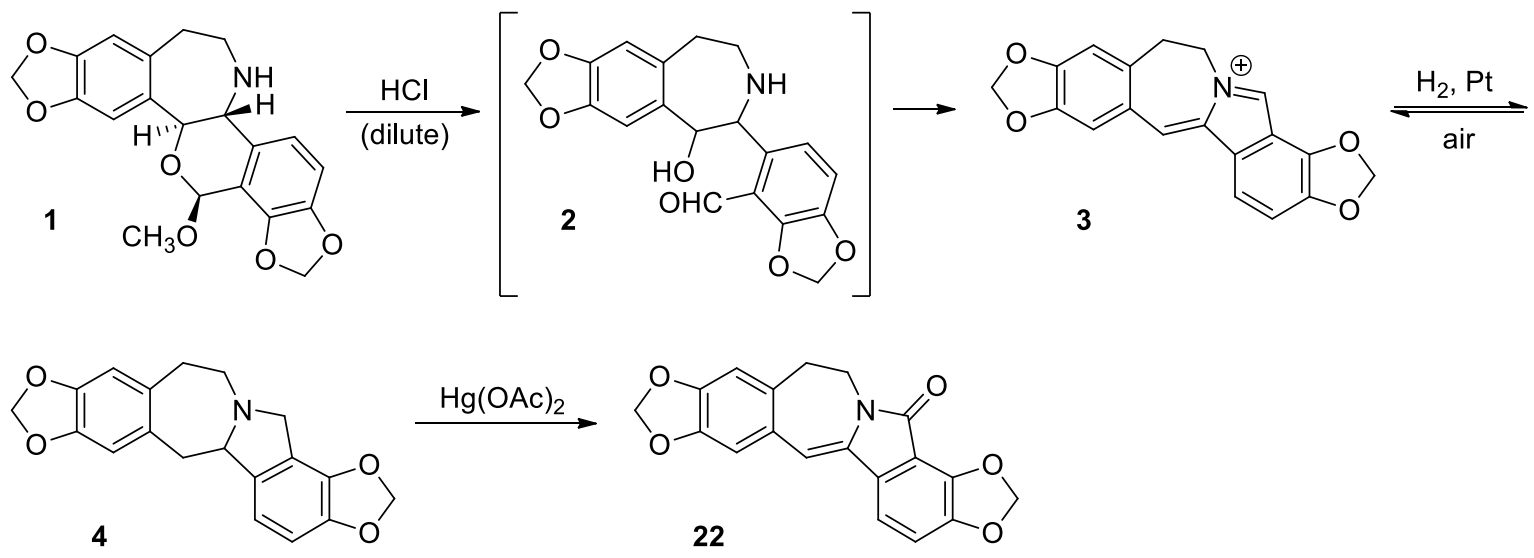

Scheme 6. Synthesis of an aporhoeadane enelactam from papaverrubine A.

The phthalide alkaloids $(-)$ - $\alpha$-narcotine and (-)- $\beta$-hydrastine have also served as starting materials for aporhoeadane synthesis. For instance, $(-)$ - $\alpha$-narcotine (23) undergoes benzylation (24), Hofmann degradation/hydrolysis (25), and hydrogenolysis to yield the opium alkaloid nornarceine (26, Scheme 7). ${ }^{16}$ 

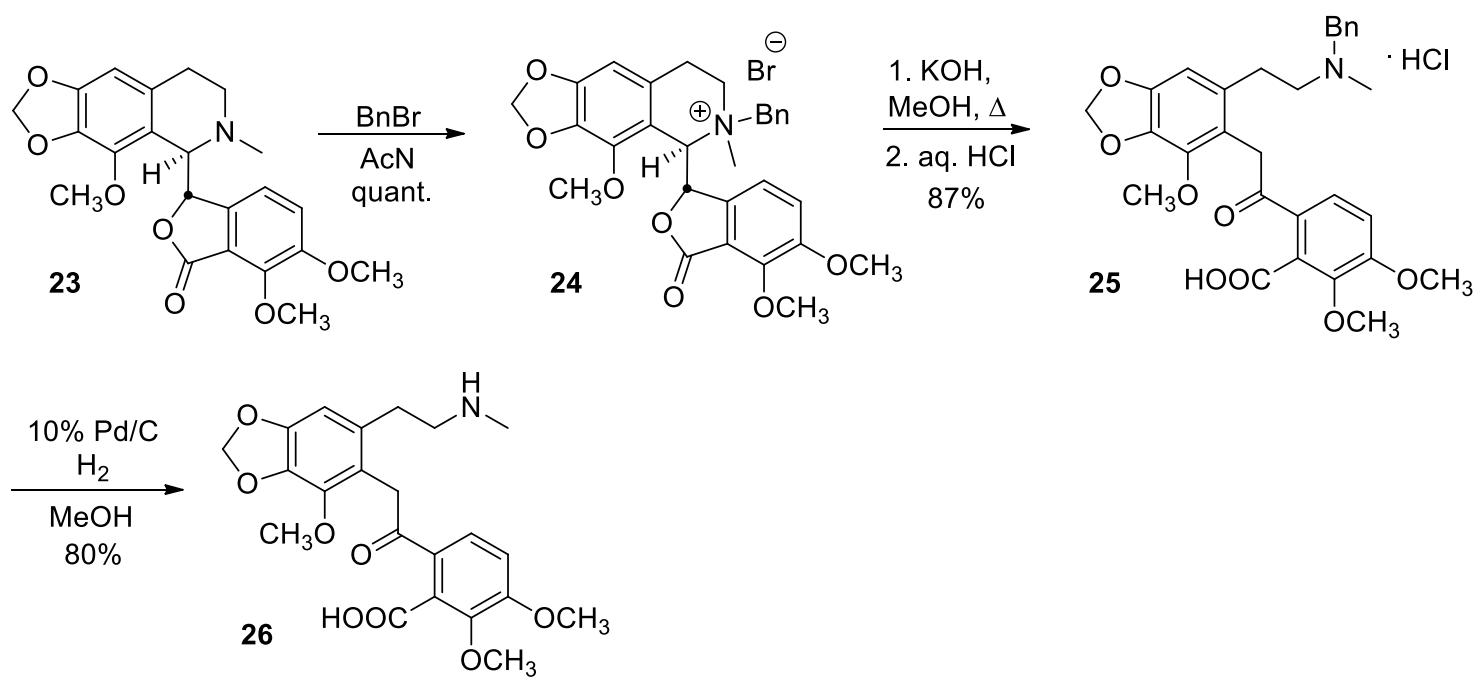

Scheme 7. The conversion of (-)- $\alpha$-narcotine to nornarceine. 27. ${ }^{17}$

Nornarceine (26) can be subjected to reversible cyclization to produce dihydrobenzazepine
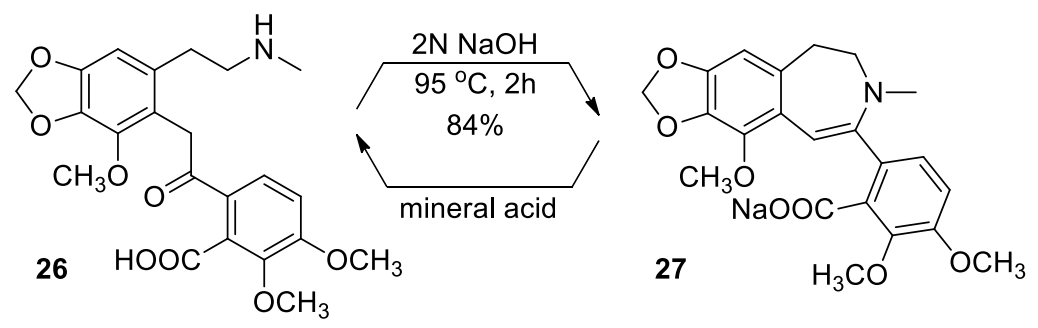

Scheme 8. Reversible cyclization of nornarceine.

A closely related analog of dihydrobenzazepine 27 has also been produced from (-)- $\beta$ hydrastine via (-)-bicuculline (28, Scheme 9). ${ }^{18}$ Bicuculline yields urethane 29 upon treatment with phenyl chloroformate and elimination, and this urethane cyclizes in base to dihydrobenzazepine 30.
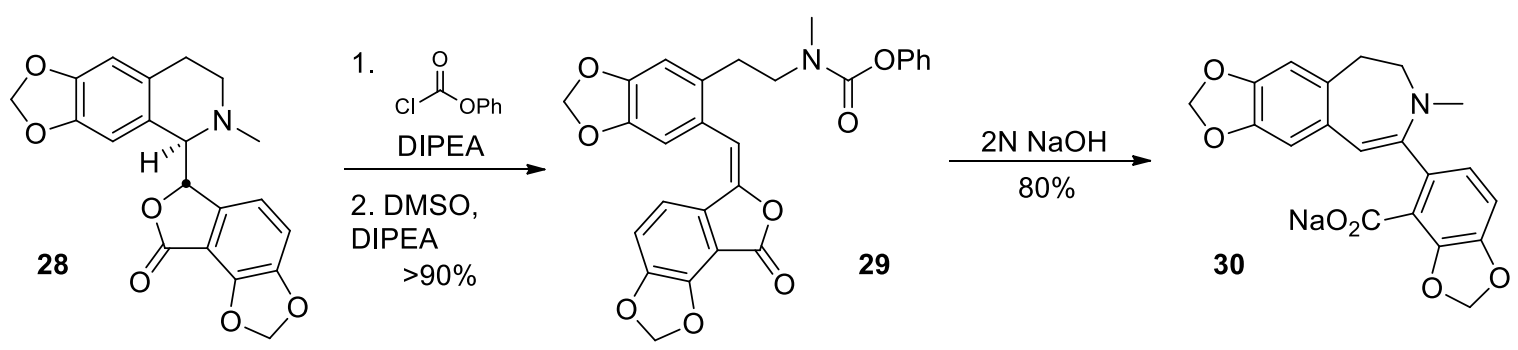

Scheme 9. Conversion of (-)- $\beta$-hydrastine to a dihydrobenzazepine. 
Dihydrobenzazepines $\mathbf{2 7}$ and $\mathbf{3 0}$ have proven to be useful intermediates in the preparation of both rheadans and aporhoeadanes. For instance, dihydrobenzazepine 27 been converted into 11methyl-2,3-methylendioxy-4,6,7,8-tetramethoxyrheadan (36, Scheme 10). ${ }^{17}$ Conversion into the spirolactone 31 was followed by oxidation to ketolactone 32. Subsequent reduction and lactonization yielded cis-lactone 34, which can be reduced with Red-Al to provide 6hydroxyrheadan (35), whose reversible etherification yields 11-methyl-2,3-methylendioxy4,6,7,8-tetramethoxyrheadan (36).
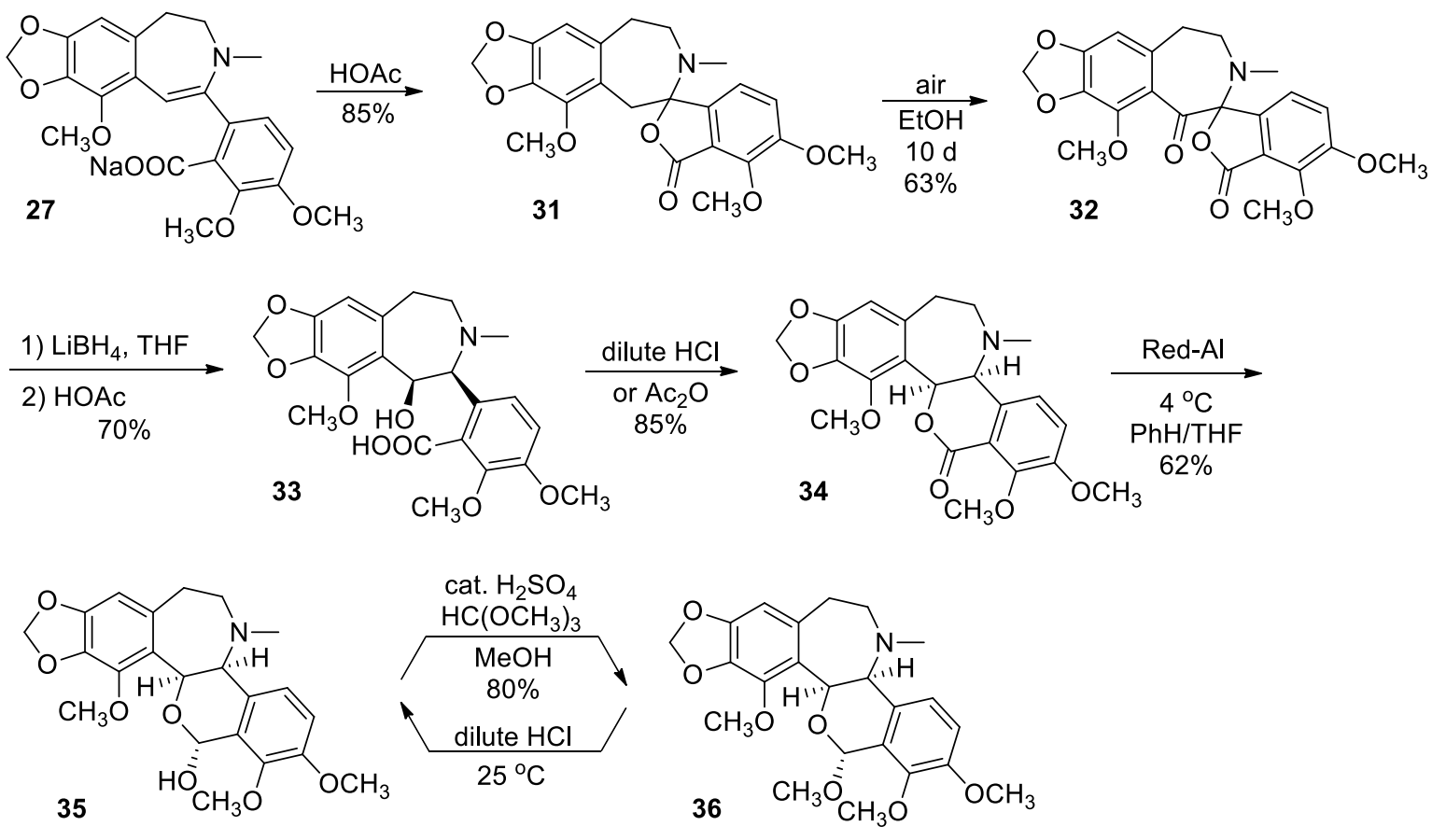

Scheme 10. Conversion of dihydrobenzazepine 27 into 11-methyl-2,3-methylendioxy-4,6,7,8tetramethoxyrheadan.

An analogous protocol with dihydrobenzazepine 30 afforded rhoeadine (Scheme 11). ${ }^{18}$

However, when treatment with acetic acid is followed immediately by reduction rather than air oxidation, the saturated amino acids 43 and 44 result (Scheme 12). ${ }^{19}$ Acetic anhydrideinduced lactamization yields lennoxamine (11) or its methoxy analog 45. Finally, diborane reduction provides Schöpf's base VI (15) or its methoxy analog 46. 

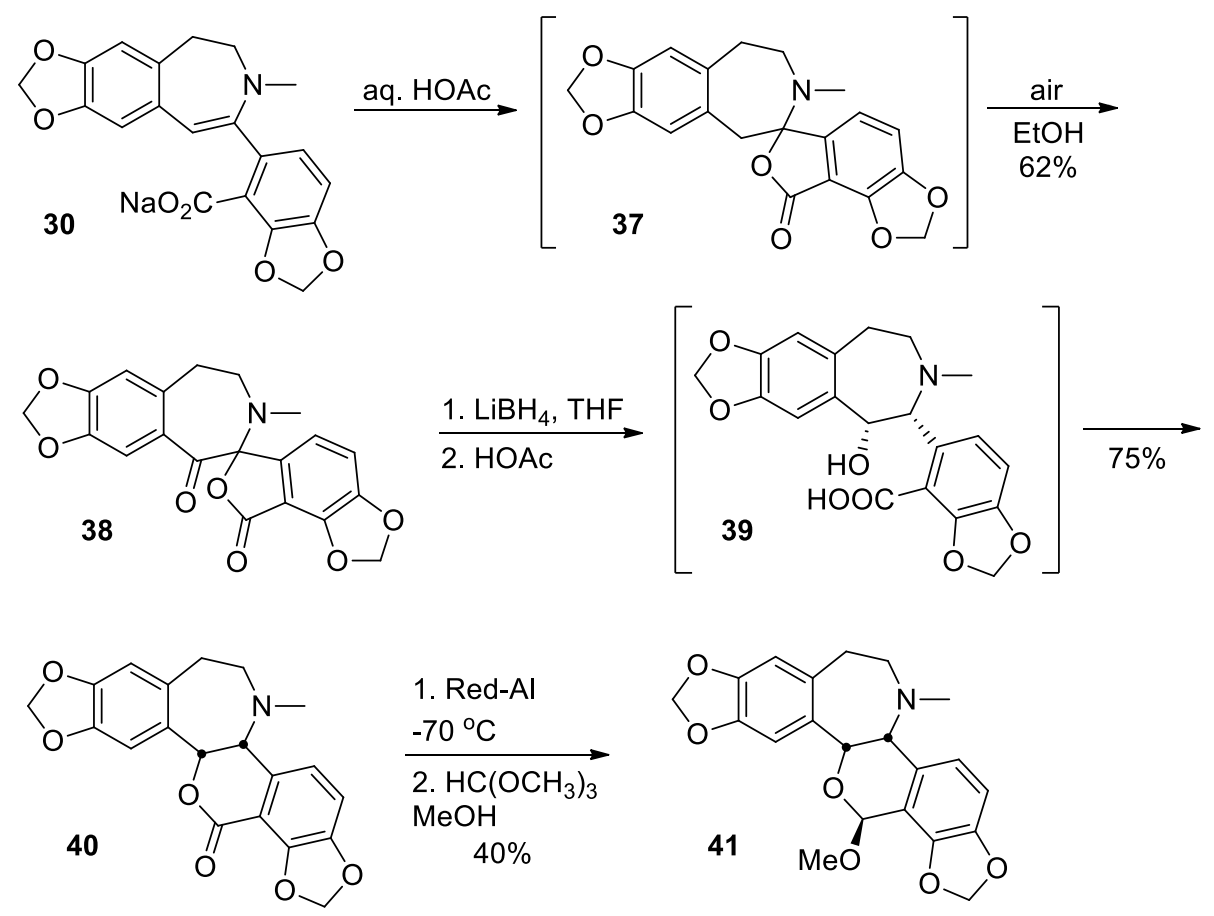

Scheme 11. Conversion of dihydrobenzazepine $\mathbf{3 0}$ to rhoeadine.

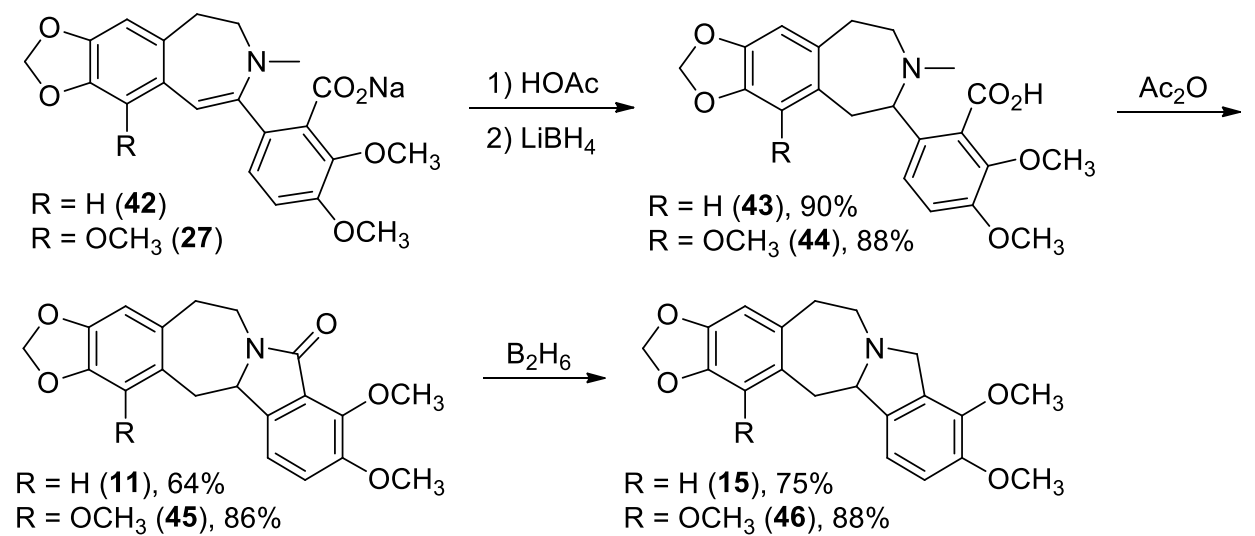

Scheme 12. Conversion of dihydrobenzazepines to lennoxamine, Schöpf's base VI, and their analogues.

Moody and Warrellow devised an approach to lennoxamine that also employs late-stage formation of the N7-C8 bond; however, their approach constructs the benzazepine system from simple substrates, rather than relying upon modification of a papaverrubine or phthalide alkaloid. $^{20,21}$ 6-Bromopiperonal (47) was converted to the mono-protected dialdehyde (48), followed by union with dimethoxybenzoate (49) under Wadsworth-Emmons conditions (Scheme 13). Liberation of the remaining aldehyde provided $(E)$-stilbene aldehyde 50. Subsequent 
condensation with methyl azidoacetate provided an unstable azide (51) that could be heated to yield the critical benzazepine $\mathbf{5 2}$ in the key step of the synthesis. The benzazepine was accompanied by a $29 \%$ yield of an undesired benzylisoquinoline side product. Reduction of both olefins of the benzazepine with sodium cyanoborohydride was accompanied by intramolecular cyclization that formed the N7-C8 bond giving the tetrahydroisoindolobenzazepine core (53). The removal of the undesired ester at C6 was accomplished by DIBAL reduction to the aldehyde (54) and decarbonylation with bis(triphenylphosphine)rhodium(I) carbonyl chloride, ultimately yielding lennoxamine (11).
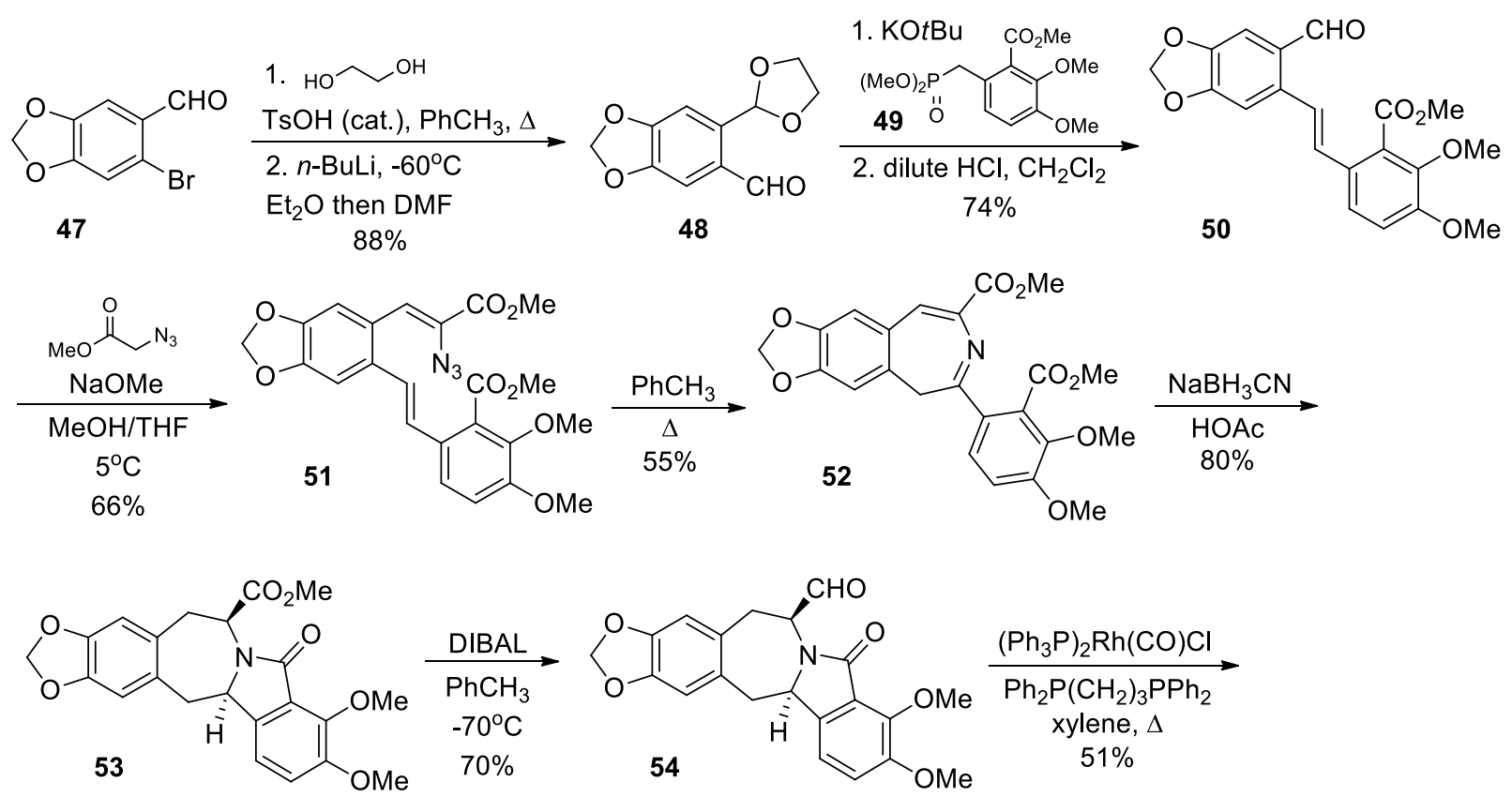<smiles>COc1ccc2c(c1OC)C(=O)N1CCc3cc4c(cc3CC21)OCO4</smiles>

Scheme 13. Synthesis of lennoxamine via azide cyclization.

\subsection{Formation of the N7-C8 and C8-C8a bonds}

Orito and co-workers investigated the synthesis of dehydrolennoxamine (dehydro-11), and therefore the formal synthesis of lennoxamine, ${ }^{73,75}$ and chilenine, ${ }^{54}$ through palladium-catalyzed carbonylation. ${ }^{29}$ Their route began with the preparation of aryl iodide $\mathbf{5 7}$ from aryl bromide $\mathbf{5 5}$ via protection of the aldehyde (56), halogen exchange, and deprotection (Scheme 14). 
<smiles>COc1ccc(C=O)c(Br)c1OC</smiles>

55

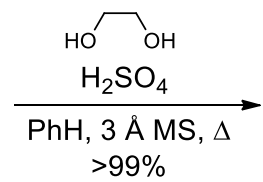<smiles>COc1ccc(C2OCCO2)c(Br)c1OC</smiles>

56

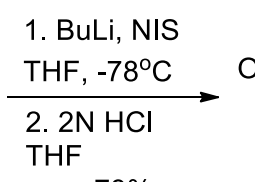

$73 \%$<smiles>COc1ccc(C=O)c(I)c1OC</smiles>

57

Scheme 14. Synthesis of aryl iodide 57.

The aryl iodide was then coupled with trifluoroacetamide 58 (Scheme 15). Cyclization under basic conditions yielded benzazepine $\mathbf{6 0}$, and at this stage palladium-catalyzed carbonylation formed the isoindolone ring of $\mathbf{6 1}$, which was immediately subjected to elimination providing dehydrolennoxamine (dehydro-11).
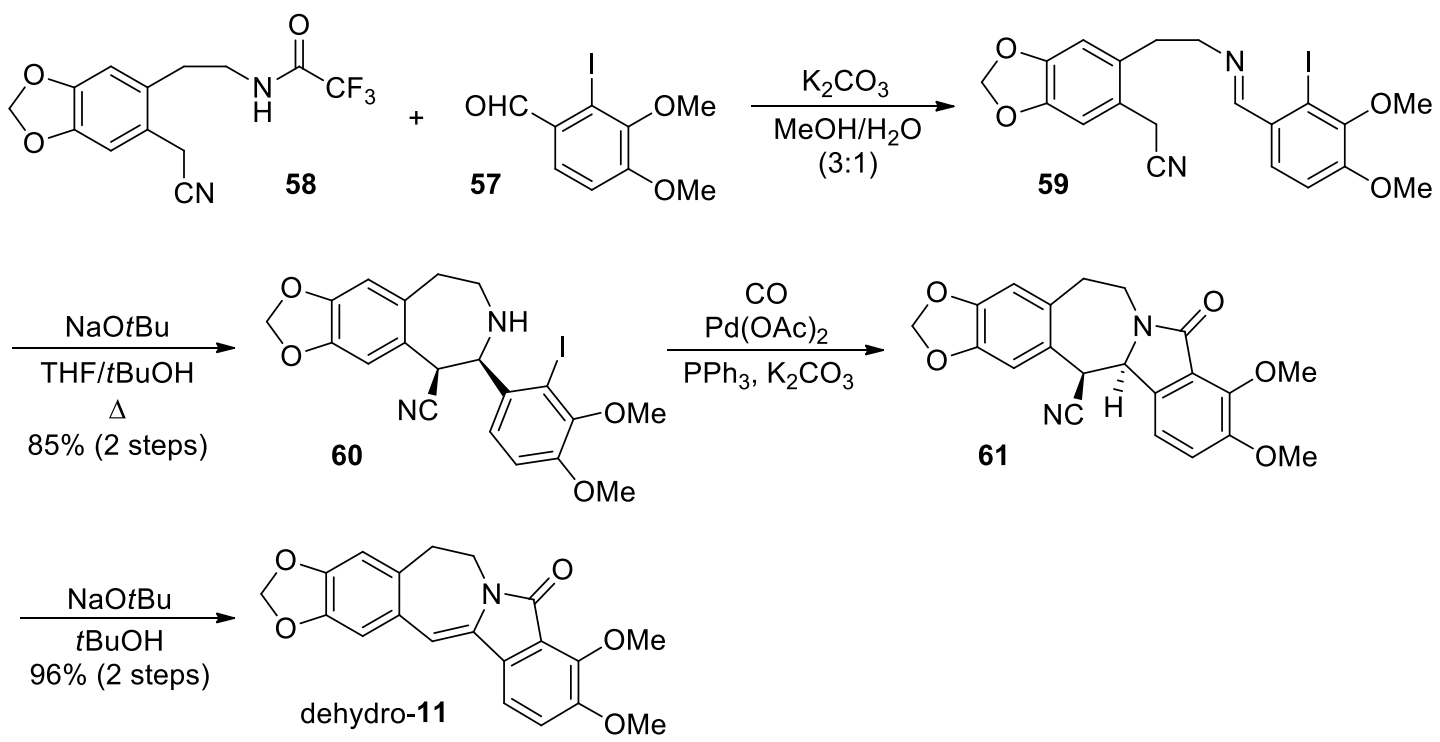

Scheme 15. Synthesis of dehydrolennoxamine through carbonylation.

A bromo-substituted benzazepine (62, Scheme 16), prepared in an analgous fashion to its iodinated counterpart $\mathbf{6 0}$, underwent migration of the cyano group under radical conditions $(\mathbf{6 3})$, and subsequent basic cyclization afforded lennoxamine (11). This was the first reported synthesis of a natural product to employ cyano group migration. ${ }^{29}$

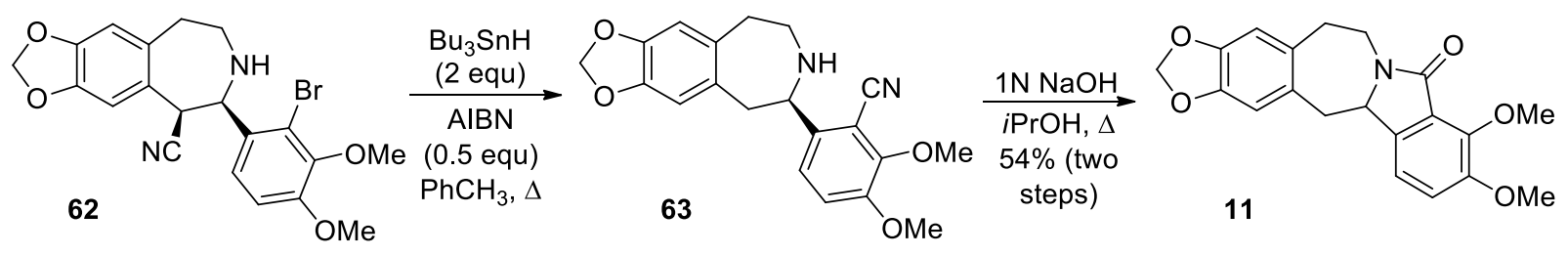

Scheme 16. Synthesis of lennoxamine through cyano migration. 


\subsection{Formation of the C12a-C13 bond}

Hanaoka and co-workers developed a synthesis of chilenamine (15) that built on their previous work using cyclization of sulfur-stabilized carbocations for the formation of alkaloids. ${ }^{22} 3,4-$ Methylenedioxyphenethylamine (64) and 6-bromo-2,3-dimethoxybenzaldehyde (65) were condensed, and the resultant imine was reduced with sodium borohydride (66, Scheme 17). $\mathrm{N}$ acylation using $\alpha$-chloro- $\alpha$-methylthioacetyl chloride and cyclization of the sulfur-stabilized carbocation yielded lactam 67. Desulfurization was performed with zinc in acetic acid (68), and reduction of the lactam afforded the enamine (69). Radical cyclization closed the isoindole ring and completed the synthesis of chilenamine (15).
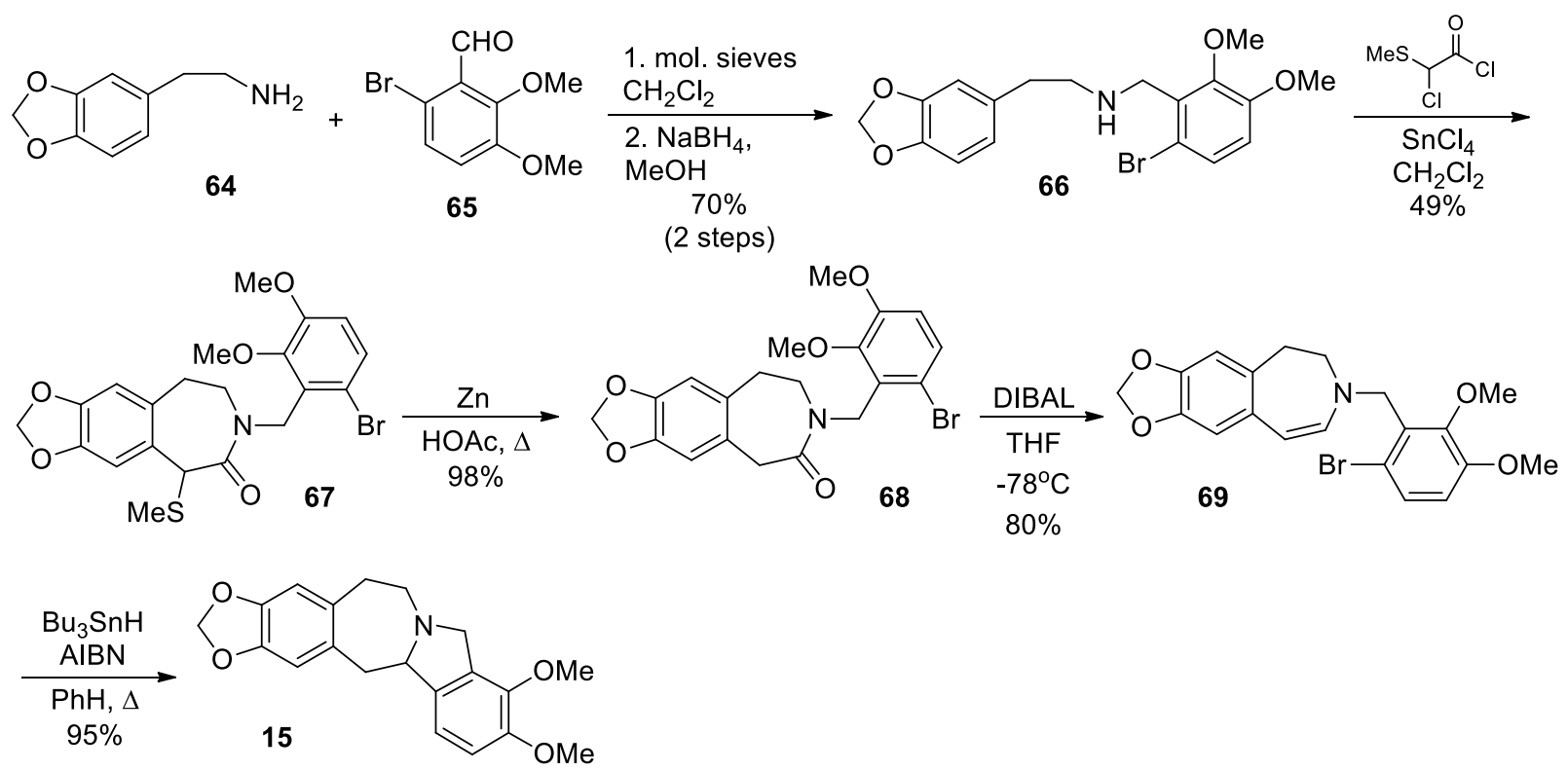

Scheme 17. Chilenamine synthesis employing cyclization of a sulfur-stabilized carbocation.

Fuchs and Funk developed an approach to the synthesis of lennoxamine (11) that relies upon an integral intramolecular EAS reaction of a 2-amidoacrolein formed via retrocycloaddition. ${ }^{23}$ The synthesis began with phenethylamine 64, which was condensed with 1,3-dioxin-5-one (Scheme 18). The imine thus formed was acylated to yield enamide 70. Exposure to Lewis acid induced a retrocycloaddition to unveil the 2-amidoacrolein (71), which immediately underwent intramolecular EAS to provide the benzazepine (72). Oxidation of the aldehyde to its corresponding acid using sodium chlorite was followed by a Kochi reaction that installed the C13-C14 olefin (73). Finally, radical cyclization produced lennoxamine (11) in 58\% yield along with $26 \%$ yield of the debrominated enamide. 

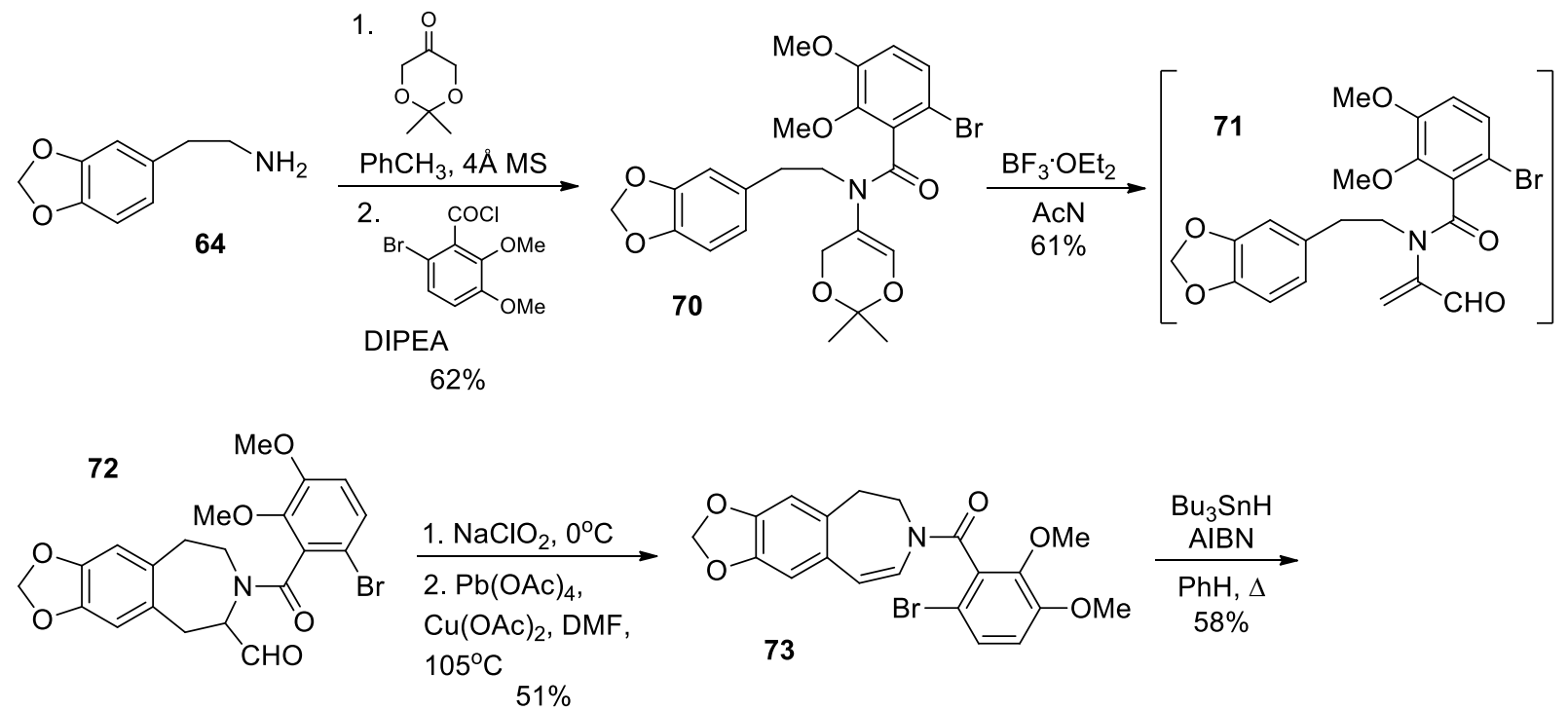<smiles>COc1ccc2c(c1OC)C(=O)N1CCc3cc4c(cc3CC21)OCO4</smiles>

Scheme 18. Synthesis of lennoxamine through key cyclization of a 2-amidoacrolein.

Honda and Sakamaki reported a synthesis of 13-deoxychilenine (12), lennoxamine (11), and chilenine (5) that relies upon a palladium-catalyzed intramolecular $\alpha$-arylation of a ketone. ${ }^{24}$ The benzazepinone (78) used as the starting material for this sequence was previously synthesized according to the method shown in Scheme 19. ${ }^{25}$
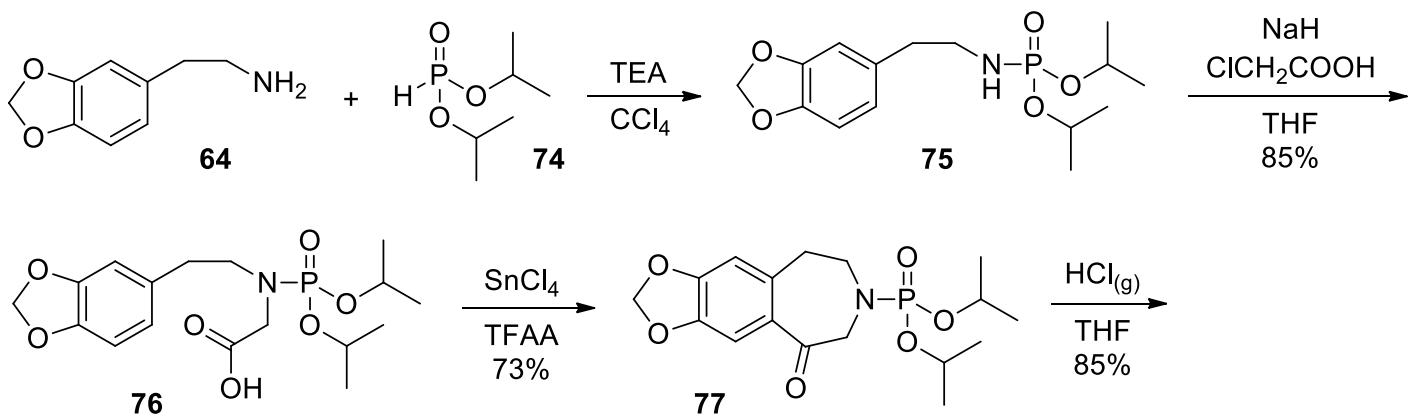<smiles>O=C1CNCCc2cc3c(cc21)OCO3</smiles>

Scheme 19. Preparation of a benzazepinone to be used in the synthesis of 13-deoxychilenine. 
Schotten-Baumann acylation of benzazepinone 78 yielded the amide 79 (Scheme 20). The key $\alpha$-arylation of the ketone then occurred using $5 \mathrm{~mol} \% \mathrm{Pd}_{2}(\mathrm{dba})_{3}, 10 \mathrm{~mol} \%$ racemic BINAP, and 1.5 equivalents of potassium tert-butoxide yielding the first synthesis of 13-deoxychilenine (12). The debrominated reactant was an accompanying byproduct (18\%).

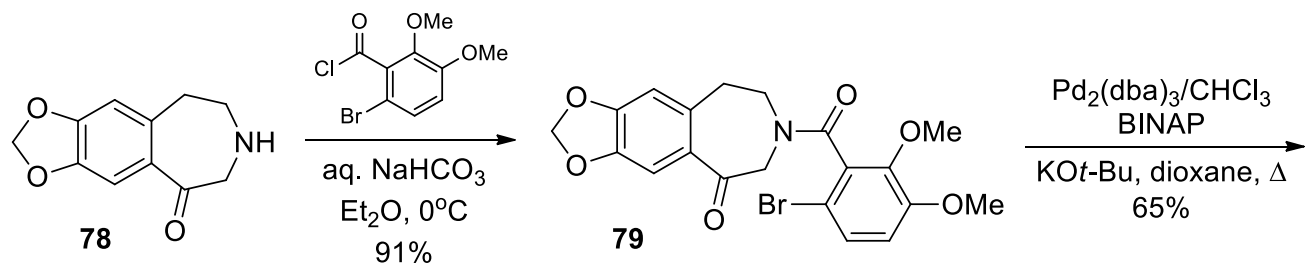<smiles>COc1ccc2c(c1OC)C(=O)N1CCc3cc4c(cc3C(=O)C21)OCO4</smiles>

Scheme 20. Synthesis of 13-deoxychilenine.

13-Deoxychilenine (12) could then be converted to lennoxamine (11) by sequential reduction with sodium borohydride and triethylsilane (Scheme 21). Alternatively, 13deoxychilenine could be transformed into chilenine (5) by reaction with sodium hexamethyldisilazane and Davis's reagent.

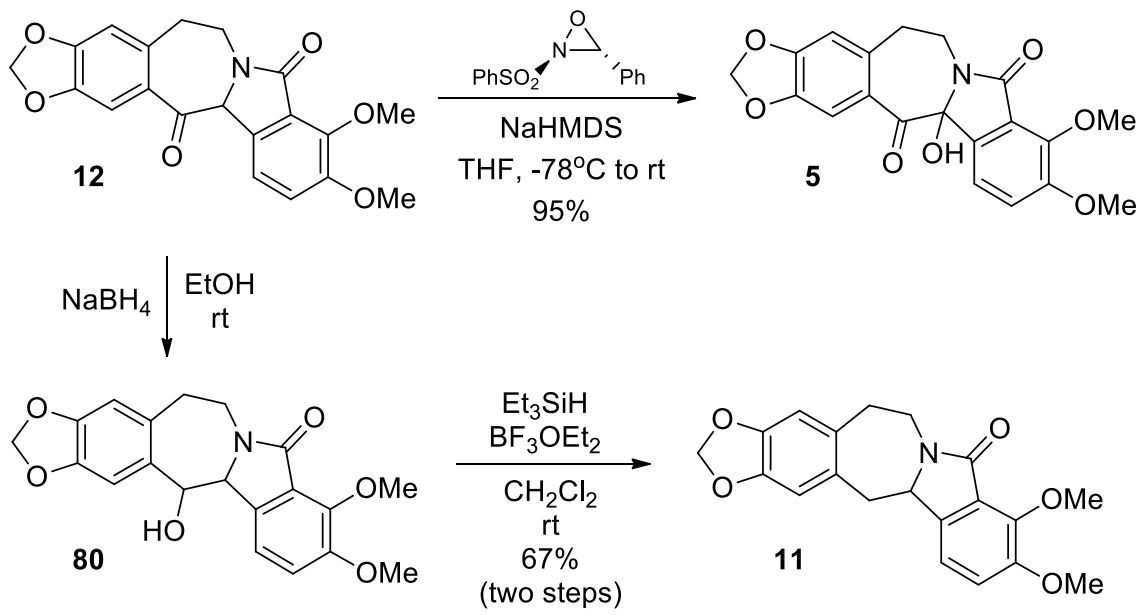

Scheme 21. Synthesis of lennoxamine and chilenine from 13-deoxychilenine.

Fuwa and Sasaki developed a route to lennoxamine (11) and chilenine (5) that relies upon the catalytic hydrosilane reduction of an $\alpha$-phosphonoxy enamide (84). ${ }^{26,27}$ Their synthesis began with 3,4-methylenedioxyphenylacetic acid (81), which was activated as the acid chloride and coupled with aminoacetaldehyde dimethyl acetal (Scheme 22). Pomeranz-Fritsch style 
cyclization to yield benzazepinone 83 was followed by hydrogenation (78) and $N$-acylation (79). At this stage, the keystone $\alpha$-phosphonoxy enamide (84) was prepared. Chemoselective hydrosilane reduction provided the corresponding enamide (73).
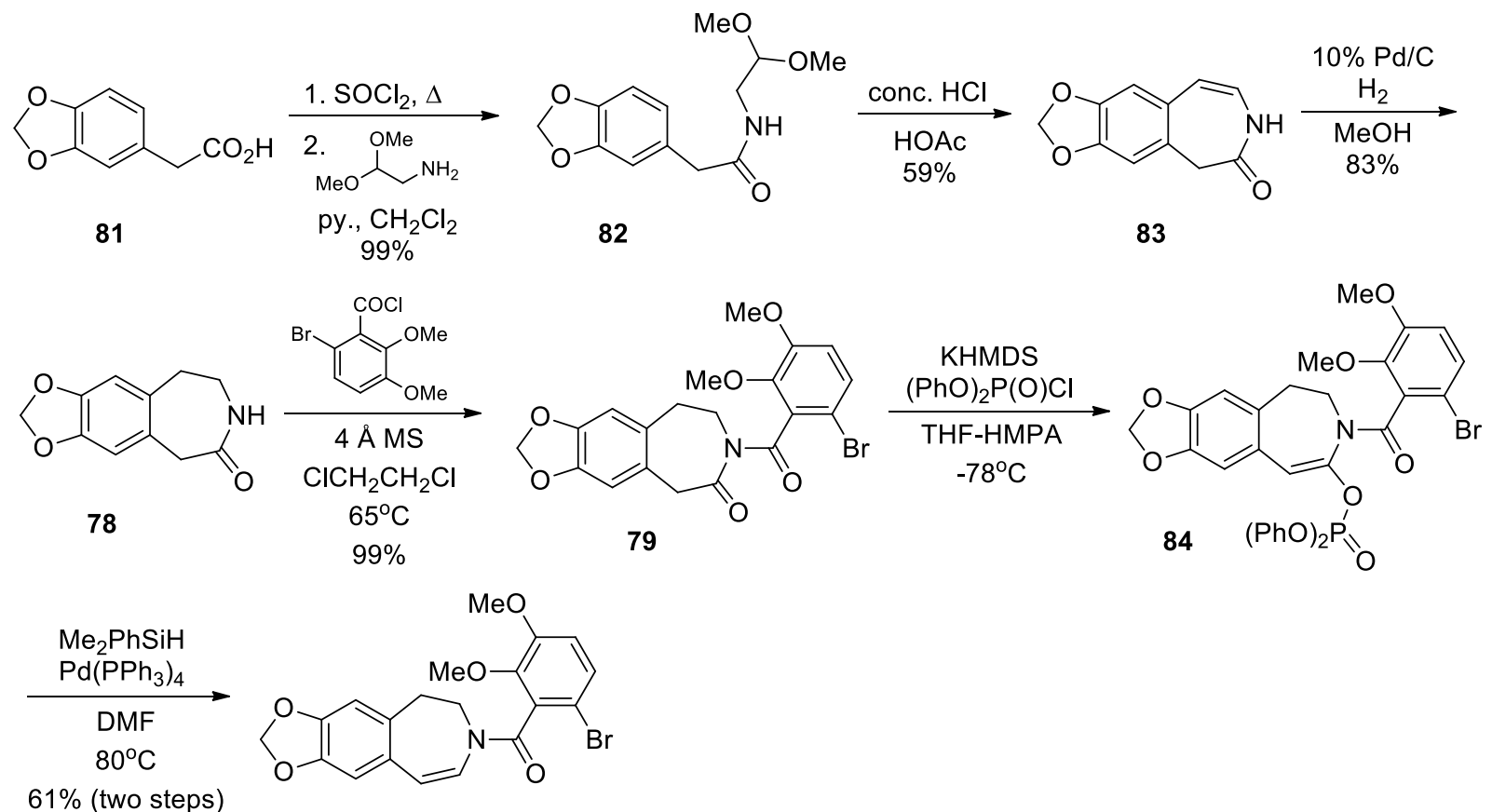

73

Scheme 22. Preparation of enamide 73 using hydrosilane reduction of an $\alpha$-phosphonoxyenamide.

Enamide 73 was converted into lennoxamine (11) using the radical cyclization previously employed by Fuchs and Funk (Scheme 23). ${ }^{23}$ Additionally, a $25 \%$ yield of the debrominated enamide was isolated as a byproduct of this reaction. This approach afforded lennoxamine in seven steps and $20 \%$ overall yield.

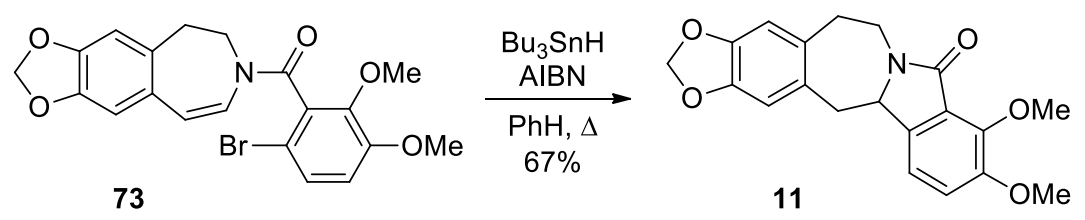

Scheme 23. Synthesis of lennoxamine from enamide 73.

Alternatively, palladium-catalyzed cyclization provided dehydrolennoxamine (dehydro-11, Scheme 24), along with 9\% recovered starting material. Dehydrolennoxamine has been converted by Fang and Danishefsky into chilenine. ${ }^{54}$ Consequently, this approach provides chilenine in seven steps and $25 \%$ overall yield. 


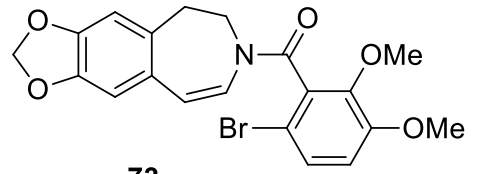

73

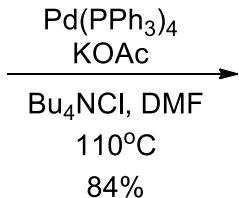

$84 \%$

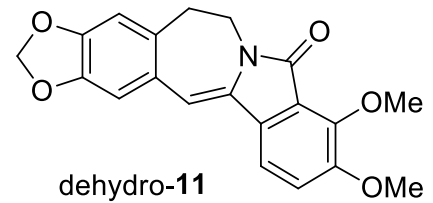

dehydro-11

Scheme 24. Palladium-catalyzed cyclization of enamide $\mathbf{7 3}$ to yield dehydrolennoxamine.

Kim and co-workers also engaged in palladium-mediated closure of the $\mathrm{C} 12 \mathrm{a}-\mathrm{C} 13$ bond. However, their approach did not require the use of an aryl halide for this cyclization. ${ }^{28}$ Phenethylamine 85 and benzoic acid 86 were coupled. Then, Stille reaction with vinyltributylstannane yielded styrene $\mathbf{8 8}$. Treatment with Oxone afforded the epoxide 89, which was cyclized to the benzazepine (90) in the presence of Lewis acid. Finally, treatment with stoichiometric palladium acetate ( 2 equivalents) induced cyclization of the isoindolone ring giving dehydrolennoxamine (dehydro-11) that has been transformed into both lennoxamine, ${ }^{73,75}$ and chilenine. ${ }^{54}$
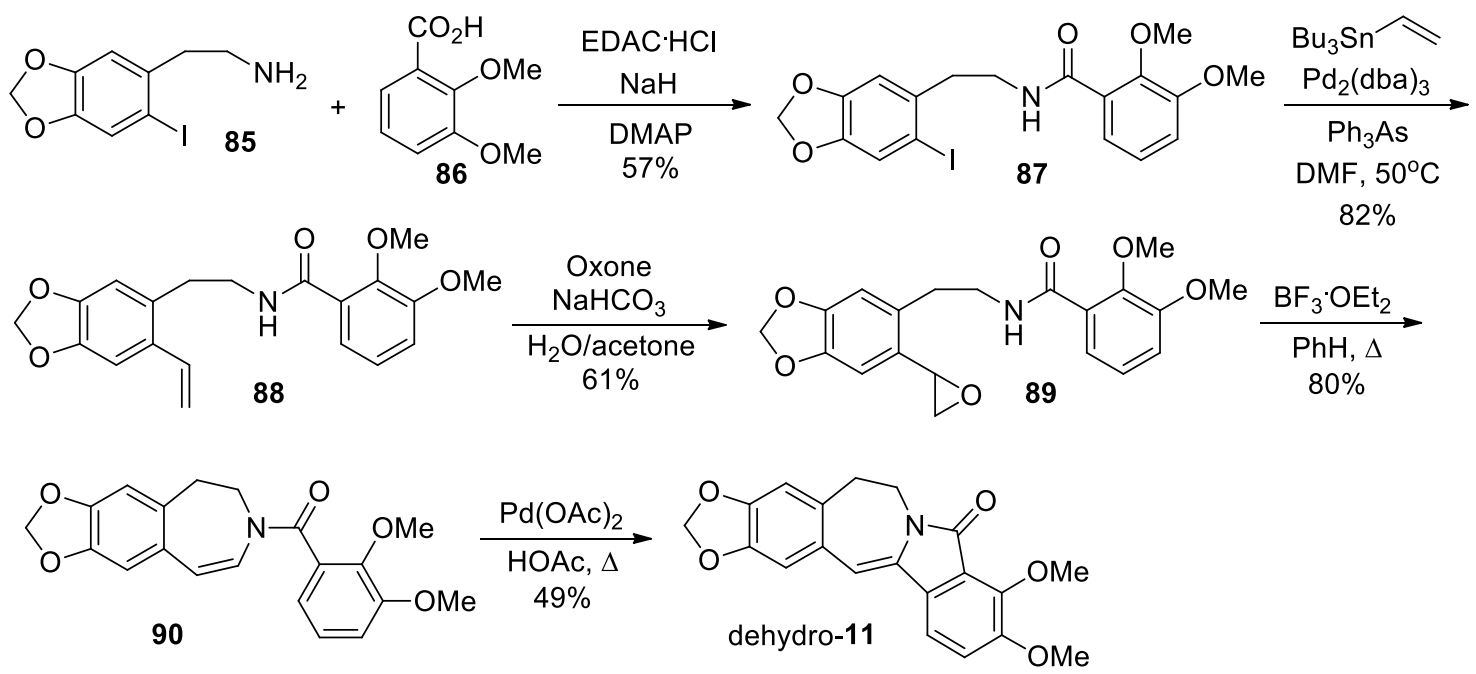

Scheme 25. Palladium-catalyzed cyclization of an enamide without an aryl halide coupling partner to yield dehydrolennoxamine.

Orito and co-workers engaged in a comparison of radical and palladium-catalyzed cyclizations for formation of the $\mathrm{C} 12 \mathrm{a}-\mathrm{C} 13$ bond. ${ }^{29}$ Both approaches relied upon a common enamide 73. To initiate preparation of the enamide, $N$-alkylation of phenethylamine 64 with bromoacetaldehyde dimethyl acetal was followed by $\mathrm{N}$-acylation with 6-bromo-2,3dimethoxybenzoyl chloride. The amide thus formed (92) was then dissolved in a mixture of sulfuric and acetic acid (1:3) in methanol, which facilitated cyclization in $85 \%$ yield over two steps. (Scheme 26) 


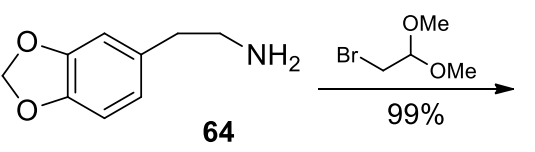<smiles>COC(CNCCc1ccc2c(c1)OCO2)OC</smiles>
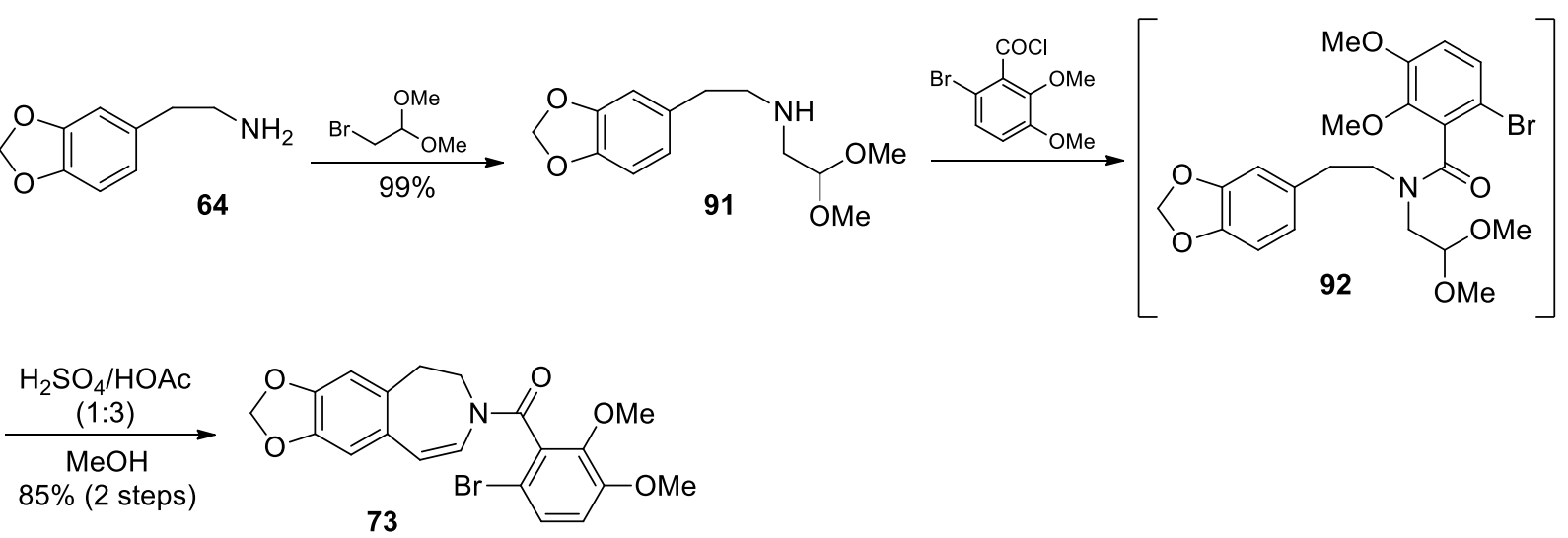

Scheme 26. Alternative preparation of enamide 73.

Enamide $\mathbf{7 3}$ could be subjected to one of two cyclizations to form lennoxamine (11) or its dehydro analogue (dehydro-11). A radical cyclization, similar to that used by Fuchs and Funk, ${ }^{23}$ yielded lennoxamine in $73 \%$ yield accompanied by $24 \%$ yield of the debrominated enamide. Alternatively, Heck cyclization, employing either triphenylphosphine as the ligand or tetrabutylammonium chloride as the additive, provided dehydrolennoxamine in greater than $90 \%$ yield. Since dehydrolennoxamine has been converted to both lennoxamine, ${ }^{73,75}$ and chilenine, ${ }^{54}$ this represents formal syntheses of these two as well.

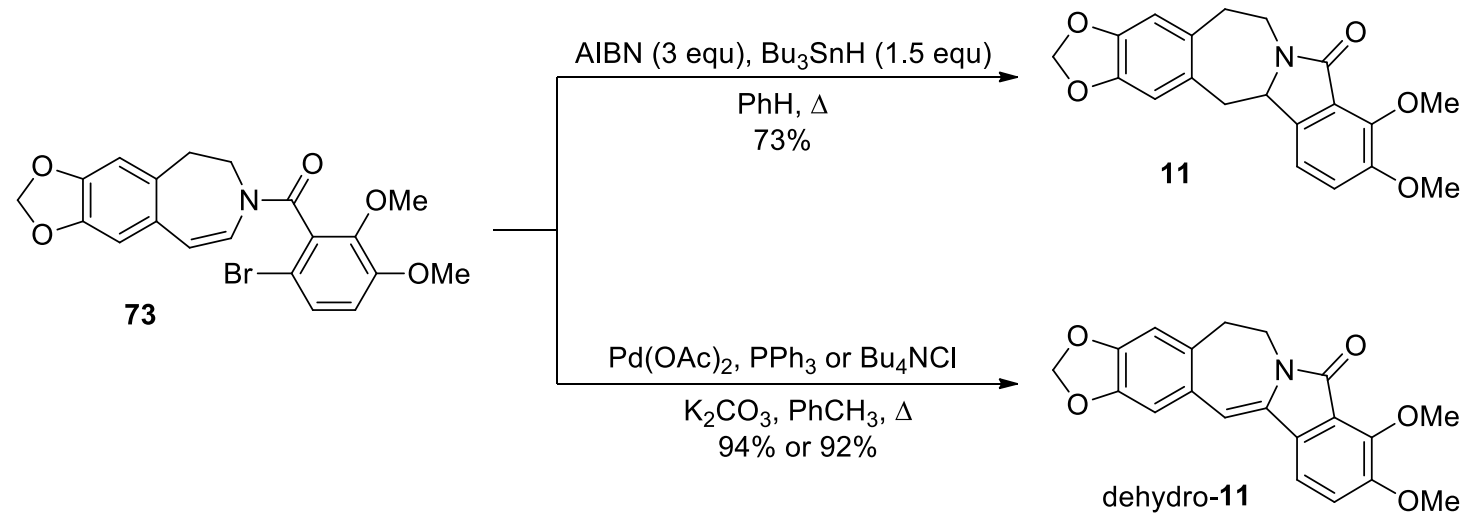

Scheme 27. Synthesis of lennoxamine or dehydrolennoxamine from enamide 73.

\section{Late-stage Synthesis of the Benzazepine}

\subsection{Formation of the C14-C14a bond}

Photochemistry has played a prominent role in this strategy for constructing the aporhoeadane skeleton. For instance, early work by Scartoni and Marsili, ${ }^{30}$ employed a vinyl bromide (93, Scheme 28) as a cyclization substrate, which provided the aporhoeadane core in enelactam 94, an 
intermediate whose analogues recur in several syntheses of the aporhoeadanes. The authors proposed a radical mechanism for the cyclization, which is supported by the observation that a good yield can be obtained by sunlight irradiation. ${ }^{31}$
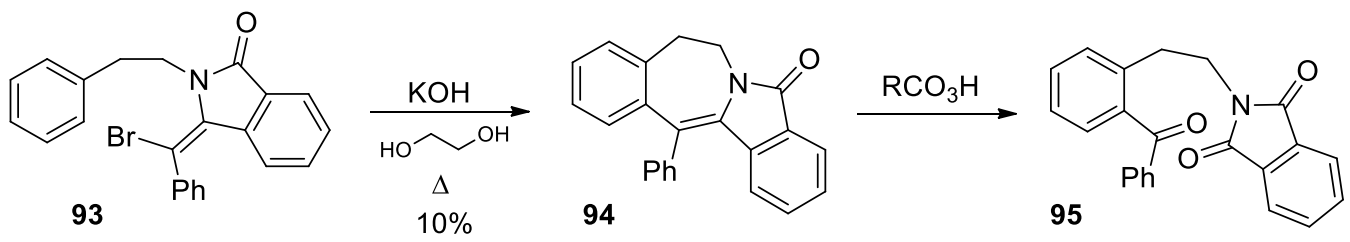

Scheme 28. Benzazepine ring closure and oxidative cleavage.

The oxidation of the enelactam with a peroxyacid afforded oxidative cleavage of the sevenmembered ring (95). This was useful in assigning the structure of the enelactam but illustrates the difficulty of achieving additional oxygenation of the isoindolobenzazepine core.

In a strategically similar approach, Bernhard and Snieckus, ${ }^{32}$ described the preparation of an aryl bromide (99) as a photocyclization substrate. Aryl bromides were used in this study because attempts to prepare vinyl bromides analogous to those used by Marsili and Scartoni resulted in the formation of angularly substituted isoquinoline derivatives from rapid Pictet-Spengler reaction, possibly due to the enhanced nucleophilicity of the aromatic ring now bearing a methylenedioxy bridge. Consequently, aryl bromides, such as 99, were used as photocyclization substrates and were obtained through coupling of phenethylamine 96 and phthalic anhydride 97 followed by regioselective Grignard reaction and dehydration. Photocyclization yielded the enelactam dehydrolennoxamine (dehydro-11) in about $20 \%$ yield.
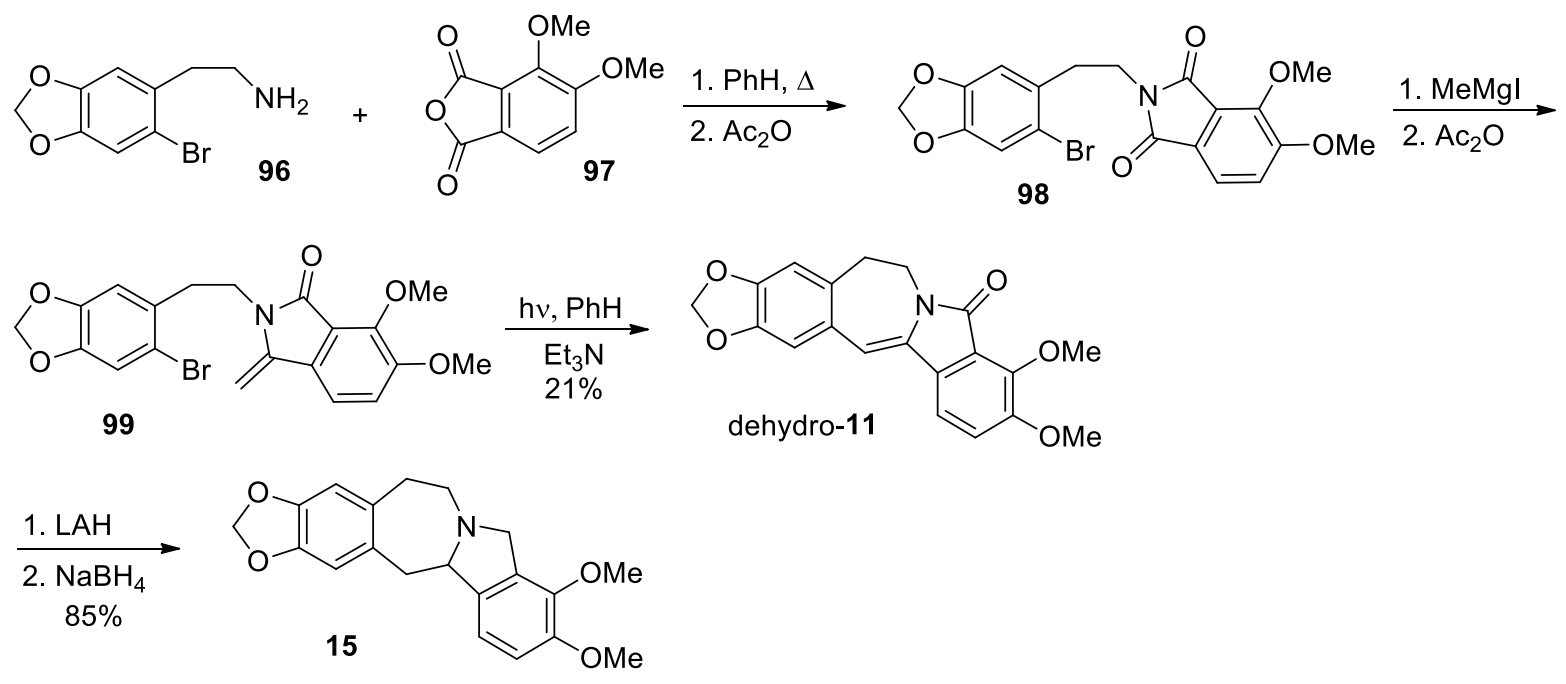

Scheme 29. Alternative photocyclization route to the seven-membered ring. 
While enelactam dehydro-11 can be fully reduced to Schöpf's base VI (15), attempts to oxidize the olefin of the enelactam, thereby installing the functionality found in chilenine, resulted only in undesired ring-opening as shown for related compounds in Scheme $30 .{ }^{33}$

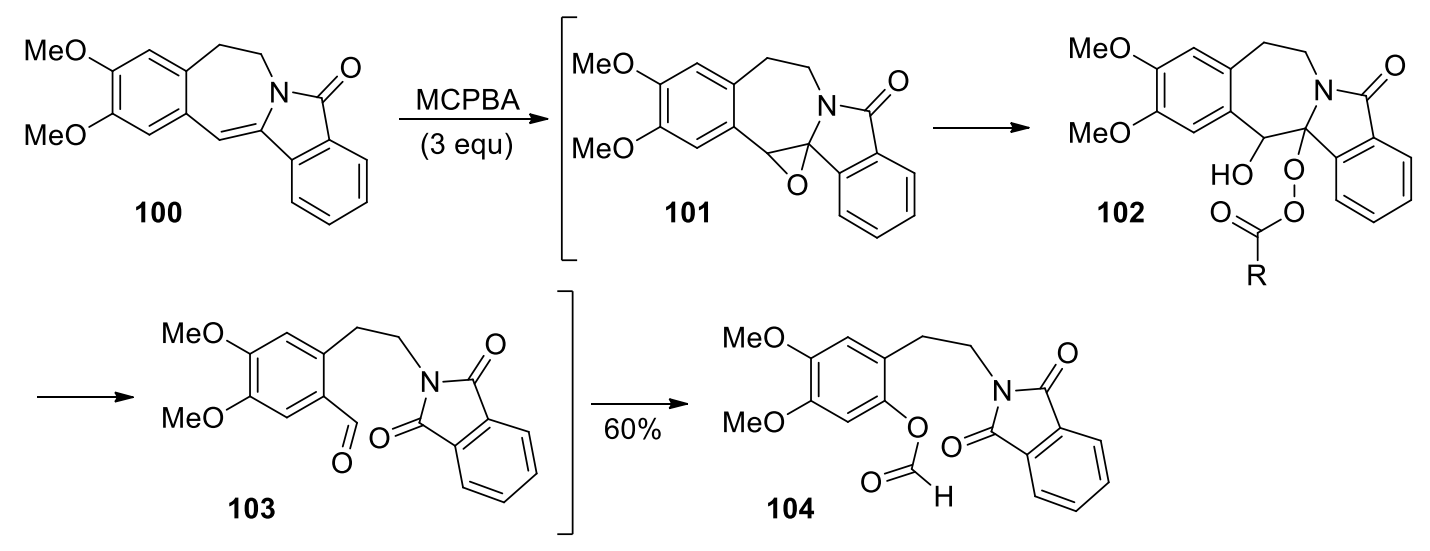

Scheme 30. Oxidative ring opening of enelactam 100.

Ishibashi, Ikeda, and co-workers reported a synthesis of lennoxamine (11) and a formal synthesis of chilenine that had at their core a critical sulfur-directed regioselective aryl radical cyclization onto an enamide (106), which provided the isoindolone ring. ${ }^{34,35}$ The radical cyclization substrate 106 was prepared in two steps from 3,4-methylenedioxyphenethylamine (64) by condensation with bis(phenylthio)acetaldehyde and $N$-acylation (Scheme 31 ). The radical cyclization proceeded with excess tributyltin hydride to afford 5-exo-trig ring closure and desulfurization (107). The corresponding sulfoxide 108 was prepared by oxidation with MCPBA.
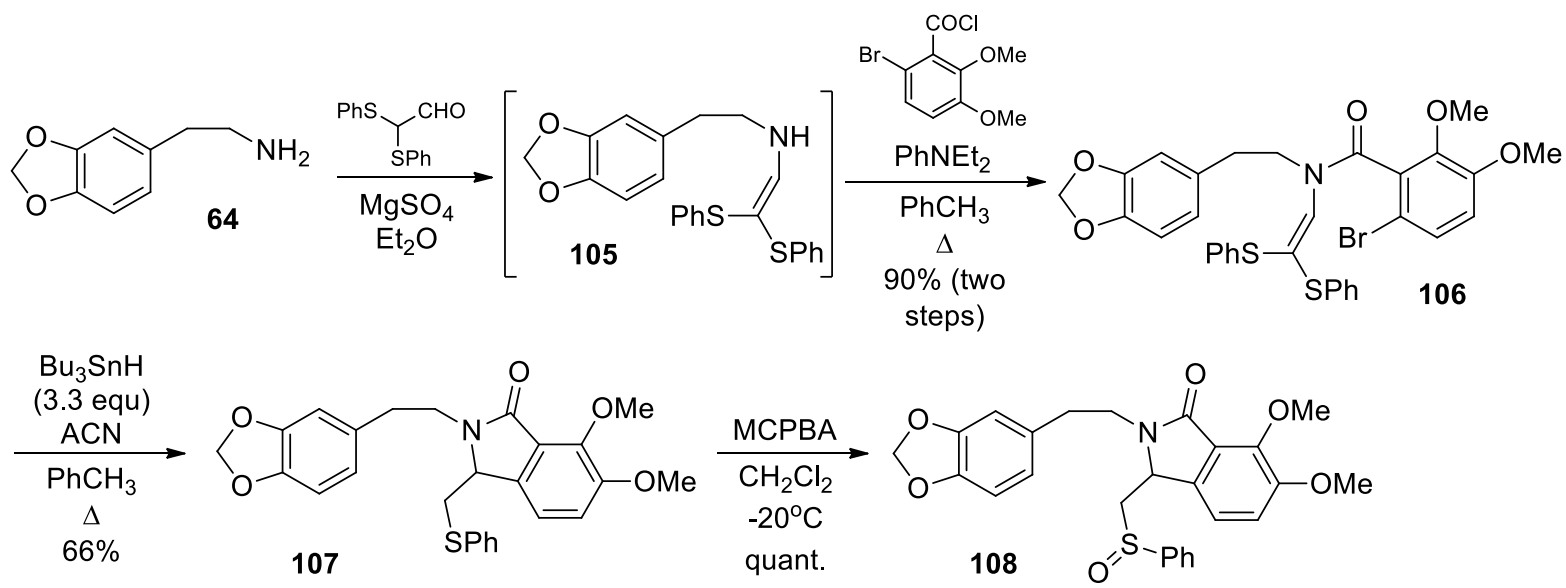

Scheme 31. Radical cyclization to prepare the isoindolone. 
Pummerer rearrangement followed by intramolecular EAS converted sulfoxide $\mathbf{1 0 8}$ to the benzazepine (109) in $80 \%$ yield as a mixture of two diastereomers (Scheme 32). However, only one diastereomer (formed in $36 \%$ yield) was capable of undergoing syn-elimination upon oxidation and subsequent heating to give dehydrolennoxamine (dehydro-11). The other diastereomer was recovered unchanged after similar treatment. However, heating the sulfoxide (108) in the presence of trifluoroacetic anhydride yielded the enamide (dehydro-11) directly in 69\% yield. Dehydrolennoxamine (dehydro-11) has been converted to chilenine by Fang and Danishefsky. ${ }^{54}$

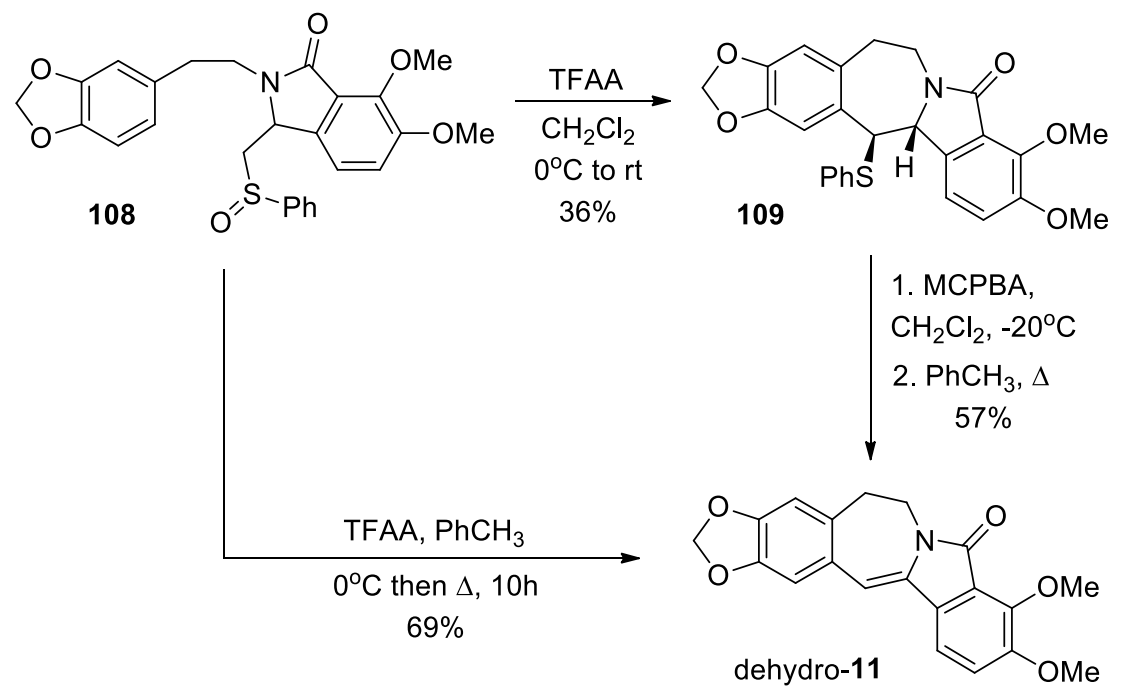

Scheme 32. Pummerer rearrangement, intramolecular EAS, and elimination to prepare dehydrolennoxamine.

Both benzazepine diastereomers (109) could be converted to lennoxamine (11) via desulfurization (Scheme 33).

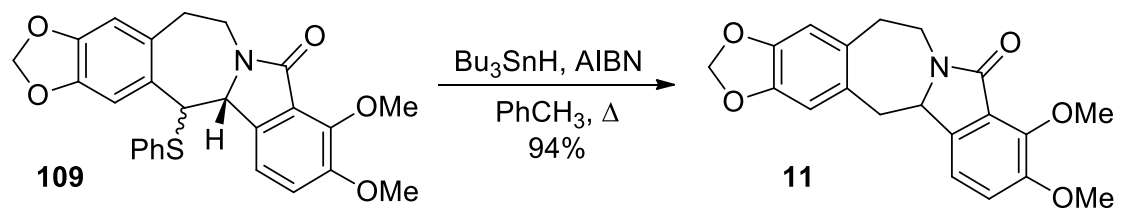

Scheme 33. Synthesis of lennoxamine via desulfurization.

A similar Pummerer cyclization was used by Montaño and Zhu in their multi-component approach to a lennoxamine-type compound. ${ }^{36}$ Initial reaction of allylamine $\mathbf{1 1 0}$ and aldehyde $\mathbf{1 1 1}$ was followed by addition of an isocyanoacetamide and camphorsulfonic acid (Scheme 34). The oxabridged tricycle thus formed (112) by domino three-component reaction and intramolecular Diels-Alder reaction was subjected to immediate fragmentation through addition of TFA at 
reduced temperature. The resultant pyrrolopyridine (113) was oxidized to the corresponding sulfoxide (114) for Pummerer cyclization, which was facilitated by the use of excess TMSOTf and Hünig's base. A 2:1 ratio of diastereomeric tetracycles (115) was isolated with the major product having the $(1 S, 2 R)$ configuration.
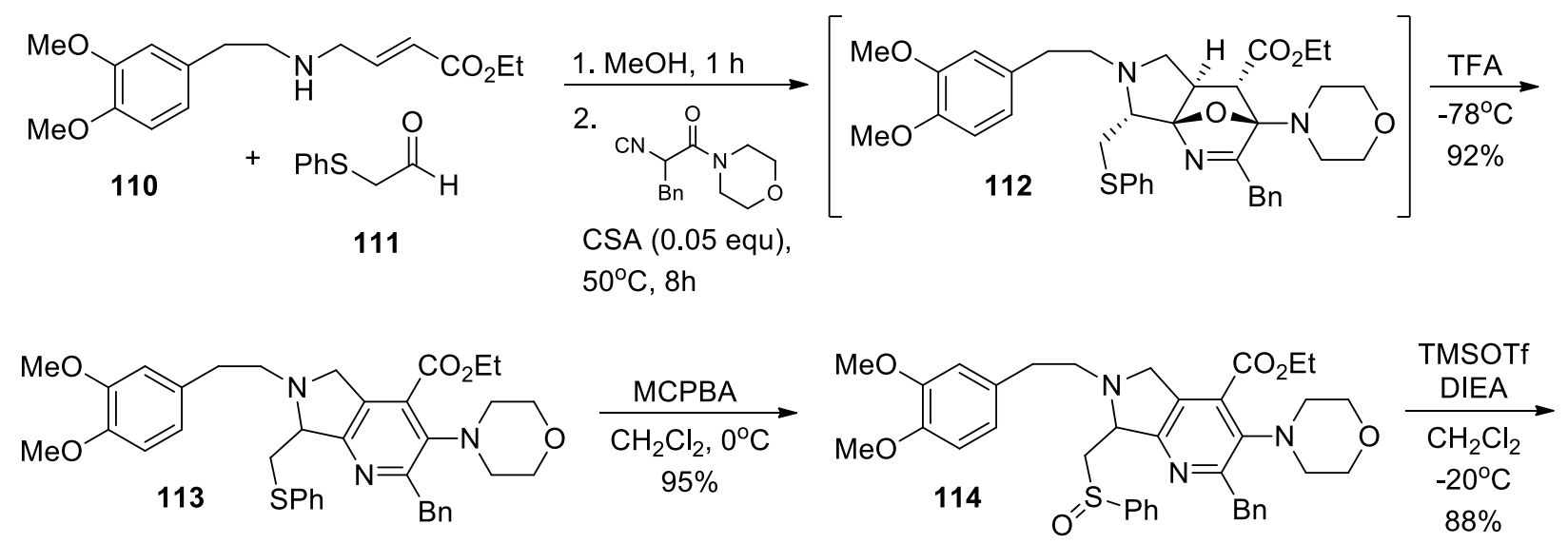<smiles>CCOC(=O)c1c2c(nc(Cc3ccccc3)c1N1CCOCC1)[C@H]1[C@H](c3ccccc3)c3cc(OC)c(OC)cc3CCN1C2</smiles>

Scheme 34. A multi-component reaction / Pummerer cyclization approach to a lennoxamine analogue.

Kim and co-workers reported construction of the C14-C14a bond using intramolecular Heck reaction. ${ }^{37}$ This approach relied upon the condensation of a keto ester (117) and an amine $(\mathbf{8 5}$, Scheme 35). The TMS-acetylene reactant was prepared via modification of the reported protocol. ${ }^{47}$ Hydration and desilylation yielded the keto ester fragment. Condensation with the phenethylamine yielded enelactam 118, the cyclization precursor. Heck cyclization proceeded in the endo fashion when tetrabutylammonium chloride was used. In the absence of this additive, exo cyclization yielded the undesired isoindoloisoquinoline. 


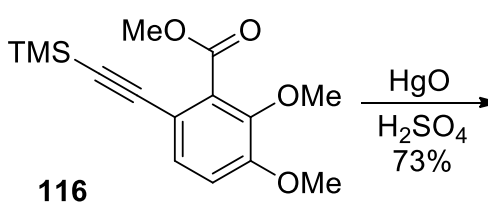<smiles>COC(=O)c1c(C(C)=O)ccc(OC)c1OC</smiles>
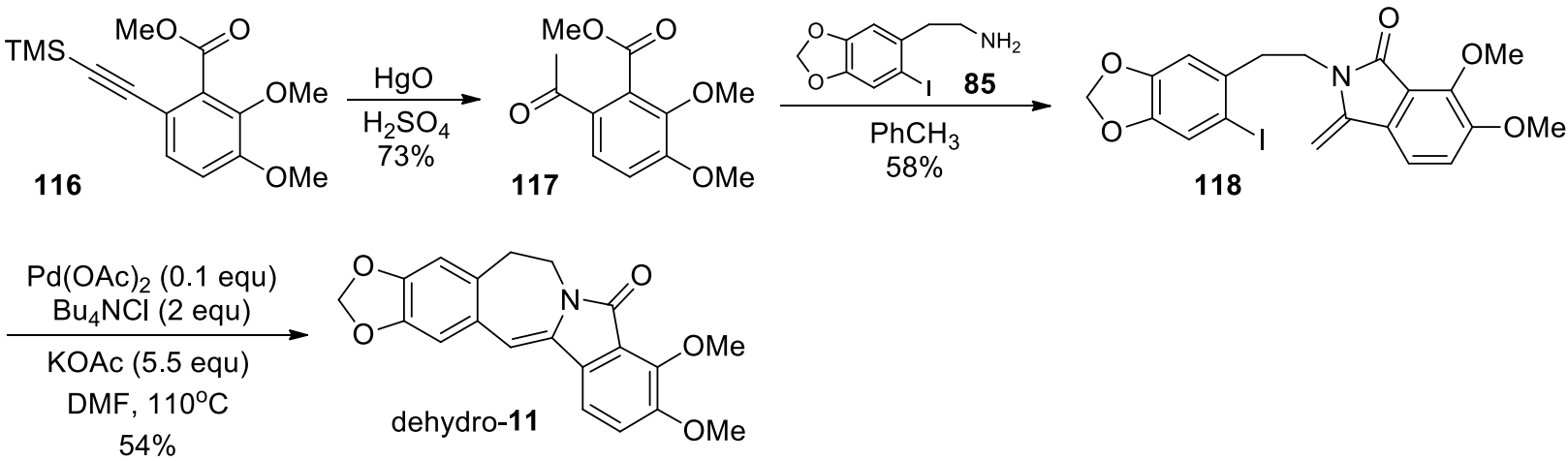

Scheme 35. Intramolecular Heck route to dehydrolennoxamine.

\subsection{Formation of the C6-N7 bond}

Narceine imide $\mathbf{1 1 9}$ has been used as a framework for building the aporhoeadane skeleton (Scheme 36) ${ }^{38}$ Hofmann elimination yielded small quantities of enelactam dehydro-45 in addition to the expected styrene derivative (121) and its $E$ isomer. The enelactam dehydro-45 is the C1-methoxy analogue of dehydrolennoxamine (dehydro-11), which was used in the Snieckus synthesis (Scheme 29).
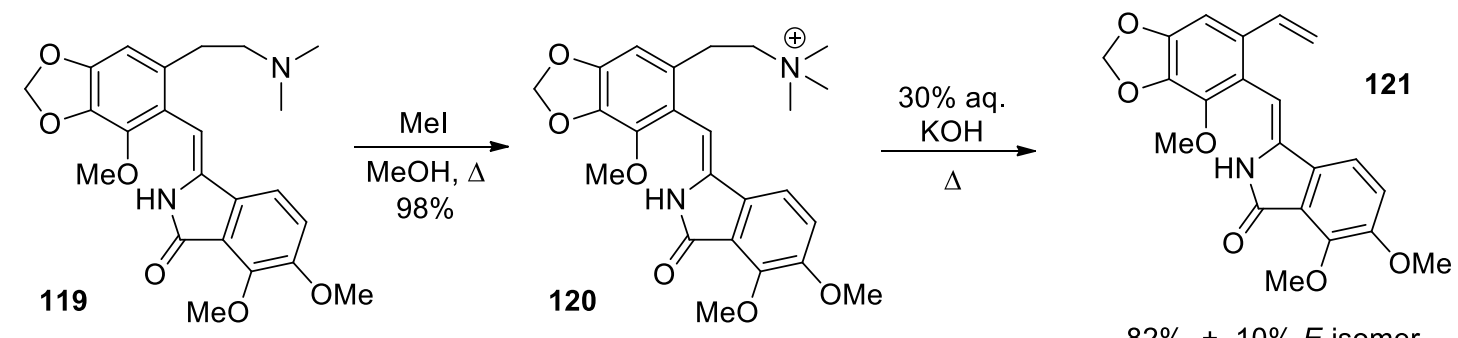

$82 \%+10 \% E$ isomer

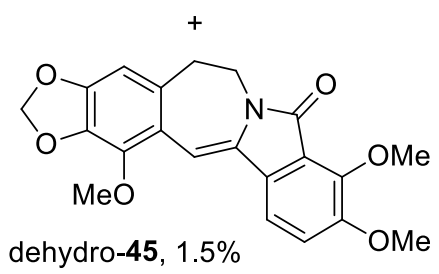

Scheme 36. Hofmann elimination of narceine imide.

Subsequent stepwise reduction of the olefin and lactam provided an analogue of Schöpf's base VI (46, Scheme 37). However, the hydrogenation of the olefin is difficult and is accompanied by small amounts of cleavage of the methylenedioxy bridge. Infrared analysis of $\mathbf{4 6}$ revealed peaks in the $2700-2800 \mathrm{~cm}^{-1}$ region suggesting trans junction of the central rings. ${ }^{39}$ 
<smiles>COc1ccc2cc3n(c(=O)c2c1OC)CCc1cc2c(c(OC)c1-3)OCO2</smiles>

dehydro-45

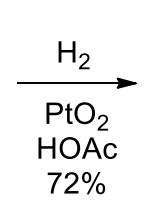

$72 \%$<smiles>COc1ccc2c(c1OC)C(=O)N1CCc3cc4c(c(OC)c3CC21)OCO4</smiles>

45

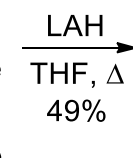

$4 \%$

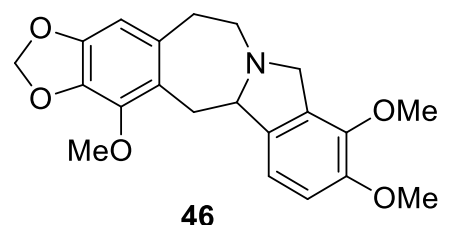

46

Scheme 37. Stepwise reduction of enelactam dehydro-45 to a Schöpf’s base VI analogue.

Comins et al. reported the first asymmetric synthesis of (+)-lennoxamine. ${ }^{40}$ The known isoindolone 125 was prepared from benzoate 123 through addition of cyanide and reduction, which led to lactamization (Scheme 38). ${ }^{41}$ At this stage, the chiral auxiliary, (+)-trans-2- $(\alpha-$ cumyl)cyclohexanol (TCC), was installed through acylation with its chloroformate.

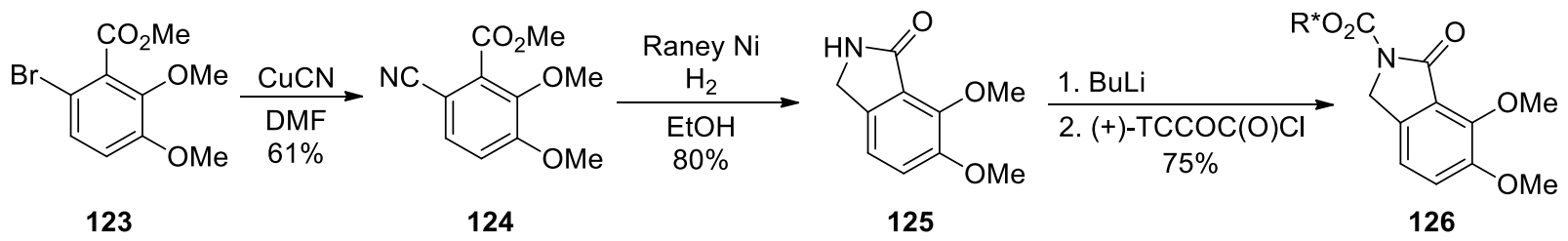

Scheme 38. Preparation of isoindolone bearing a chiral auxiliary.

This isoindolone (126) required a benzylic bromide coupling partner (129), which was prepared from 6-bromopiperonal (47, Scheme 39). The Levine reagent was used in olefination of the starting aldehyde. This was followed by a three-step one-pot procedure in which lithiumbromide exchange, formylation, and reduction occurred to afford the benzylic alcohol (128). Hydrogenation and bromination yielded the benzylic bromide fragment (129).

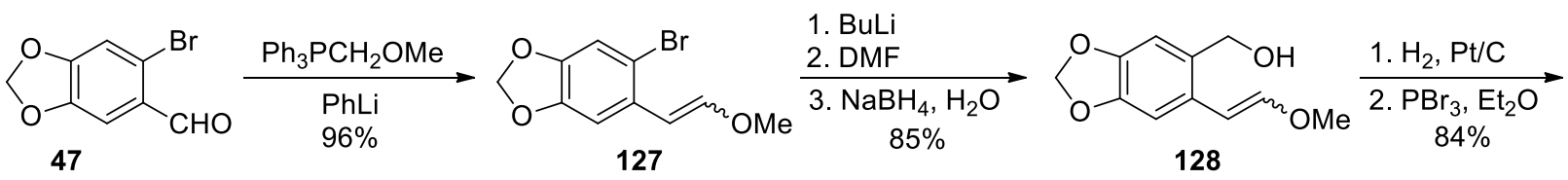<smiles>COCCc1cc2c(cc1CBr)OCO2</smiles>

129

Scheme 39. Synthesis of the benzylic bromide fragment.

Union of the fragments occurred upon exposure to NaHMDS at low temperatures (Scheme 40). The electron-rich nature of the isoindolone ring rendered the anion somewhat unstable, making this coupling challenging. Aluminum trichloride and sodium iodide cleaved only the 
methyl alkyl ether and the auxiliary, which allowed the C6-N7 bond to be formed when the alcohol (131) was converted to its mesylate and the nitrogen was deprotonated with sodium hydride.

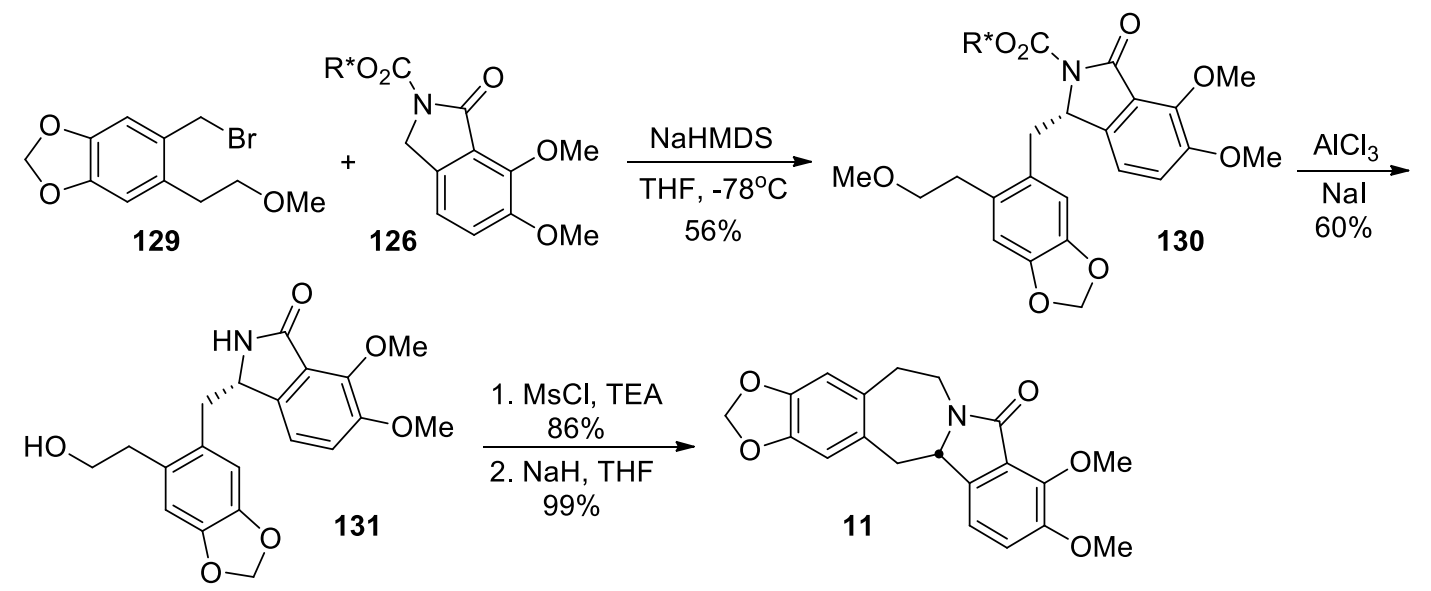

Scheme 40. Synthesis of (+)-lennoxamine.

Yoda and co-workers developed a synthesis of lennoxamine that hinged upon the chemoselective desulfurization of a $\gamma$-phenylthio-substituted aromatic lactam (135) using lithium aluminum hydride in the presence of copper(I) iodide (Scheme 41). ${ }^{42}$ The synthesis began with $N$-PMB-3,4-dimethoxyphthalimide (132), which was reduced to the hydroxylactam using DIBAL-H and immediately converted to the $\gamma$-phenylthiolactam 133. This phenylthiolactam was then coupled with benzylic chloride 134 (prepared from 6-bromopiperonal) under basic conditions. The $\gamma$-phenylthio-substituted lactam thus formed (135) underwent chemoselective desulfurization (136). The isoindolone was then deprotected (137), and the olefin was dihydroxylated, oxidatively cleaved, and reduced to alcohol 138. The alcohol was converted to its mesylate and displaced by the isoindolone nitrogen upon treatment with base to yield lennoxamine (11). 

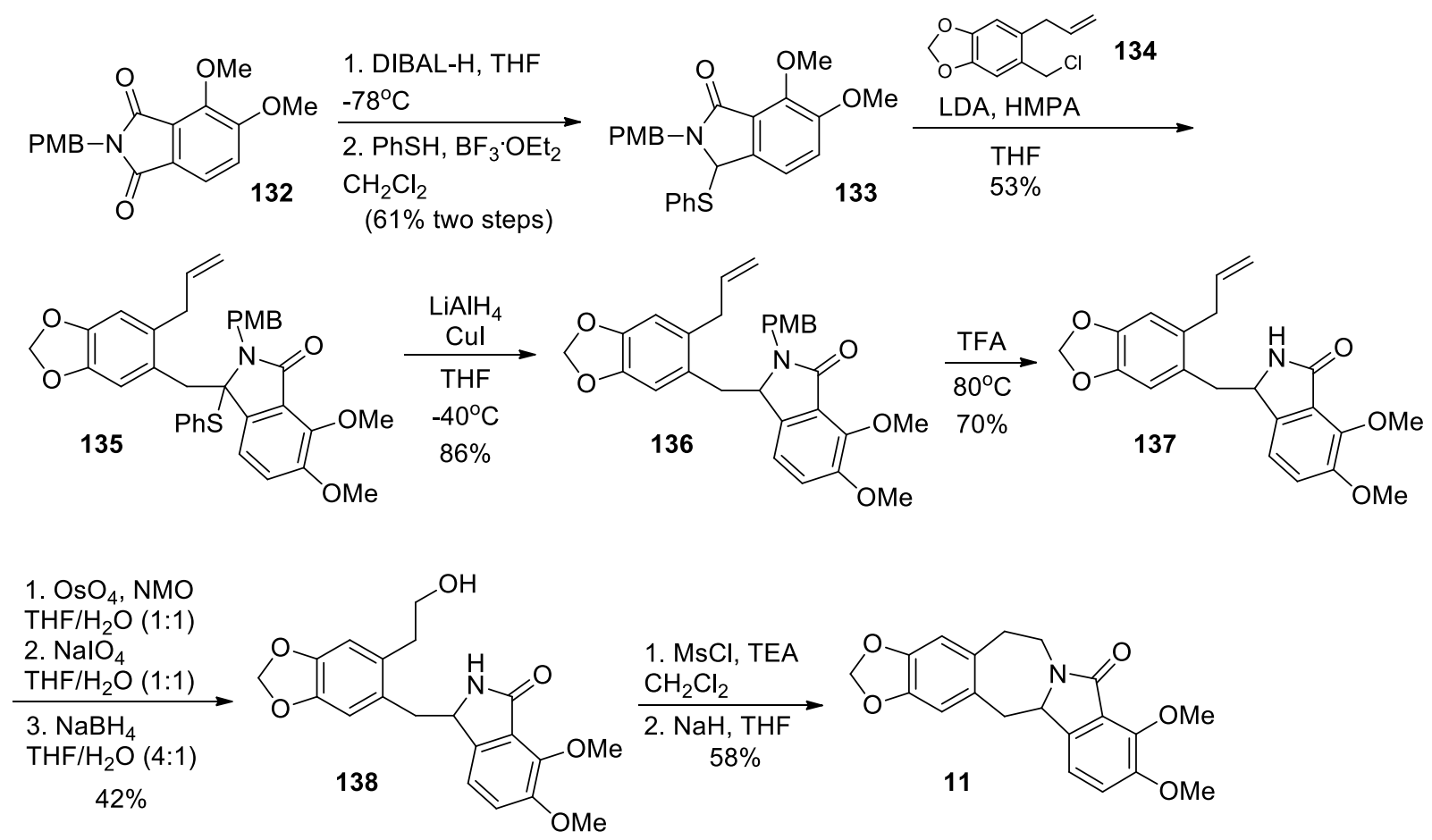

Scheme 41. Lennoxamine synthesis relying upon chemoselective desulfurization.

\subsection{Formation of the $\mathrm{C} 4 \mathrm{a}-\mathrm{C} 5$ bond}

Scartoni and co-workers pioneered this approach, which first establishes the phthalimide ring through reaction of 3-benzylidenephthalide (139) with glycine in basic media (Scheme 42). ${ }^{43}$ This yields sodium 3-benzyl-3-hydroxyphthalimidin-2-ylacetate, which is then protonated with $\mathrm{HCl}$ at reduced temperature to give the corresponding carboxylic acid. Dehydration provides 3benzylidenephthalimidin-2-ylacetic acid (140) as a 4:1 mixture of its $E$ and $Z$ isomers. Subsequent intramolecular electrophilic aromatic substitution in polyphosphoric acid forms the benzazepine system of $\mathbf{1 4 1}$.

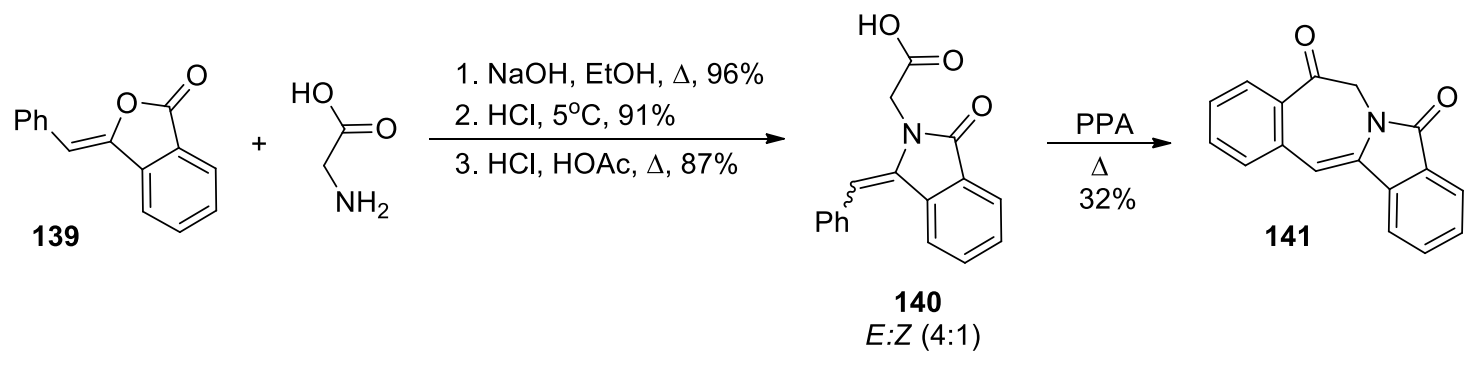

Scheme 42. Stepwise formation of the isoindole and benzazepine systems.

The tetracycle 141 can then undergo a variety of transformations (Scheme 43) to the enol acetate (144), the acetal (143), or the oxime (142). Additionally, Schmidt reaction with hydrazoic 
acid ultimately induces fragmentation of the seven-membered ring to the phthalimidine (147) and contraction of the seven-membered ring to the isoindoloisoquinolinedione (148).

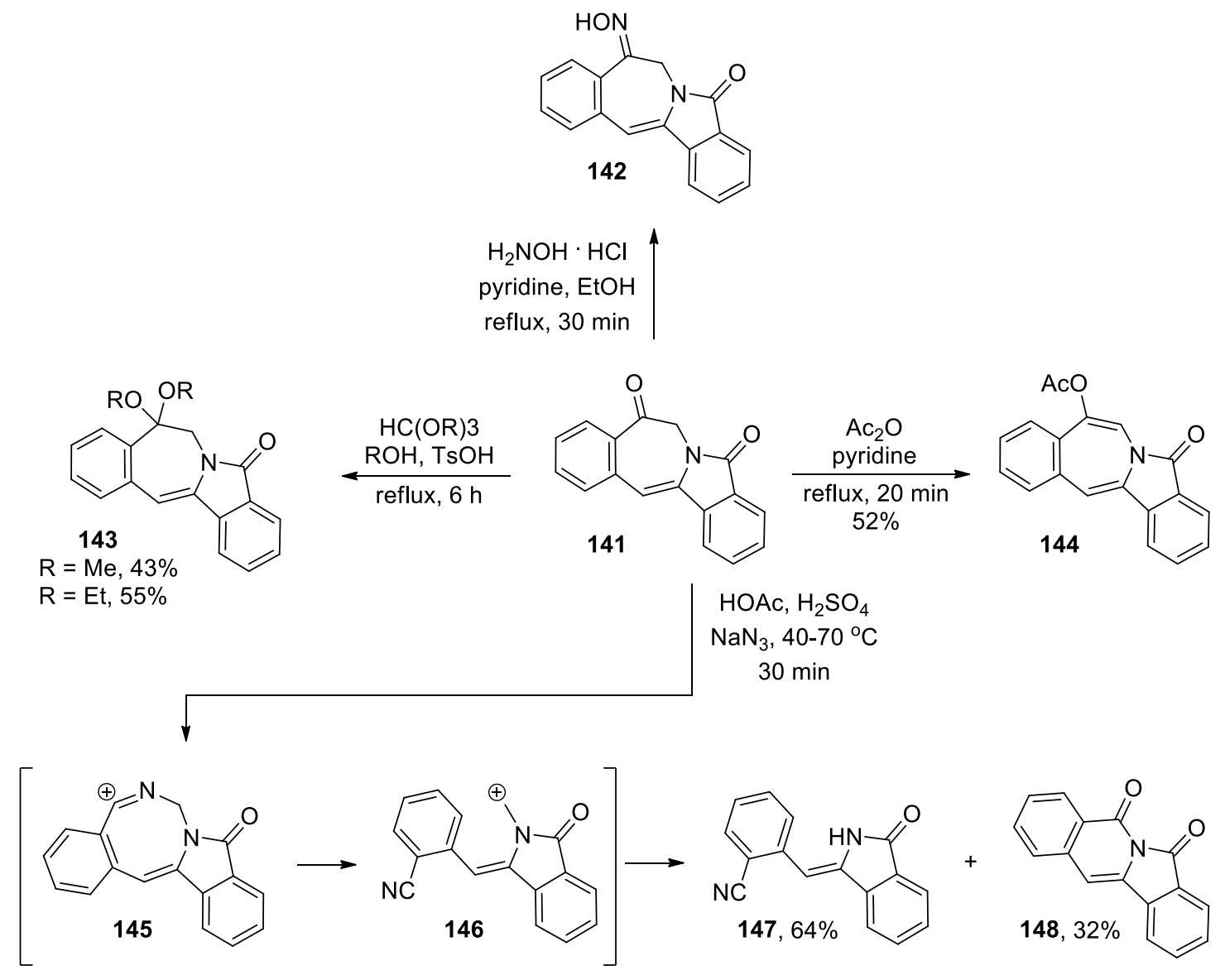

Scheme 43. Reactions of the benzylic ketone.

Significantly, the oxidation state of various sites on the seven-five system can be manipulated. Wolff-Kishner reduction of the benzylic ketone of 141 yielded enelactam 149, which can undergo addition of bromine and a nucleophilic solvent across the olefin (150, Scheme 44).
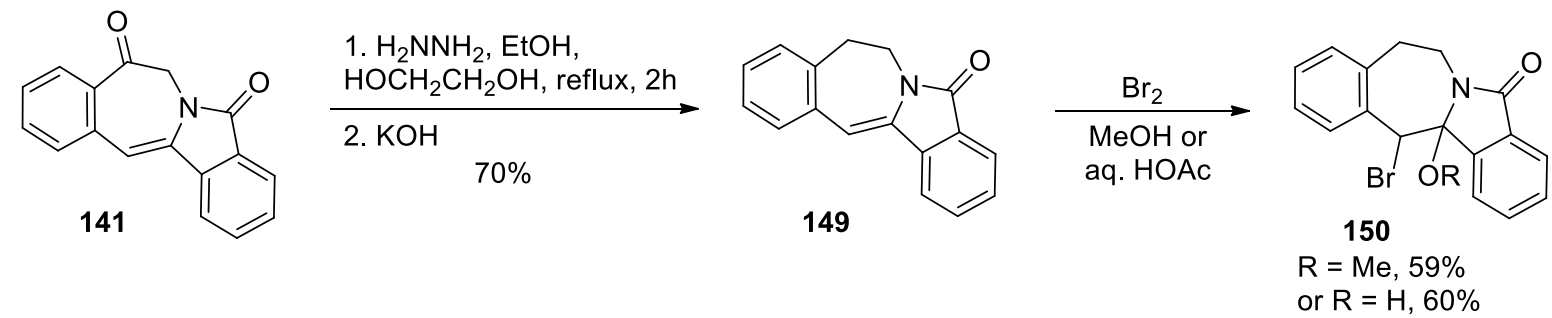

Scheme 44. Wolff-Kishner reduction and electrophilic addition. 
Alternatively, hydrogenation reduces both the benzylic ketone and the olefin (151), while the resultant alcohol can be readily reoxidized using Jones' reagent (152, Scheme 45).<smiles>O=C1CN2C(=O)c3ccccc3C2=Cc2ccccc21</smiles>

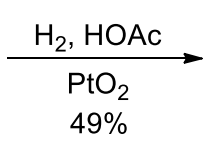<smiles>O=C1c2ccccc2C2CC(O)c3ccccc3CN1C2</smiles>
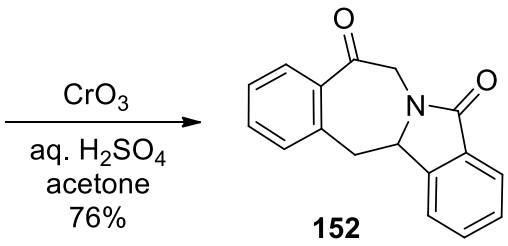

Scheme 45. A reduction-oxidation route to an isoindolobenzazepinedione.

The same product (152) results directly from intramolecular electrophilic aromatic substitution of phthalimidine 153 (Scheme 46). However, this cyclization suffers a reduction in yield due to the formation of isoindoloisoquinolinone $\mathbf{1 5 4}$ via the extrusion of carbon monoxide from the intermediate acylium ion.

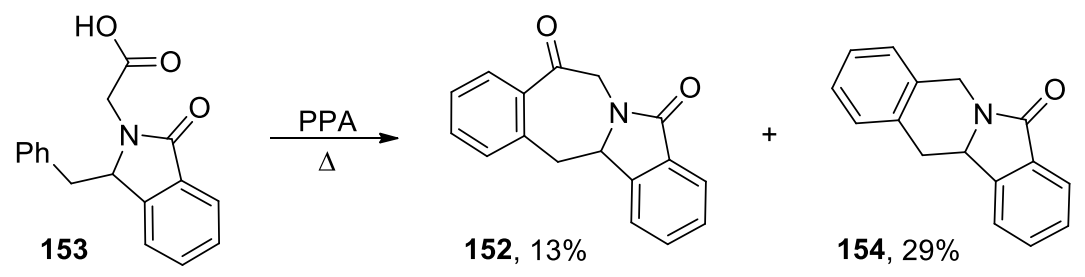

Scheme 46. An EAS route to an isoindolobenzazepinedione.

Notably, both the Wolff-Kishner reduction product 149 and the electrophilic addition products 150 can be reduced to the isoindolobenzazepinone (155) via catalytic hydrogenation (Scheme 47). Subsequent lithium aluminum hydride reduction of the lactam yields an unstable isoindolobenzazepine (156), which can be alkylated to produce the methiodide 157.

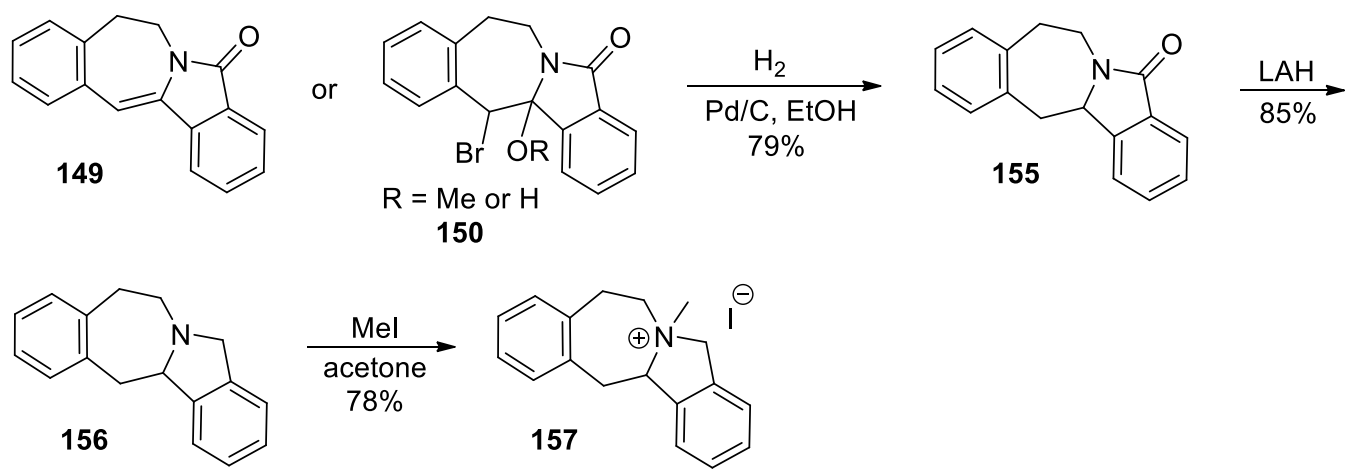

Scheme 47. Further reduction of enelactam 149. 
Others ${ }^{44}$ have commented on the tantalizing statement at the conclusion of the manuscript by Scartoni, et al. stating that "Work is in progress to test whether the series of reactions described above can be applied to similar products, bearing appropriate substitutents in the benzene rings, in the hope of finding a new route to alkaloids of the protopine, and possibly of the rhoeadine series" (Figure 5). Therein lies an opportunity for further investigation that would tremendously enhance the synthetic utility of this pathway.

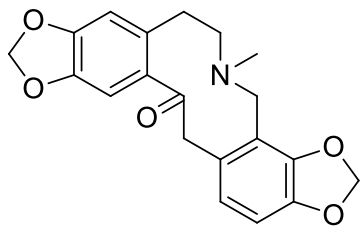

protopine (158)

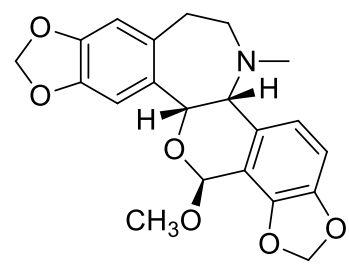

rhoeadine (41)

Figure 5. Protopine and rhoeadine.

Some progress was made toward this goal by Marsili and co-workers. ${ }^{45}$ Phthalimide derivative 159 (Scheme 48) was prepared, as a mixture of its $E$ and $Z$ isomers, in a fashion similar to that reported previously (refer to Scheme 42). ${ }^{43}$ Hydrogenation and cyclization, also accomplished in the familiar fashion, provided the isoindolobenzazepinedione (161), which was subsequently protected as its acetal (162). Reduction of the lactam using lithium aluminum hydride yielded an unstable amine (163) that was immediately converted to its methiodide (164). The methiodide was passed over an ion-exchange resin pretreated with sodium hydroxide and then heated to induce degradation to compound $\mathbf{1 6 5}$, which could be considered a protopine analogue.

Napolitano et al. devised a synthesis of lennoxamine and chilenamine that relies upon a key intramolecular cyclization through alkylation (Scheme 49). ${ }^{46}$ Their synthesis began with a phthalide, which was condensed with aminoacetaldehyde dimethyl acetal to yield phthalimide 166. Reduction of the olefin yielded the cyclization substrate (167), and cyclization was achieved by treatment with acetyl chloride followed by zinc chloride. An additional hydrogenation yielded lennoxamine (11), and literature precedent, ${ }^{19}$ allowed conversion to chilenamine (15). 

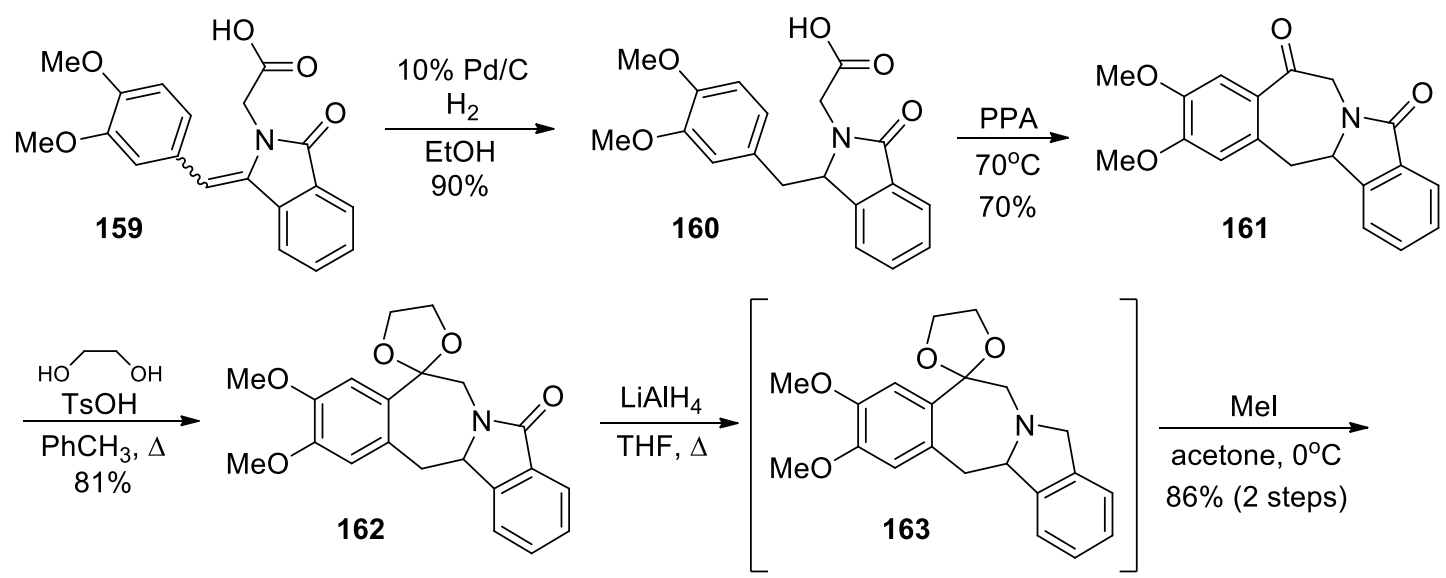

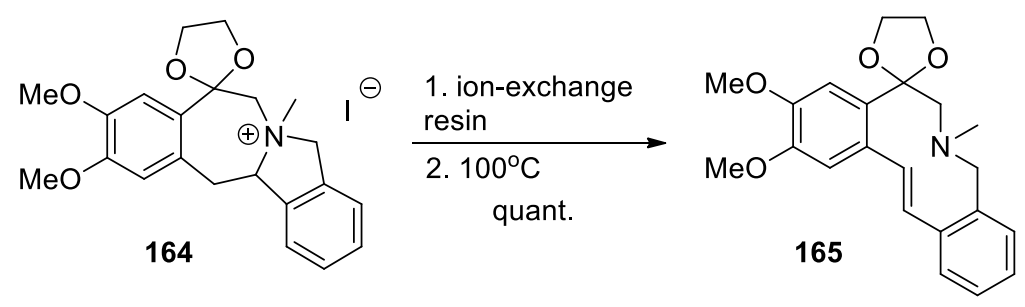

Scheme 48. Preparation of a protopine analogue via an aporhoeadane.
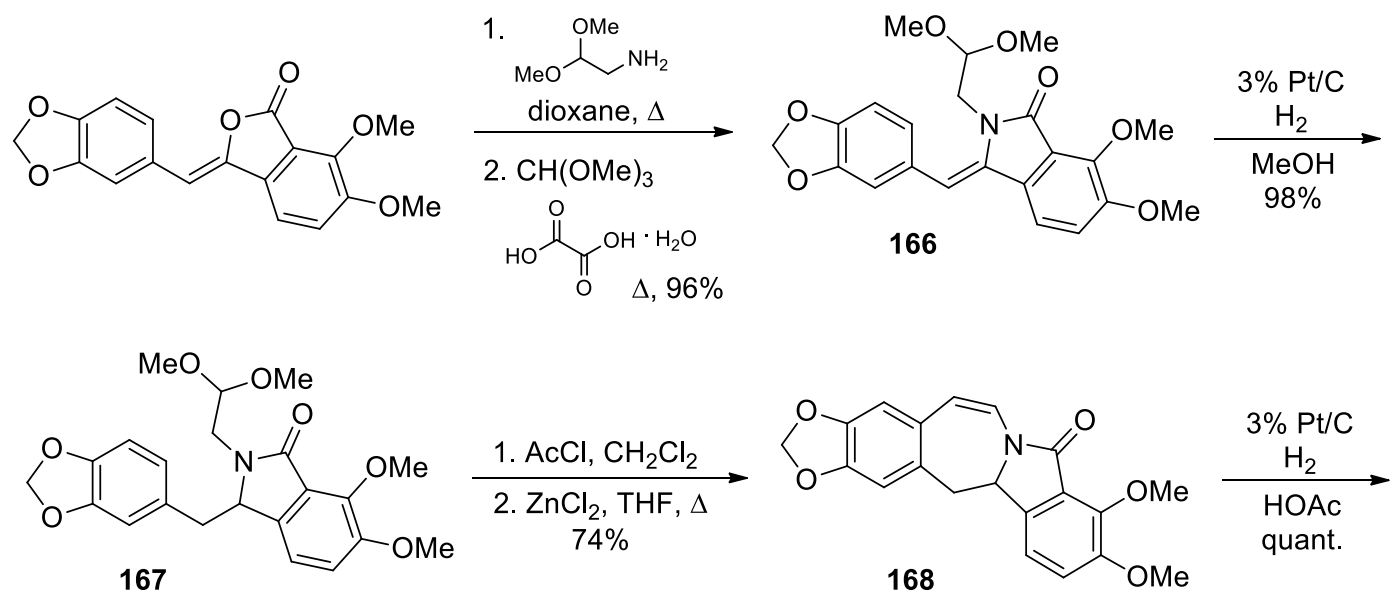<smiles>COc1ccc2c(c1OC)C(=O)N1C=Cc3cc4c(cc3CC21)OCO4</smiles>

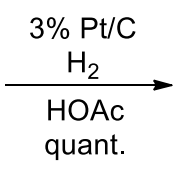<smiles>COc1ccc2c(c1OC)C(=O)N1CCc3cc4c(cc3CC21)OCO4</smiles>

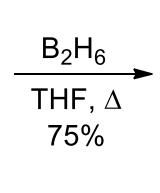<smiles>COc1ccc2c(c1OC)CN1CCc3cc4c(cc3CC21)OCO4</smiles>

Scheme 49. Synthesis of lennoxamine and chilenamine. 
Koseki and Nagasaka reported a formal synthesis of lennoxamine in which the key steps include palladium-catalyzed arylation and subsequent intramolecular cyclization of an $o$ ethynylbenzamide (174). ${ }^{47}$ Their synthesis began with the reduction of lactone 169 (Scheme 50). The resultant acid (170) was coupled with 2-(benzyloxy)ethylamine using diethyl pyrocarbonate. The amide (171) was protected using Meerwein's reagent, and then the trimethylsilylacetylene was installed. Subsequent deprotection of the amide yielded the substrate for palladiumcatalyzed arylation (173). The arylation product (174) was treated with LiHMDS to induce intramolecular cyclization giving isoindolone 175. The isoindolone could also be prepared in $61 \%$ yield via a one-pot procedure in which palladium-catalyzed arylation was followed immediately by the addition of 2 equivalents LiHMDS. The benzyl group was removed via hydrogenolysis, which also reduced the olefin. Swern oxidation and immediate formation of the dimethyl acetal yielded 167, which was previously converted to lennoxamine (refer to Scheme 49). ${ }^{48}$
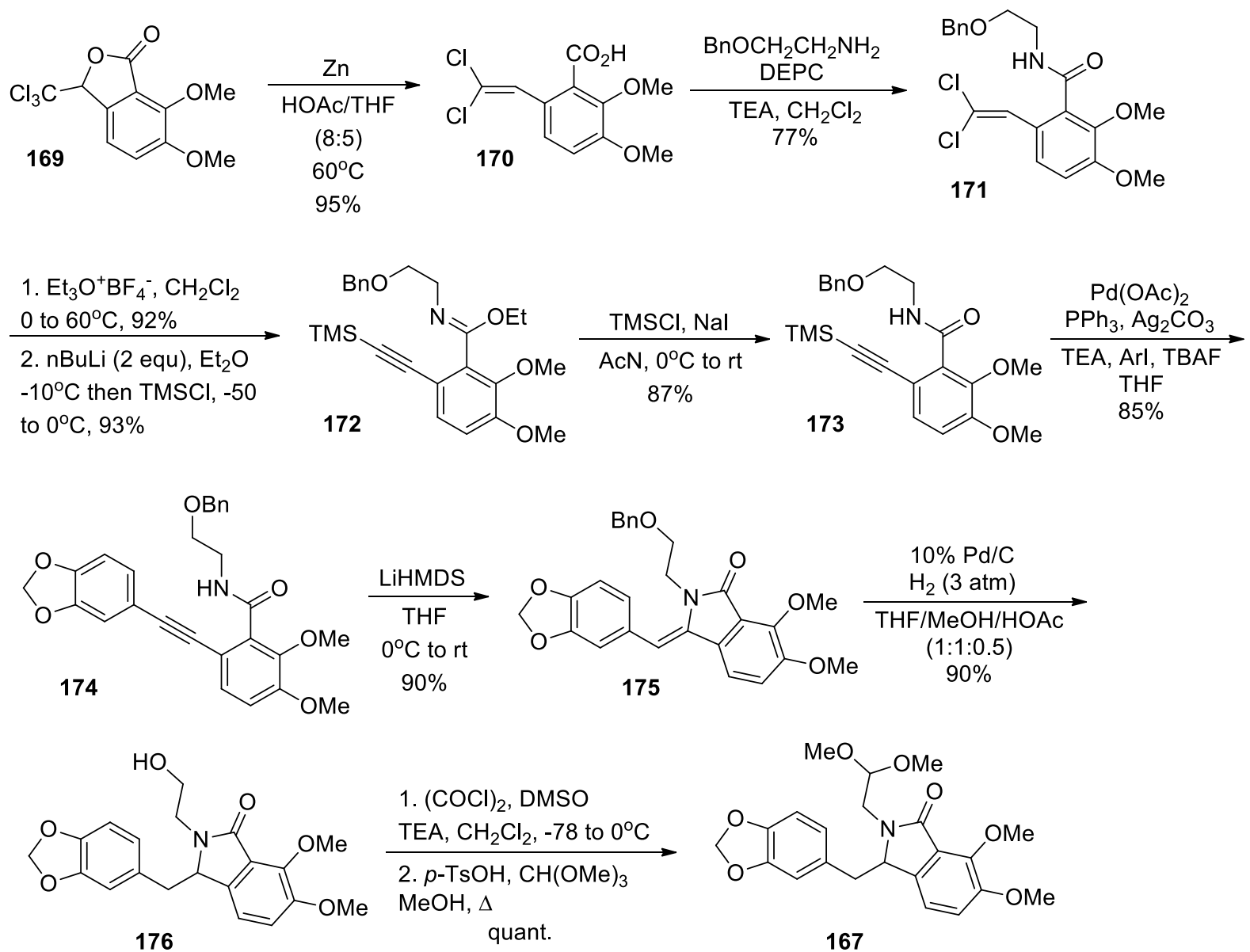

1. $(\mathrm{COCl})_{2}$, DM
TEA, $\mathrm{CH}_{2} \mathrm{Cl}_{2},-$
$\begin{aligned} & \text { 2. } p-\mathrm{TsOH}, \mathrm{CH} \\ & \mathrm{MeOH}, \Delta \\ & \text { quant. }\end{aligned}$

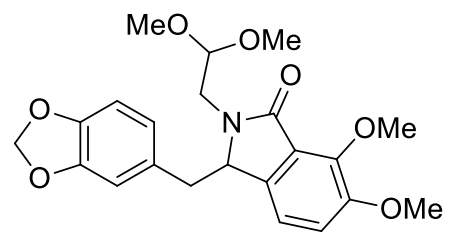

176

Scheme 50. Alternative preparation of the dimethyl acetal 167. 
Couture et al. reported a synthesis of lennoxamine that has at its core a basic cyclization of a phosphorylated benzamide (180) followed by a Horner coupling. ${ }^{48}$ Regioselective metallation of 4-fluoroveratrole (177) and trapping with carbon dioxide yielded benzoic acid 178 (Scheme 51). After activation as the acid chloride, this fragment was coupled with phosphorylated amine 179

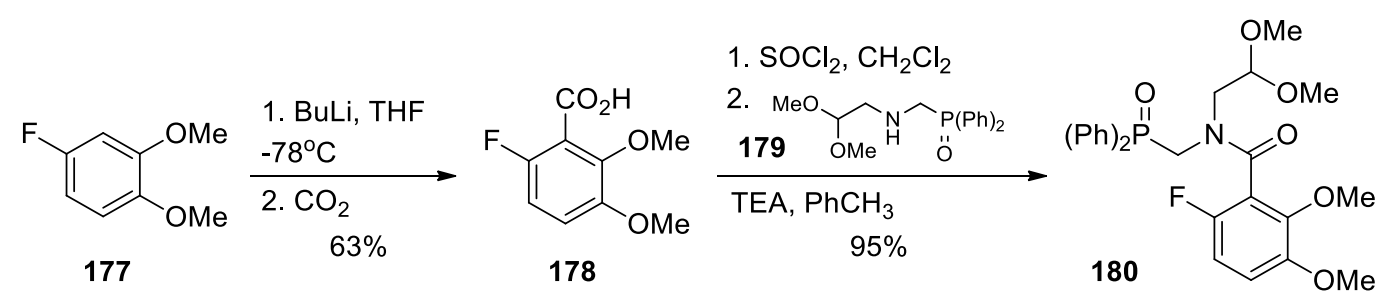

Scheme 51. Phosphorylated benzamide synthesis.

The phosphorylated amine (179) was prepared from aminoacetaldehyde dimethyl acetal (181) in two steps: Mannich reaction to form the hexahydrotriazine (182) and fragmentation through exposure to diphenylphosphine oxide (Scheme 52).

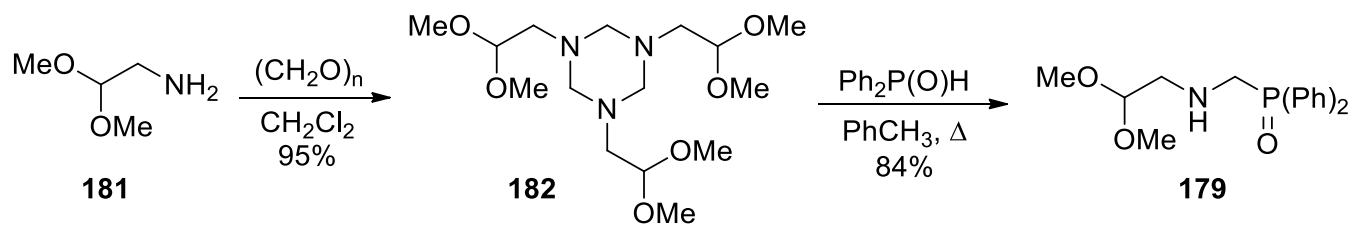

Scheme 52. Phosphorylated amine synthesis

The benzamide (180) thus derived underwent regioselective cyclization to form the isoindolone 183 (Scheme 53). This phosphorylated isoindole was united with piperonal through a Horner reaction (166). The olefin was reduced, and cyclization under acidic conditions yielded the benzazepinone (168). One further hydrogenation produced lennoxamine (11). 

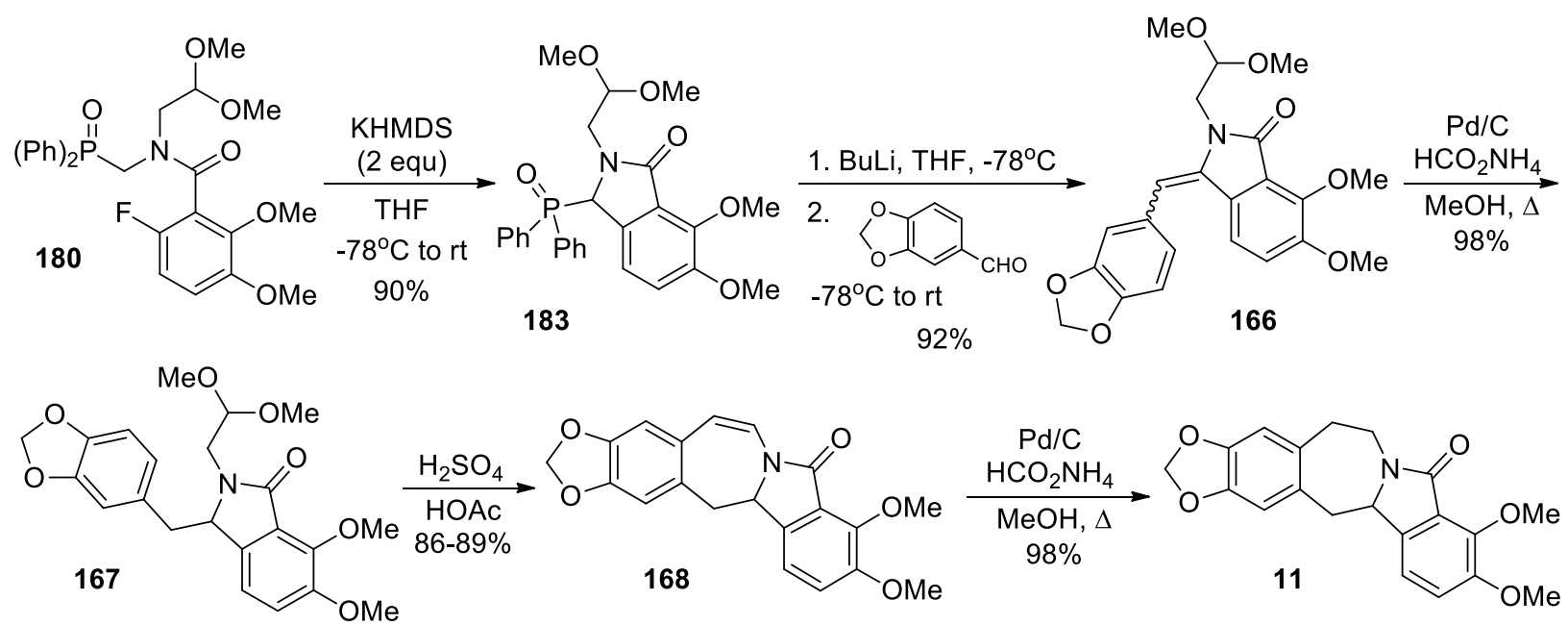

Scheme 53. Conversion of a phosphorylated benzamide to lennoxamine.

Two analogues of lennoxamine (184 and 185, Figure 6) were also prepared in an analogous fashion, from phosphorylated $o$-bromobenzamides.
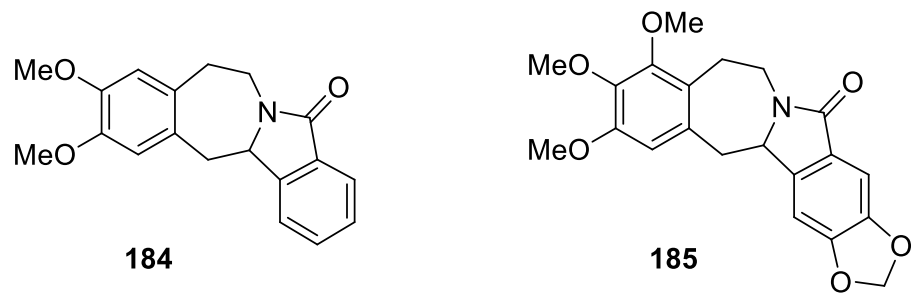

Figure 6. Lennoxamine analogues prepared from phosphorylated $o$-bromobenzamides.

Meyer, Cossy, and co-workers described a synthesis of lennoxamine in which Heck-SuzukiMiyara domino reactions were used to construct the isoindolone and add the framework for the benzazepine. ${ }^{49,50}$ The necessary ynamide (189) was prepared from 2,3-dimethoxybenzoic acid (186, Scheme 54). Bromination using 1,3-dibromo-5,5-dimethylhydantoin was followed by coupling with aminoacetaldehyde dimethyl acetal via the acid chloride. The secondary amide thus formed (187) was deprotonated with KHMDS, and TMS-acetylene was then installed using the alkynyliodonium salt. Desilylation of $\mathbf{1 8 8}$ provided the desired ynamide (189). 

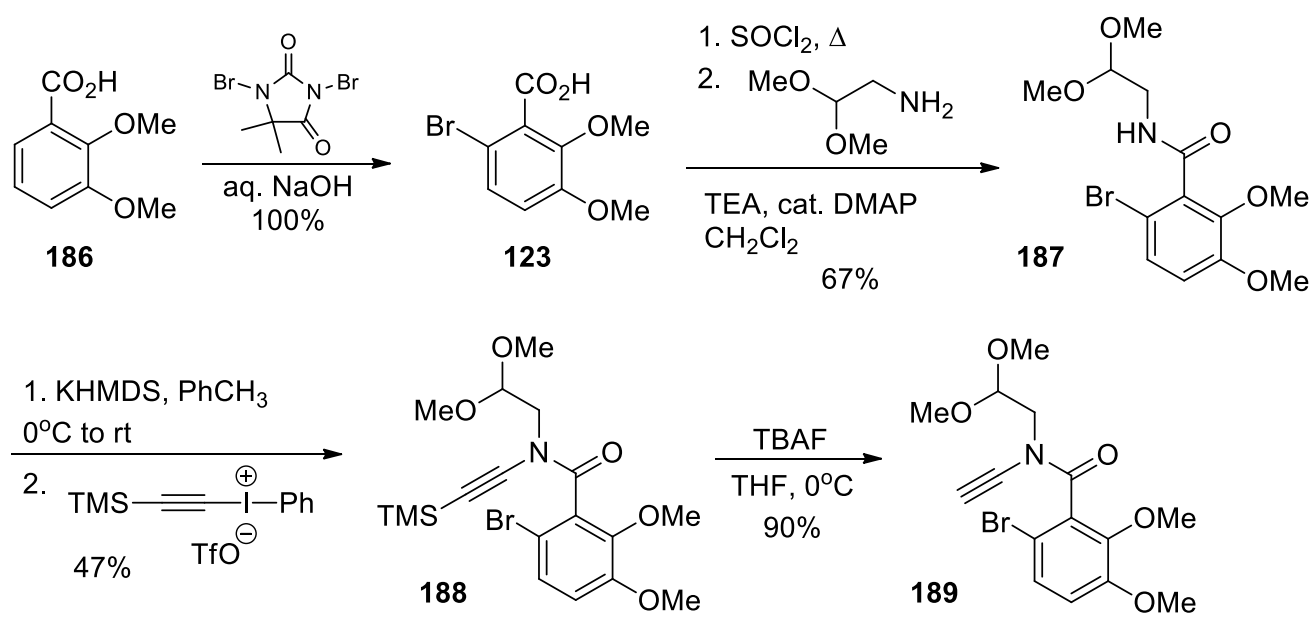

Scheme 54. Synthesis of the ynamide for Heck-Suzuki-Miyara domino reaction.

When treated with 3,4-(methylenedioxy)phenylboronic acid in the presence of catalytic palladium acetate and triphenylphosphine the domino sequence provided the isoindolone (166, Scheme 55) as an 85:15 mixture of the $E$ and $Z$ isomers. Hydrogenation was followed by ring closure in $\operatorname{acid}^{48}$ to yield enamide $\mathbf{1 6 8}$, and an additional hydrogenation provided lennoxamine (11) in eight steps and 7\% overall yield.
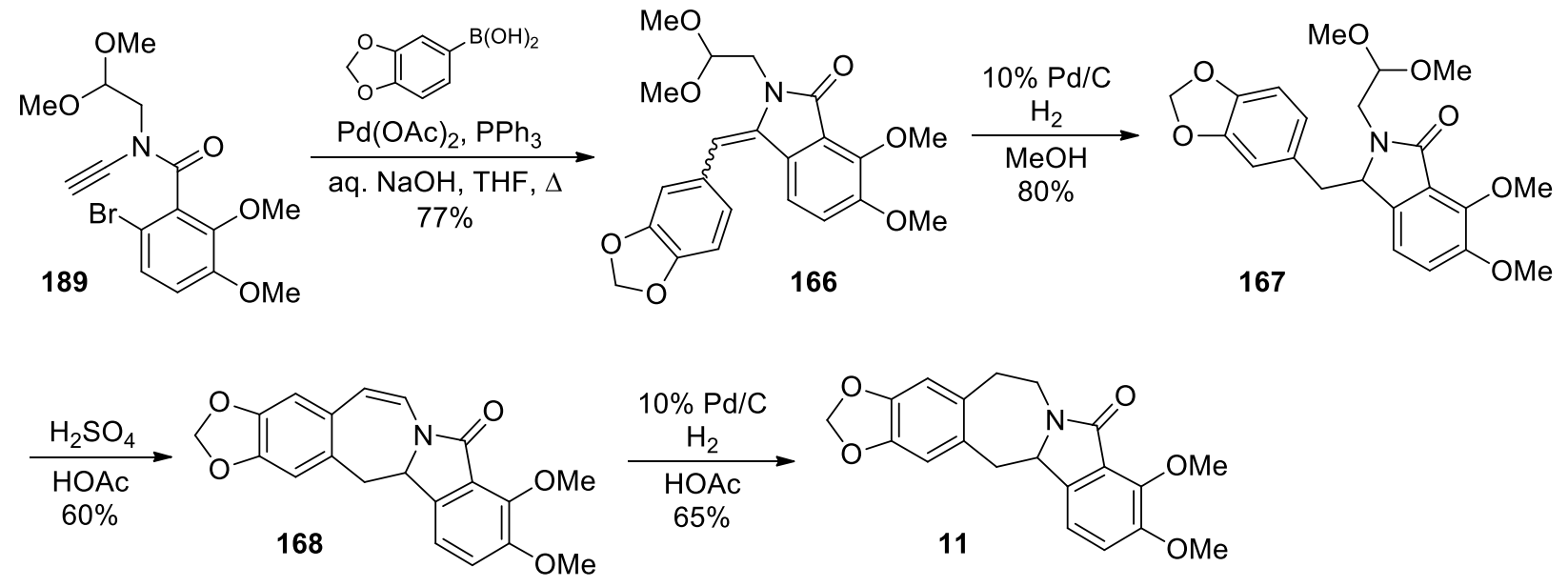

Scheme 55. Heck-Suzuki-Miyara domino reaction and completion of the lennoxamine synthesis.

\subsection{Formation of the C13-C14 bond}

Building on the inspiration provided by earlier photochemical attempts, King and Mazzocchi revisited this strategy utilizing benzyl thioethers, benzyl phenyl ethers, and benzyl diphenyl amines as photocyclization substrates. ${ }^{44}$ Of these, the benzyl thioethers proved to be the most promising substrates. A benzyl $t$-butyl thioether substrate (196) was prepared in six steps from homoveratric acid (190, Scheme 56). Electrophilic aromatic substitution and concomitant 
cyclization provided isochromanone (191). Ring opening with $t$-butyl thiol in the presence of acetic anhydride, acetic acid, and perchloric acid provided a benzyl $t$-butyl thioether (192). Subsequent esterification, amidation, and reduction yielded phenethylamine 195 that was condensed with phthalic anhydride to install the phthalimide fragment.
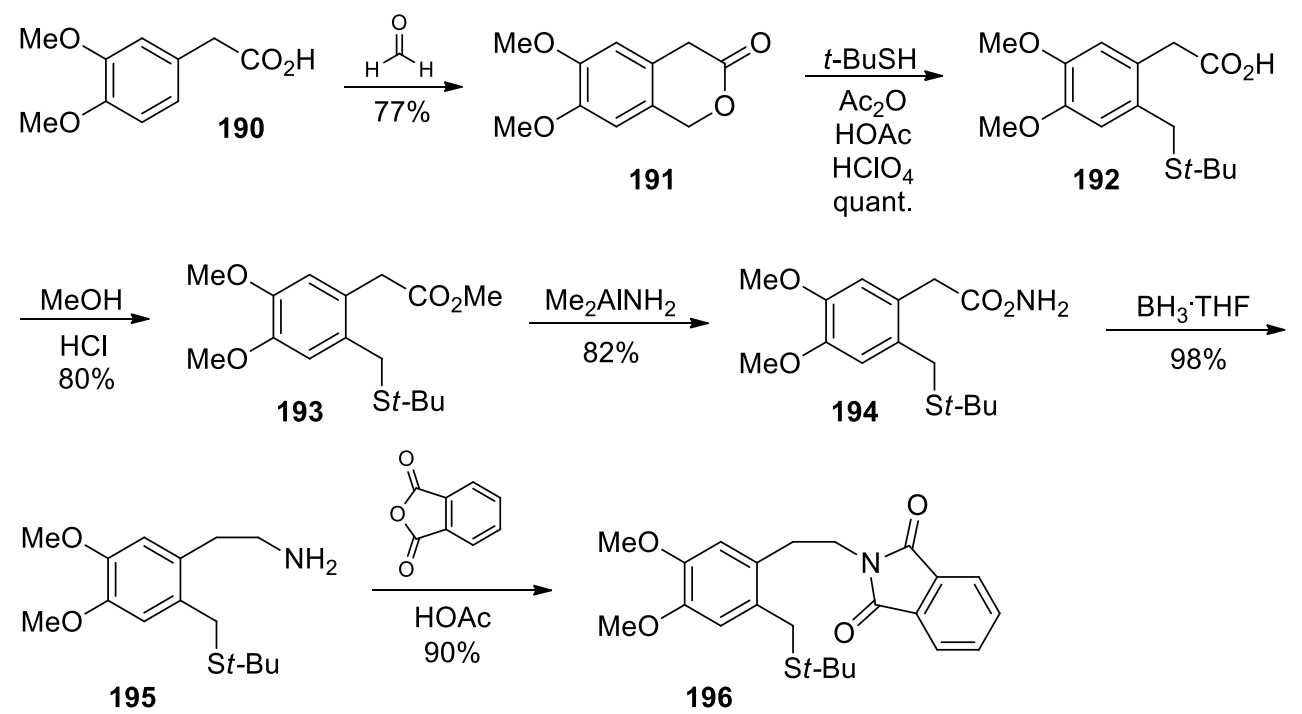

Scheme 56. Preparation of a benzyl $t$-butyl thioether photocyclization substrate.

Photocyclization successfully formed the seven-membered ring in $71 \%$ yield (197, Scheme 57) as a diastereomeric mixture in which the cis arrangement predominated and was expected to be more stable due the potential for the trans isomer to undergo spontaneous epoxide formation. Dehydration yielded a thioenol ether (198) that was expected to be a critical intermediate for the subsequent installation of the ketone and hydroxyl groups of chilenine. However, attempts to hydrolyze the thioenol ether yielded only the enelactam (100) familiar from the Snieckus approach (refer to Scheme 30). ${ }^{33}$
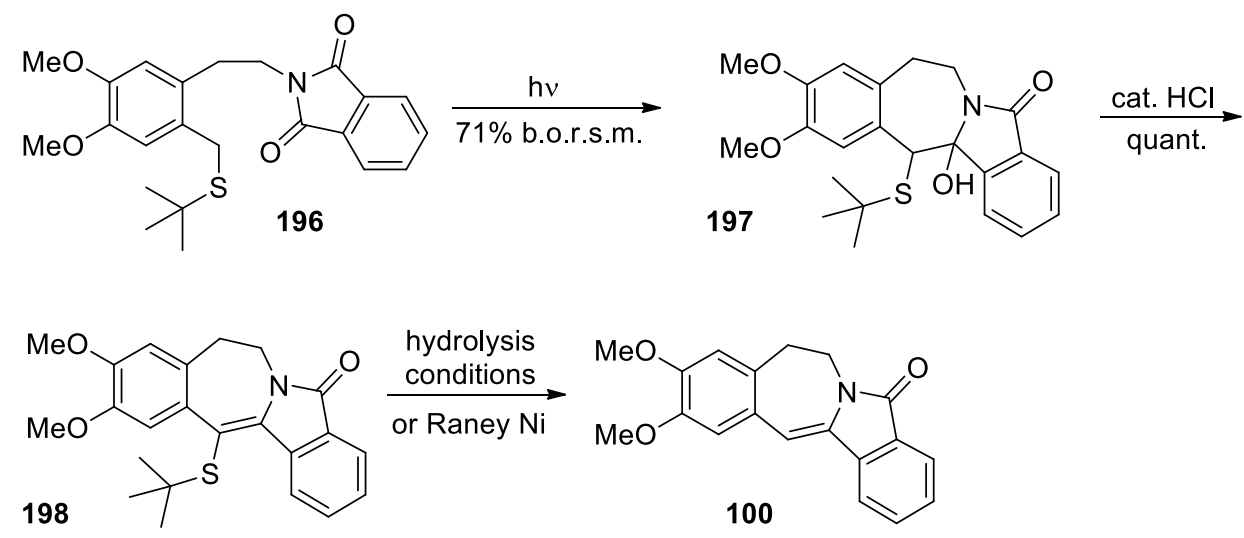

Scheme 57. Photocyclization of a benzyl $t$-butyl thioether. 
An alternative approach employed a benzaldehyde derivative masked as its dithiane (201, Scheme 58), which was prepared in two steps from an appropriate phthalimide (199).<smiles>COc1ccc(CCN2C(=O)c3ccccc3C2=O)cc1OC</smiles>

199
1.

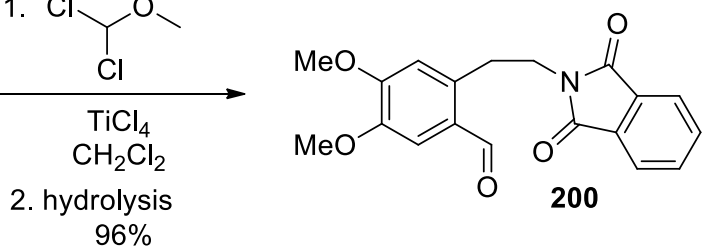<smiles>CCOCCOCCOc1cc(CCN2C(=O)c3ccccc3C2=O)c(C2SCCCS2)cc1OC</smiles>

Scheme 58. Preparation of a dithiane photocyclization substrate.

Photocyclization successfully installed the seven-membered ring in $38 \%$ yield (202, Scheme 59); however, yet again most attempts to hydrolyze the dithiane met with formation of the familiar enelactam (100).

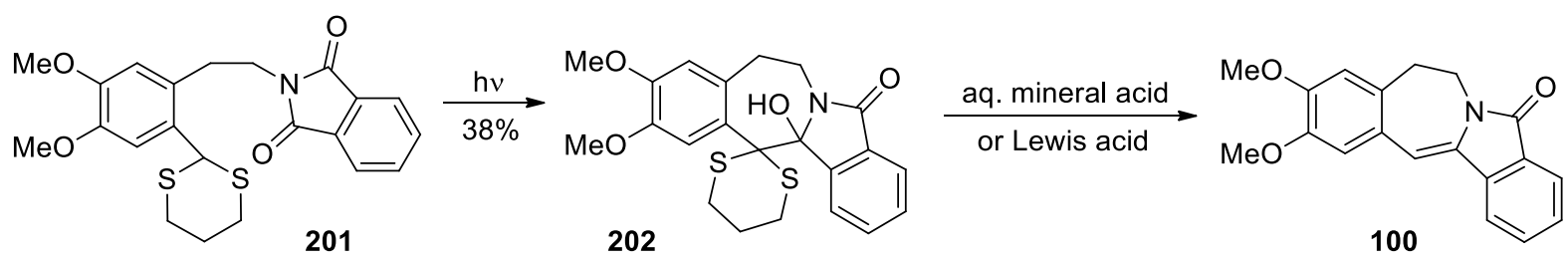

Scheme 59. Photocyclization of a dithiane.

Treatment with cupric nitrate on montmorillonite clay led to seven-membered ring scission (Scheme 60).

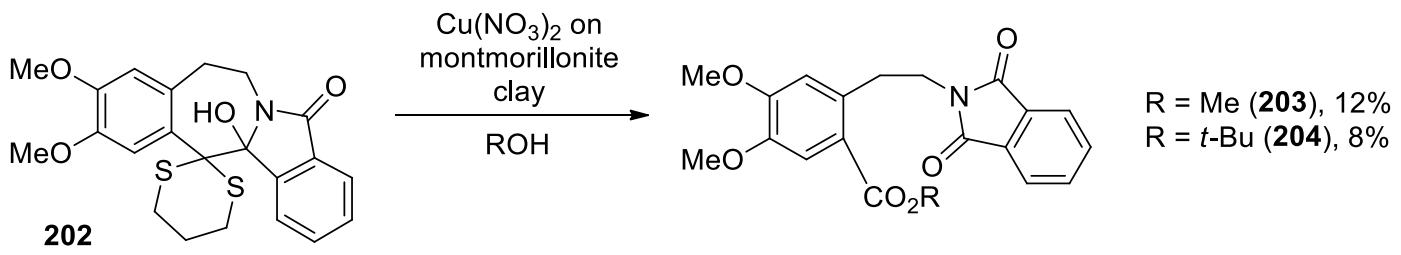

Scheme 60. Ring cleavage of the benzazepine. 
However, exposure of dithiane $\mathbf{2 0 2}$ to cupric oxide and cupric chloride in acetone at reflux produced an enol ether (205) through hydrolysis, solvent incorporation, and [3,3]-sigmatropic rearrangement (Scheme 61). Unfortunately, hydrolysis of this enol ether or its analogue derived from acetophenone was not successful.
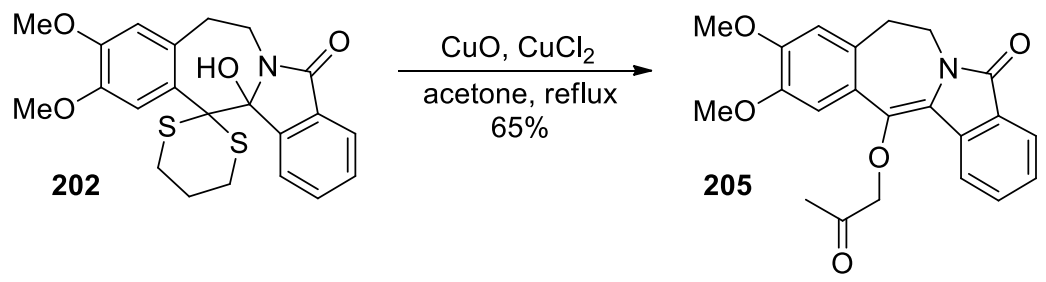

Scheme 61. Enol ether formation.

Despite the setbacks in functionalizing the photocyclization product as desired, the preparation of dithiane 201 suggested to the investigators that a more efficient synthesis of the initial benzyl $t$-butyl thioether photocyclization substrate (196) could be accomplished as outlined in Scheme 62. Compound 199, which is readily prepared from 3,4dimethoxyphenethylamine and phthalic anhydride, could be converted into the photocyclization substrate via formylation, reduction, and condensation with $t$-butyl thiol. ${ }^{51}$
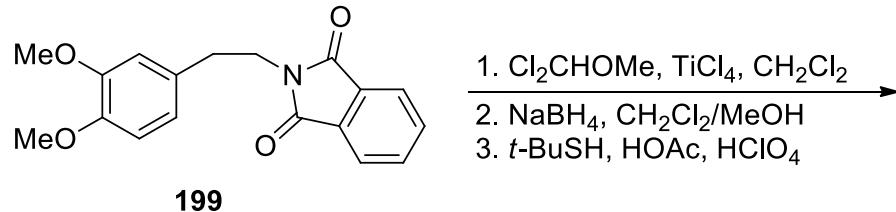

3. $t$-BuSH, $\mathrm{HOAc}, \mathrm{HClO}_{4}$

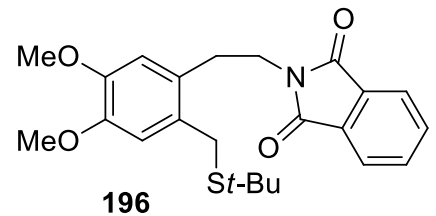

Scheme 62. More efficient preparation of benzyl $t$-butyl thioether photocyclization substrate.

Photocyclization and subsequent acid-catalyzed dehydration provided the thioenol ether (198, Scheme 63) in 68\% overall yield from phthalimide 199.

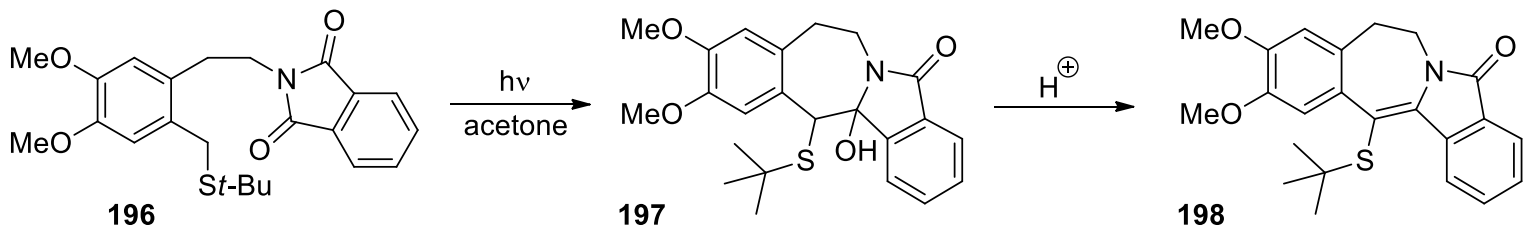

Scheme 63. Photocyclization and dehydration of a benzyl $t$-butyl thioether.

Their return to this photochemical substrate and the resultant thioenol ether 198 prompted the examination of alternative methods of transforming the thioenol ether into the desired hydroxyketone (207). Treatment with lead tetraacetate followed by MCPBA produced an 
unusual hexacyclic orthoester (206, Scheme 64), the structure of which was elucidated via X-ray crystal analysis. This orthoester effectively served as a protecting group for the desired functionality, and indeed cleavage of the orthoester with potassium carbonate in methanol yielded the much sought after hydroxyketone (207), in seven steps and $17.7 \%$ overall yield. ${ }^{51}$

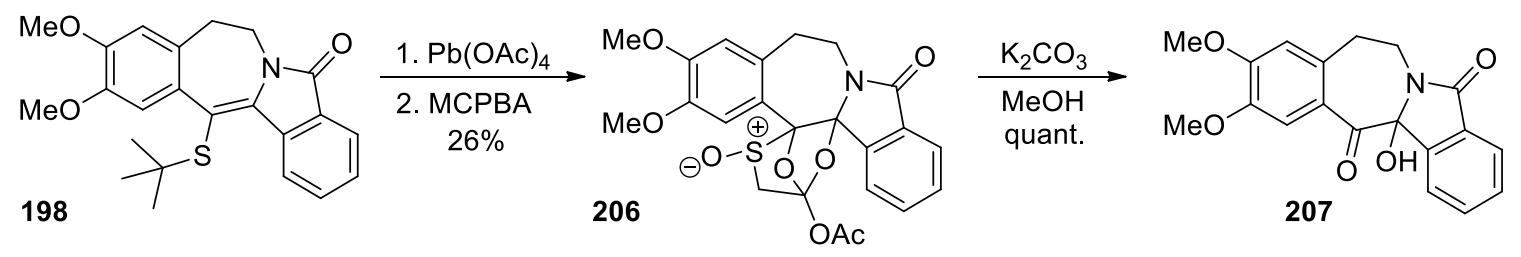

Scheme 64. Formation of the hydroxyketone via a hexacyclic orthoester.

This success naturally prompted King and Mazzocchi to examine photocyclization substrates with substitution on the phthalimide ring, which could potentially yield a structure all but identical to the natural product chilenine. With a single methoxy group on the phthalimide ring (208), photocyclization was still successful, although which isomeric product (209 or 210) was formed was unclear (Scheme 65). ${ }^{44}$

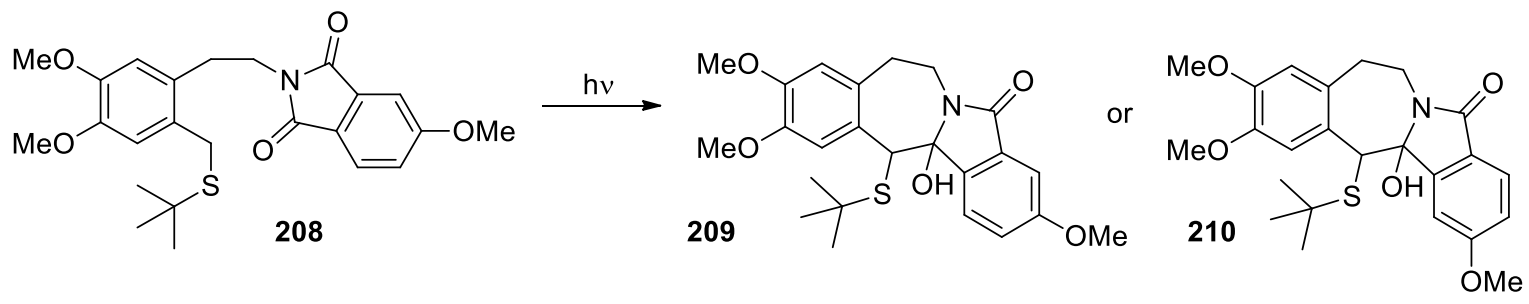

Scheme 65. Photocyclization of a substrate bearing a single methoxy group on the phthalimide.

Disappointingly, the analogous reaction with a dimethoxysubstituted phthalimide was unsuccessful. The authors proposed that the reduction potential of the phthalimide is altered by the substitution such that electron transfer is no longer a favorable process or such that back electron transfer becomes more favorable.

An analogous photochemical approach to the aporhoeadane skeleton was investigated by Kessar and co-workers. ${ }^{52,53}$ In this instance, the photochemical substrates were derived from a dihydroisoquinoline (211, Scheme 66) by reaction with 2-carboethoxybenzoyl chloride (212) and subsequent masking of the benzaldehyde (200) with ethane-1,2-thiol or propane-1,3-thiol (213 or 201, respectively). 

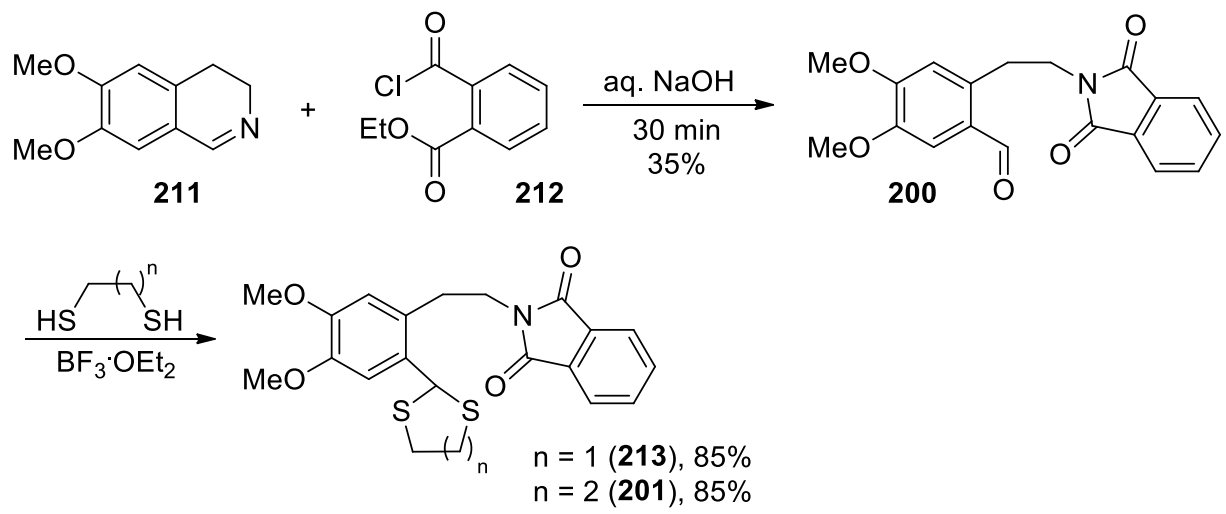

Scheme 66. Preparation of photochemical substrates from a dihydroisoquinoline.

Photochemical substrate 201 was the same as that used by King and Mazzocchi. ${ }^{44}$ In this case, photocyclization was followed by successful deprotection of the ketone using $\mathrm{N}$ chlorosuccinimide and silver nitrate in aqueous acetonitrile to give chilenine analogue 207 (Scheme 67). Alternatively, complete reduction of both the dithiane and the hydroxyl group could be accomplished using Raney Ni to afford lennoxamine analogue 216.
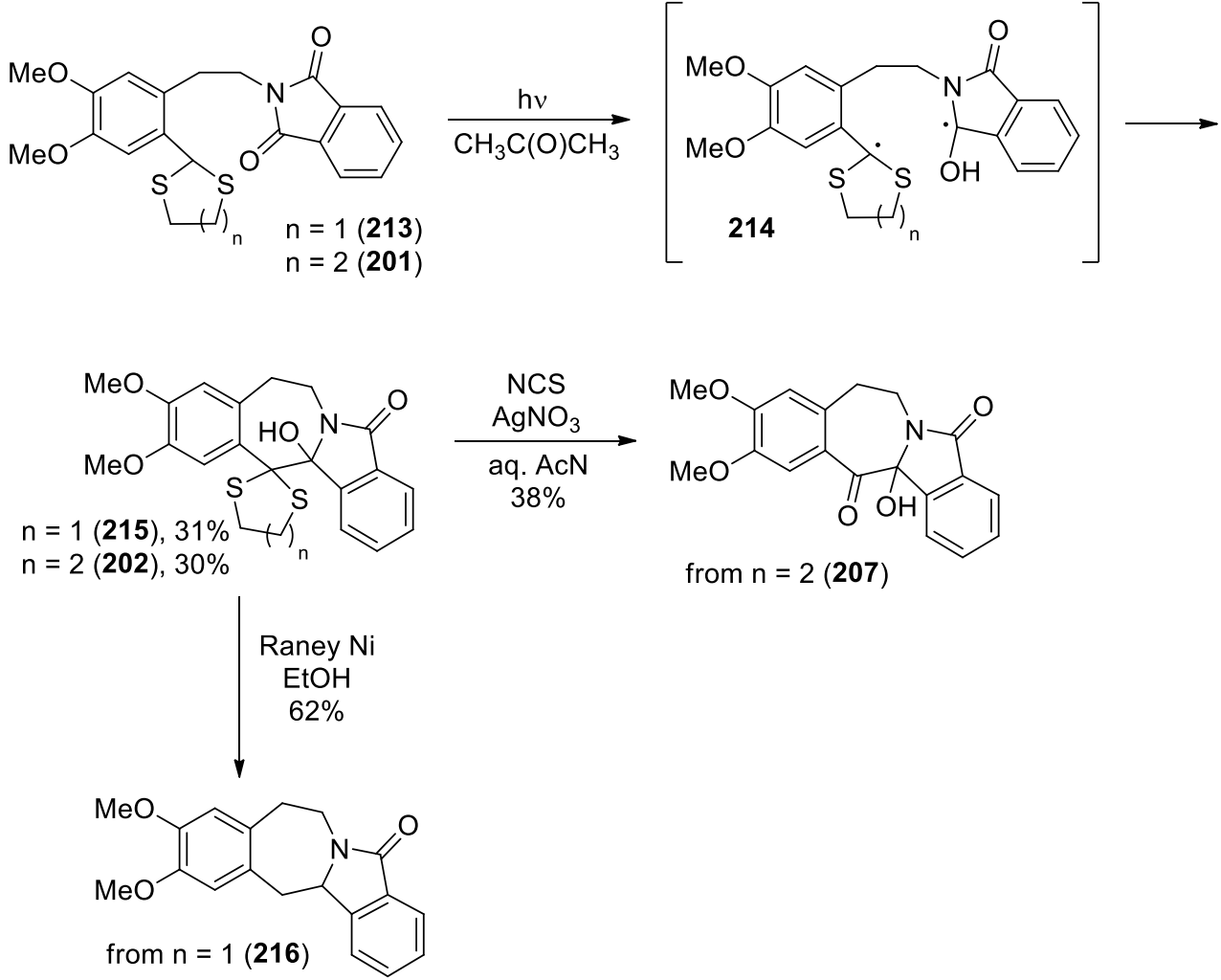

Scheme 67. Photocyclization and deprotection or reduction of the masked hydroxyketone. 
The absence of substrates bearing a substituted phthalimide suggests that, as with King's work, the photocyclization may have been detrimentally affected by the presence of electrondonating groups on this ring.

Fang and Danishefsky employed reductive coupling mediated by either tungsten hexacarbonyl or rhodium(II) acetate to form the C13-C14 bond. ${ }^{54}$ Their synthesis began with the acylation of dihydroisoquinoline 217 to provide an inseparable mixture of 219 and 220, both of which were converted to the corresponding dithiolane 221 (Scheme 68). Catalytic base incited phthalimide ring closure (222), and Lawesson's reagent provided the desired monothiophthalimide 223.
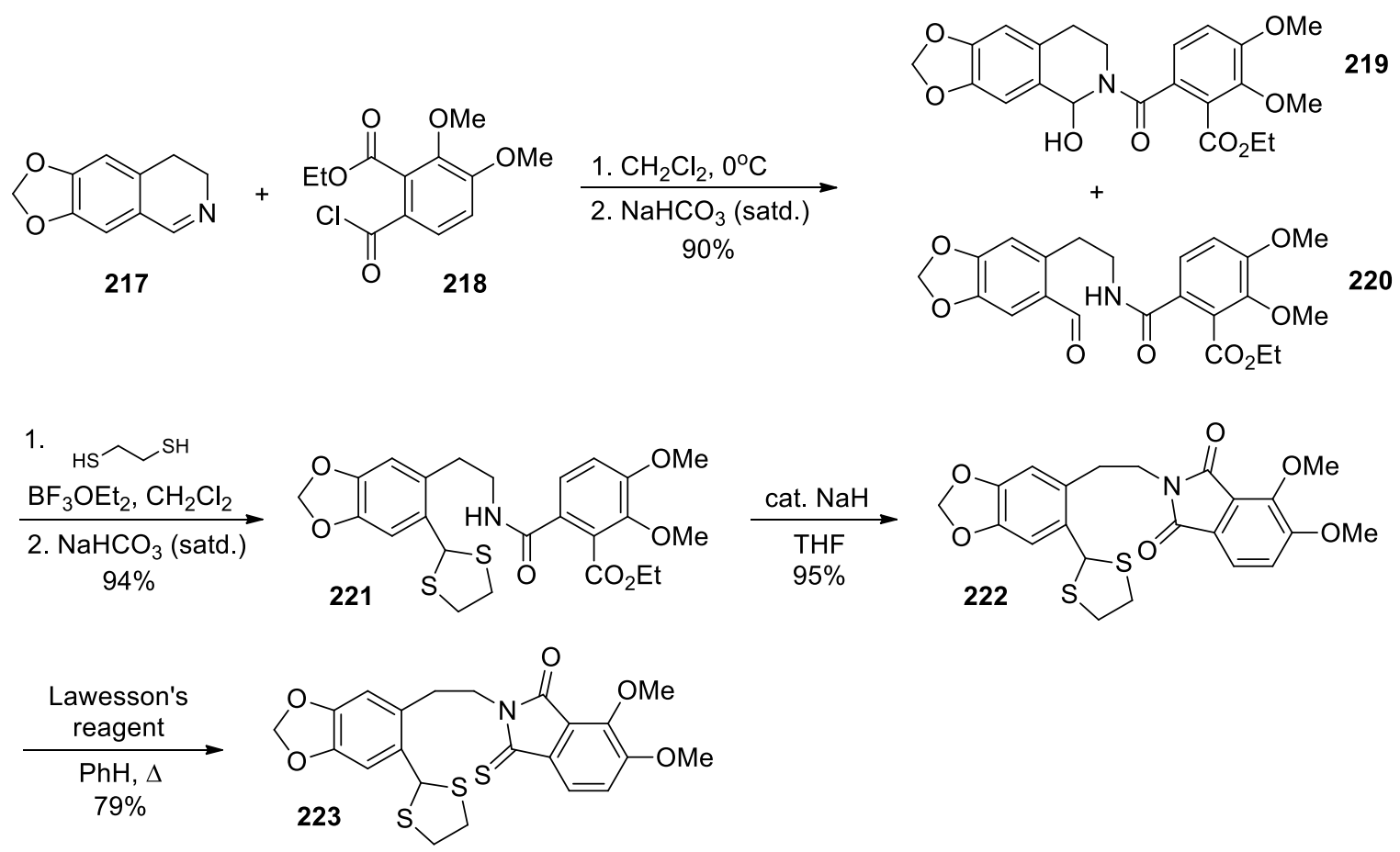

Scheme 68. Preparation of a monothiophthalimide.

Treating the dithiolane directly with tungsten hexacarbonyl yielded the enelactam dehydrolennoxamine (dehydro-11, Scheme 69) in 38\% yield. However, an alternative approach to the enelactam unveiled the aldehyde (224), converted it to the hydrazone (225), and employed rhodium(II) acetate for the reductive coupling yielding the enelactam in $53.5 \%$ yield over the three-step sequence.

The authors circumvented the $\mathrm{C} 13-\mathrm{C} 14$ bond cleavage that had been previously observed ${ }^{33}$ when using MCPBA in an attempt to install the $\mathrm{C} 13$ and $\mathrm{C} 14$ oxygenation. In one route, treatment with osmium tetraoxide followed by workup with hydrogen sulfide yielded the $c i s$-diol 226 (Scheme 70). Treatment with acetic anhydride in pyridine led to dehydration, giving the enol acetate (227). This enol acetate yielded chilenine (5, in $40 \%$ yield over the three-step sequence) 
when oxidized with osmium tetraoxide, again using a hydrogen sulfide workup. Alternatively, direct exposure of enelactam dehydro-11 to two equivalents of dimethyl dioxirane, followed by addition of saturated aqueous sodium bicarbonate, provided chilenine directly in $38 \%$ yield. The authors attributed the success of this method to the non-nucleophilic nature of dimethyl dioxirane, as opposed to the peroxy acids used in previous reports (refer to Scheme 30) which opened the intermediate epoxide before it could rearrange to a ketone or enol whose subsequent oxidation would yield chilenine.

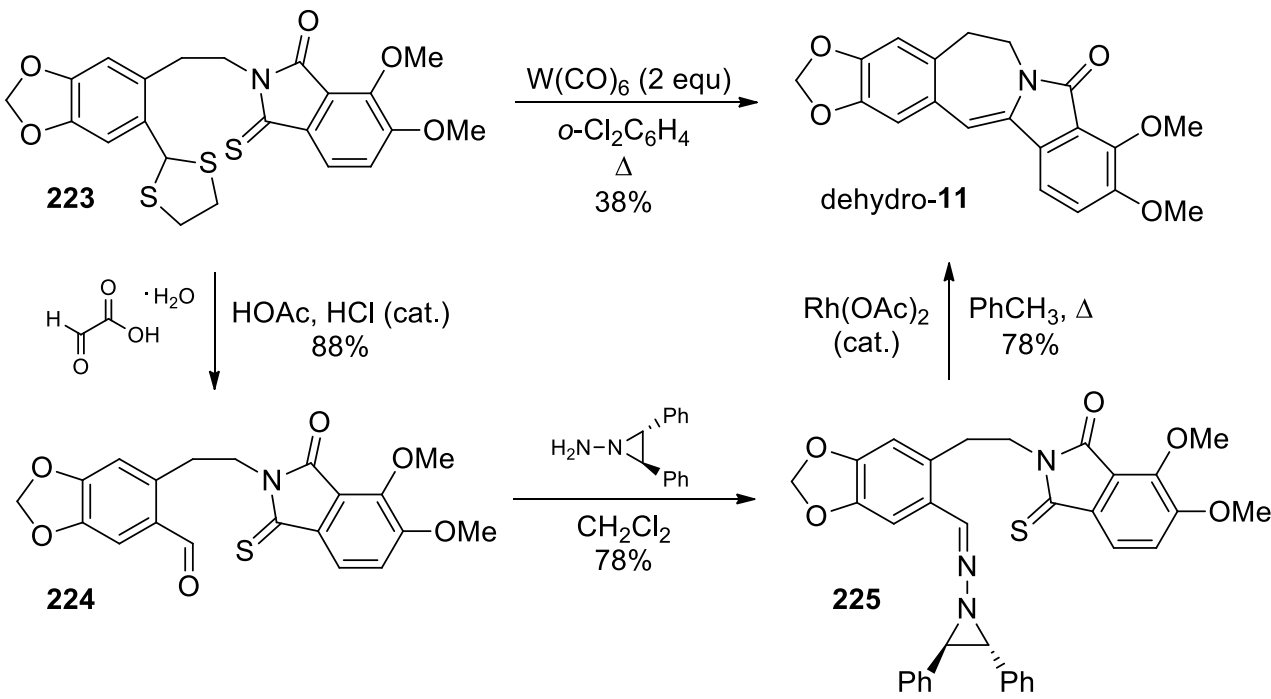

Scheme 69. Intramolecular reductive coupling of the monothiophthalimide.
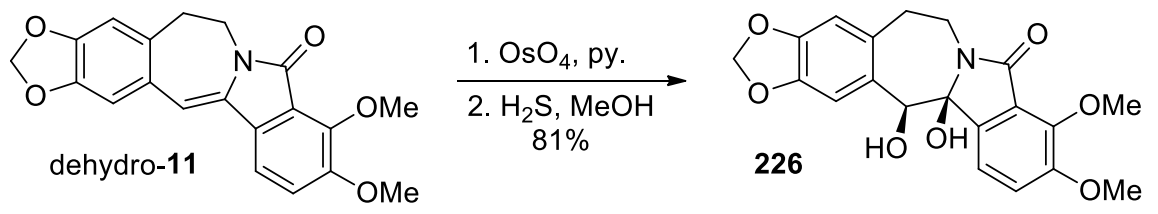

1.
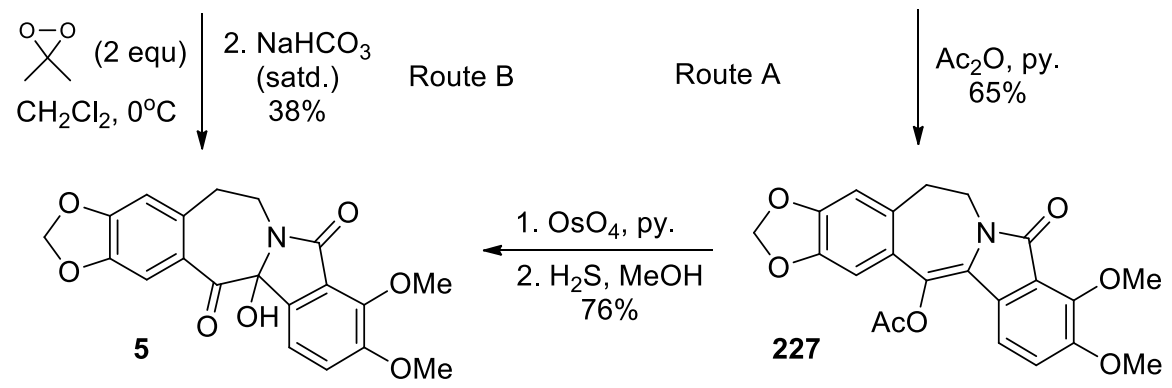

Scheme 70. Oxidation of dehydrolennoxamine.

Padwa et al. demonstrated the utility of Stevens [1,2]-rearrangement in the synthesis of the isoindolobenzazepine core (Scheme 71) ${ }^{55}$ In a model study, amido ester 228 was converted to 
the diazo amide (229) through addition of DBU and tosyl azide. Subsequent treatment with rhodium(II) acetate dimer in refluxing toluene provided the aporhoeadane core (231), presumably through the formation of a spriocyclic ammonium ylide (230), which then underwent Stevens [1,2]-rearrangement in which the benzylic carbon migrated preferentially.
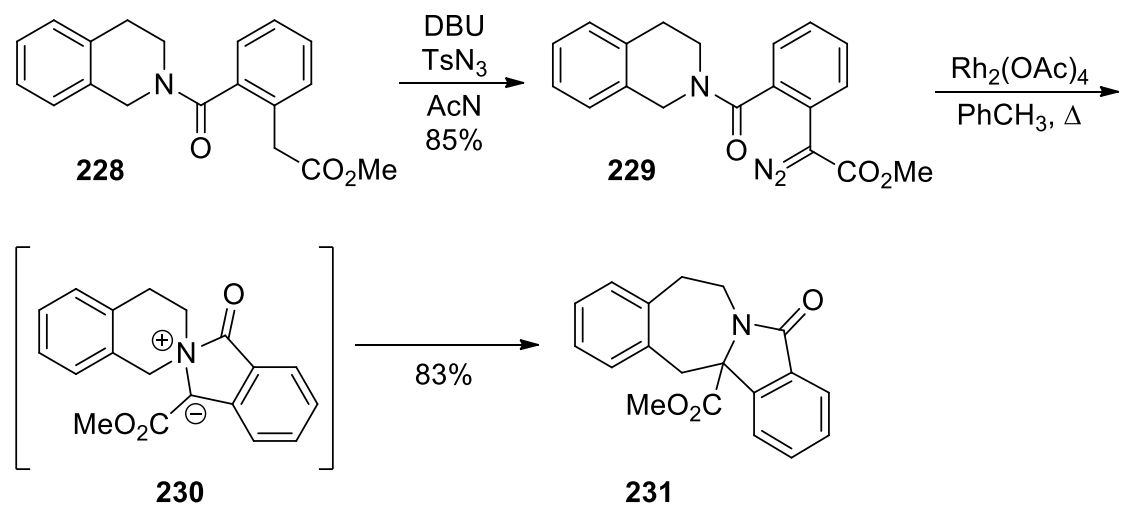

Scheme 71. Synthesis of aporhoeadane core through Stevens rearrangement.

This method could be applied to substrates with some, but not all, of the substituents present in the natural product lennoxamine (Scheme 72). Benzoic acid 232 was converted to the corresponding acid chloride and coupled with isoquinoline 217 to yield amido ester 233. This amido ester could be transformed into the diazo compound (234); however, attempts to do the same with an amido ester bearing a second methoxy substituent that would lead to the requisite C10 methoxy substitution of lennoxamine were unsuccessful. The additional methoxy group diminished the acidity of the benzylic hydrogens, which rendered diazo transfer ineffective. Nevertheless, diazo amide $\mathbf{2 3 4}$ did successfully undergo the Stevens rearrangement to yield a more fully elaborated aporhoeadane (235).
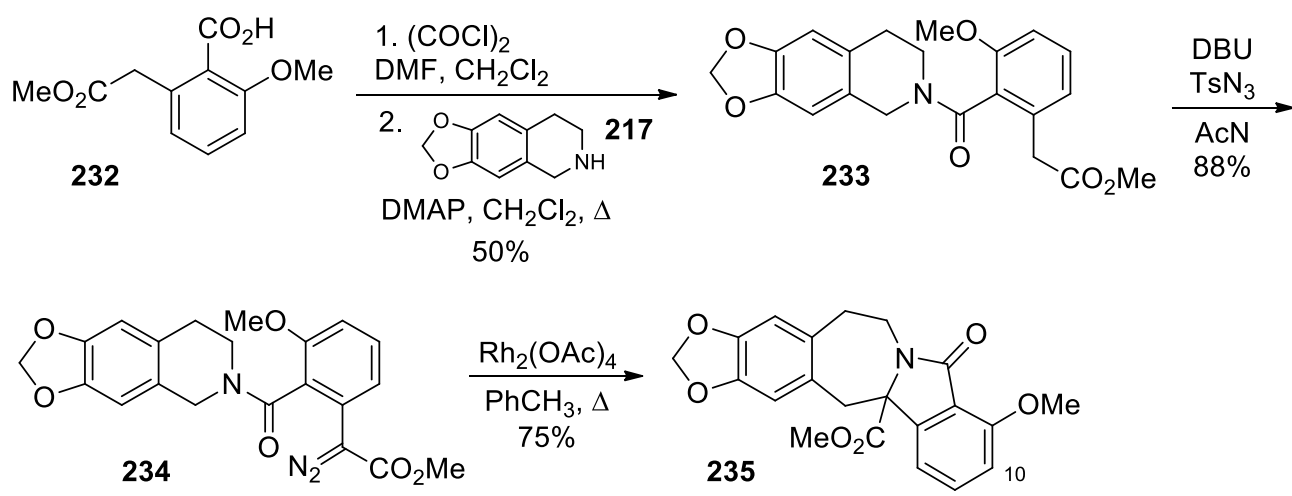

Scheme 72. Synthesis of a lennoxamine analogue through Stevens rearrangement. 
Yoda et al. constructed the C13-C14 bond using a samarium iodide-mediated pinacolic coupling as the key step. ${ }^{56}$ The synthesis began with bromopiperonal (47), which was protected as its acetal and then subjected to aromatic allylation to yield $\mathbf{2 3 6}$ (Scheme 73). Removal of the acetal was followed by reduction of the aldehyde. The incipient alcohol (237) was then protected as its 4-methoxybenzyl (MPM) ether (238), after which dihydroxylation, oxidative cleavage of the diol, and reduction provided alcohol $\mathbf{2 3 9}$.

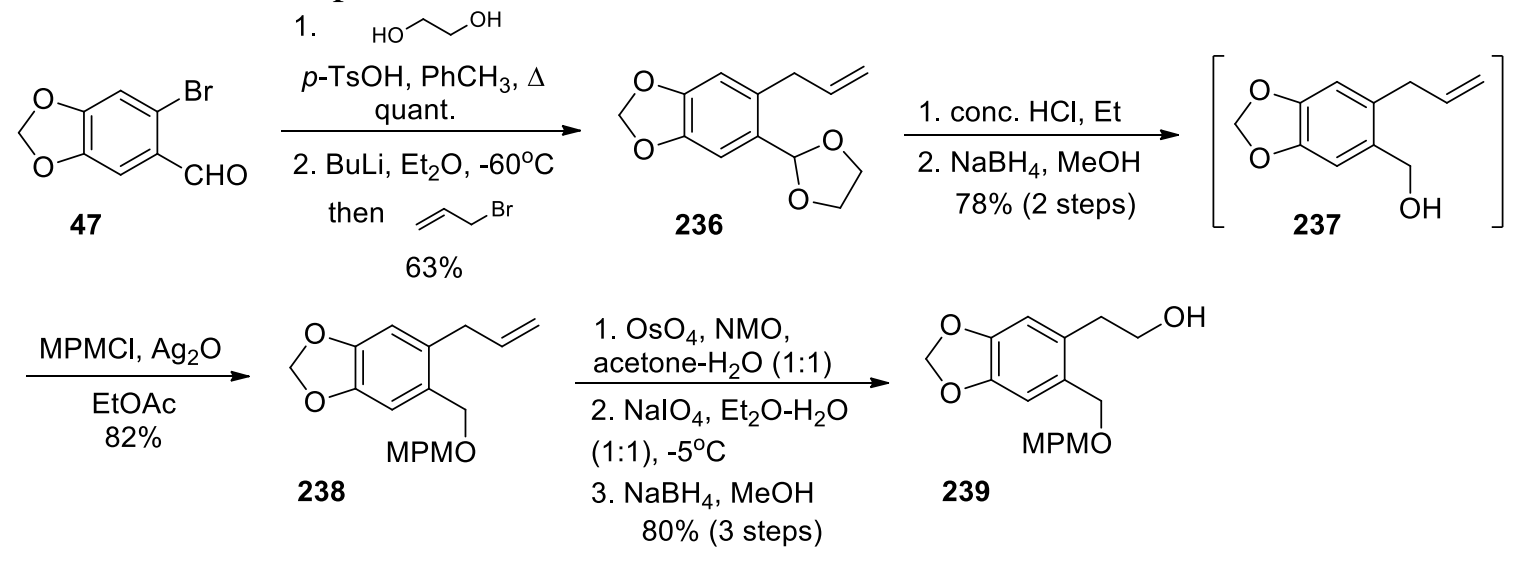

Scheme 73. Synthesis of the benzodioxole fragment.

The other building block was derived from 3,4-dimethoxy-2-ethoxycarbonylbenzoic acid (240), which was coupled with MPM-amine using DCC (Scheme 74). Removal of the protecting group led to ring closure, providing phthalimide 241.

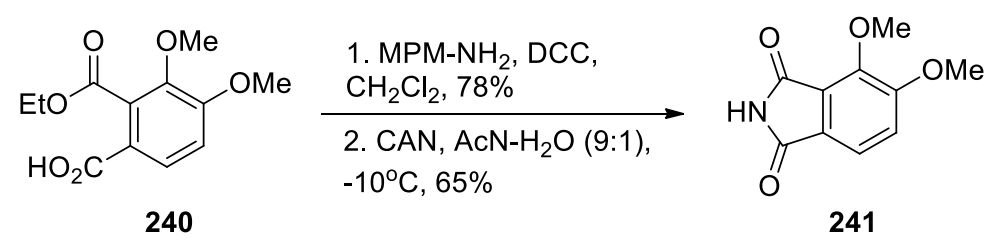

Scheme 74. Synthesis of the phthalimide fragment.

The two fragments were united using Mitsunobu conditions (Scheme 75), after which DDQ removed the remaining MPM group and oxidized the benzyl alcohol. The aldehyde thus formed (243) underwent an intramolecular pinacol coupling when treated with samarium iodide to yield diol 226 as a 3:1 mixture of the cis and trans diastereomers. Since Danishefsky and co-workers had previously converted this diol into chilenine, ${ }^{54}$ the work of Yoda $e t$ al. constitutes a formal total synthesis of chilenine. 

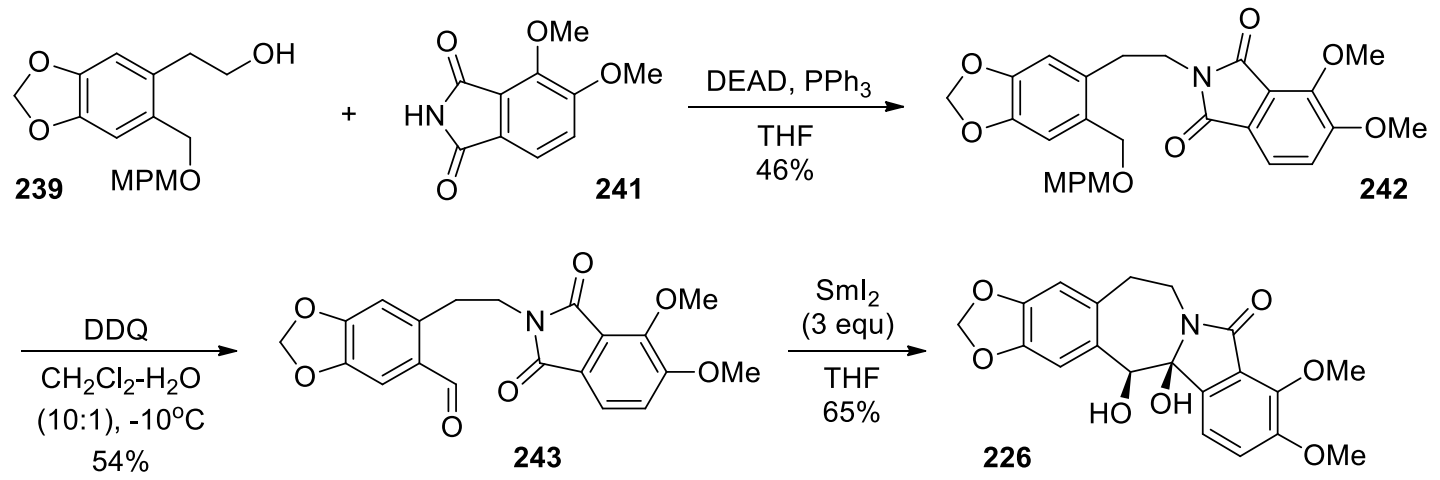

Scheme 75. Union of the fragments and pinacol ring closure.

Yoda and co-workers also utilized a Lewis acid-mediated tandem reaction of $\gamma$-phenylthiosubstituted lactams to prepare chilenine. ${ }^{57}$ Their synthesis began with phthalimide 242 (Scheme 76), whose synthesis they had previously reported (refer to Scheme 75). ${ }^{56}$ Regioselective DIBAL-H reduction provided the hydroxylactam as an intermediate that was treated directly with thiophenol to yield the $\gamma$-phenylthiolactam 244. Removal of the MPM protecting group with DDQ proceeded with concomitant oxidation of the newly liberated benzyl alcohol to give aldehyde 245. Base-induced cyclization installed the benzazepine ring (246), and TPAP selectively oxidized the alcohol to the ketone (247) without oxidation of the sulfur. Finally, the tandem desulfurization and hydroxylation developed by these investigators provided chilenine (5).
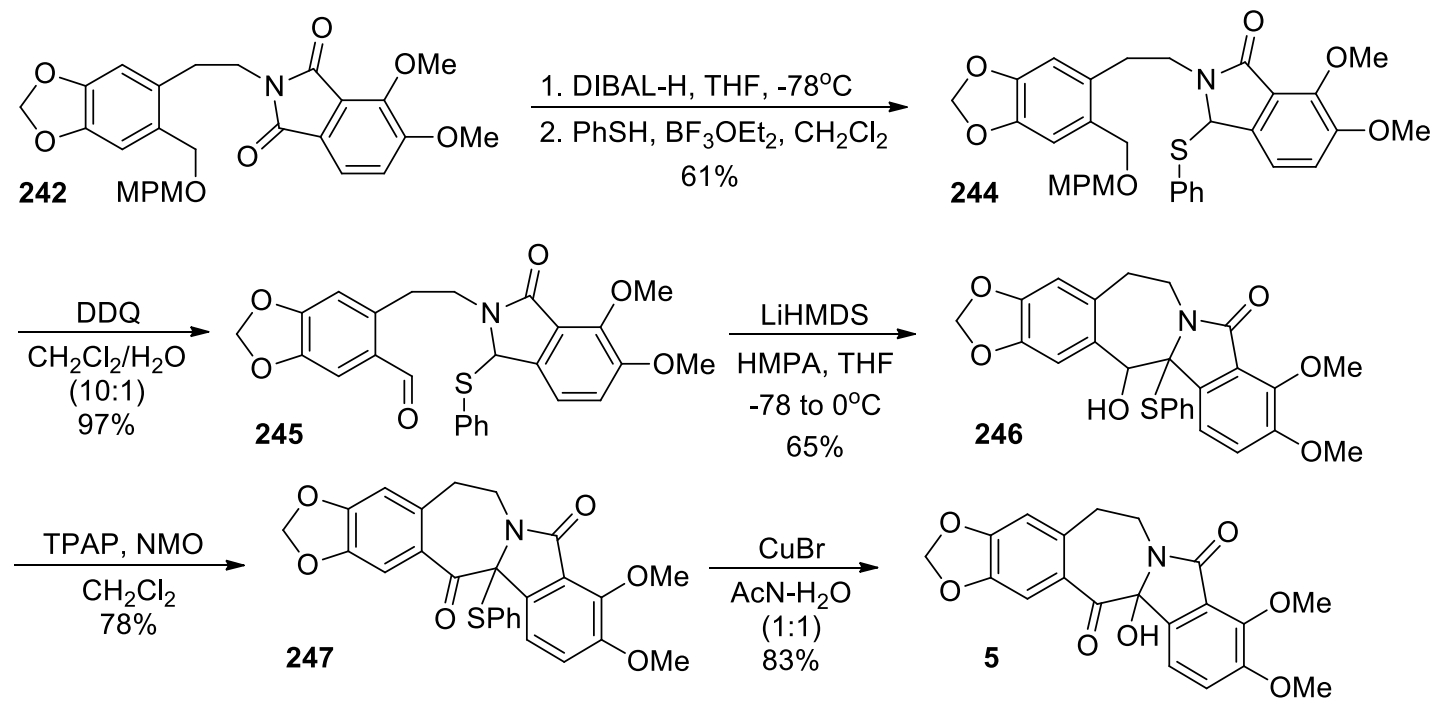

Scheme 76. Synthesis of chilenine using tandem desulfurization and hydroxylation 


\section{Concurrent Synthesis of the Seven/Five Ring System}

\subsection{Formation of the N7-C13 bond}

Schöpf and Schweikert reported that the reduction of berberine-phenol (248) in zinc and acetic acid provided two products, a tetrahydroberberine (249) as well as the rearrangement product bearing a fused seven/five ring system at its core (15, Scheme 77). ${ }^{58}$ This was the first reported synthesis of chilenamine, which occurred nearly twenty years before its isolation.

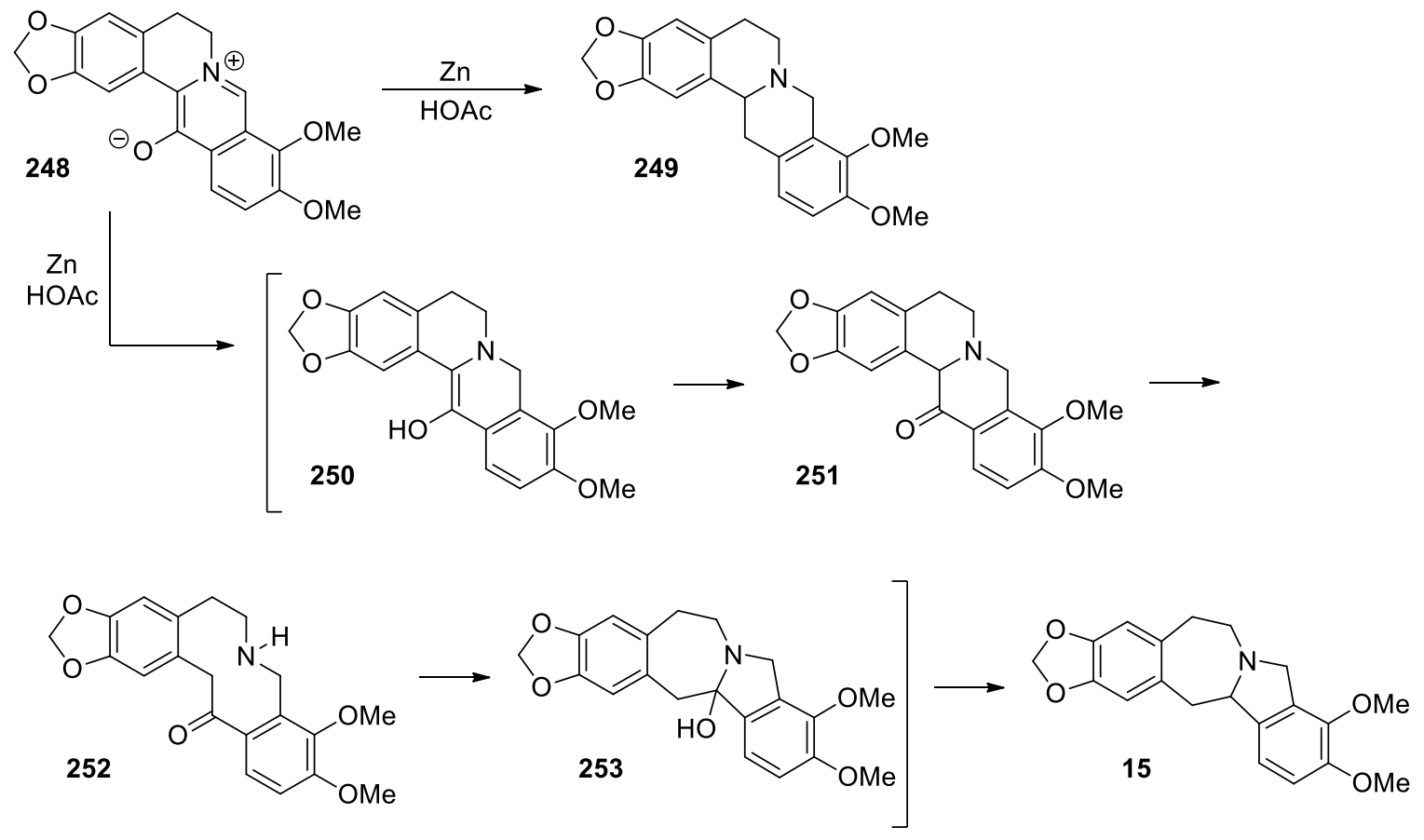

Scheme 77. Reduction of berberine-phenol in zinc and acetic acid.

It has been noted ${ }^{59}$ that the rearrangement is analogous to that observed in the rearrangement of the $\alpha$-amino ketone 254 under Clemmensen reduction conditions (Scheme 78). ${ }^{60}$

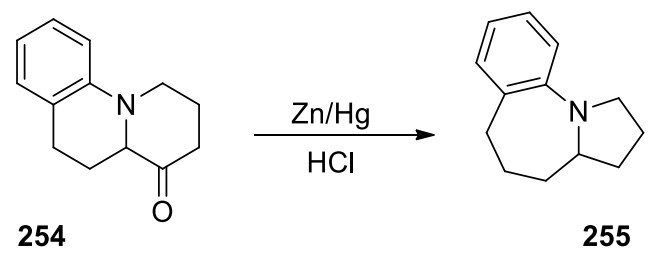

Scheme 78. Clemmensen reduction of an $\alpha$-amino ketone.

Shamma and co-workers also reported a method for the synthesis of aporhoeadanes, but this time from berberine itself. ${ }^{6,61}$ Berberine (6, Scheme 79) was dimerized to oxybisberberine (256) 
using postassium ferricyanide. The dimer could be cleaved nearly quantitatively with pyridine hydrochloride in pyridine to yield the homoannular $\alpha$-ketocarbinolamide 7 (which could also be called prechilenine or 8,13-dioxo-14-hydroxycanadine) along with recovered berberine in a 1:1 ratio. Treatment of $\mathbf{7}$ with ammonium hydroxide in chloroform resulted in a carbinol-carbonyl transposition. This likely proceeds through deprotonation of the hydroxyl group followed by fragmentation to yield 257, which can undergo transannular cyclization onto the closer ketone, forming the N7-C13 bond and providing chilenine (5) five years prior to its isolation.

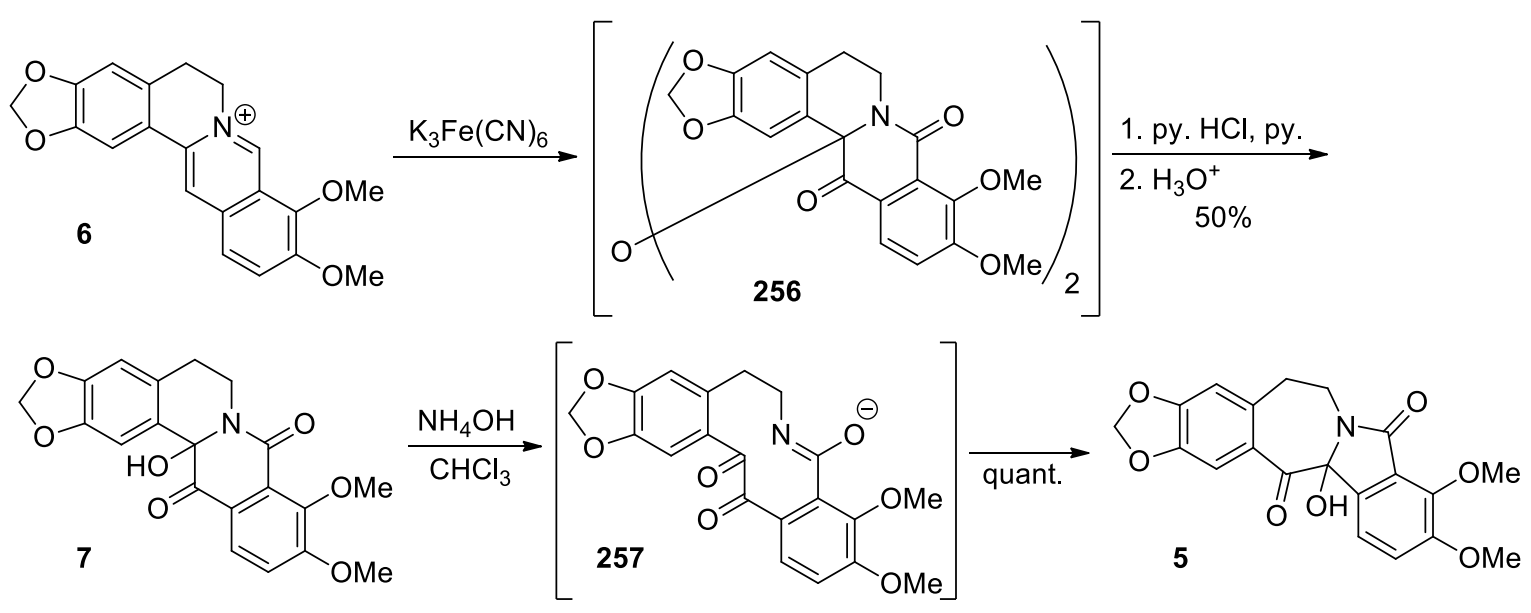

Scheme 79. Synthesis of chilenine from berberine.

As an aside, chilenine has also been prepared as a very minor side product $(2 \%)$ of the pyrolysis of 8,13-dioxo-14-methoxycanadine (i.e. prechilenine, 7) via an analogous mechanism. ${ }^{62}$

While the methods outlined above utilized a natural product derivative as the starting material, some other approaches have built the framework from simpler substrates. In one example, Kessar et al. described a chilenine synthesis that used the known base induced carbinol-carbonyl transposition, ${ }^{6,61}$ but constructed the substrate, prechilenine, from simple building blocks (Scheme 80). ${ }^{63}$ Their synthesis began with the known condensation ${ }^{64}$ of dihydroisoquinoline 217 and 6,7-dimethoxyphthalide (258), which was prepared from $o$ vanillin. ${ }^{65}$ The lactam that resulted (259) could be oxidized to ketone $\mathbf{2 6 0}$, however, since the ketone was unstable, the lactam was oxidized directly to hydroxyketone 7 using excess PCC and longer reaction times. The method of Shamma, ${ }^{6,61}$ was used to convert hydroxyketone 7 to chilenine (5). 

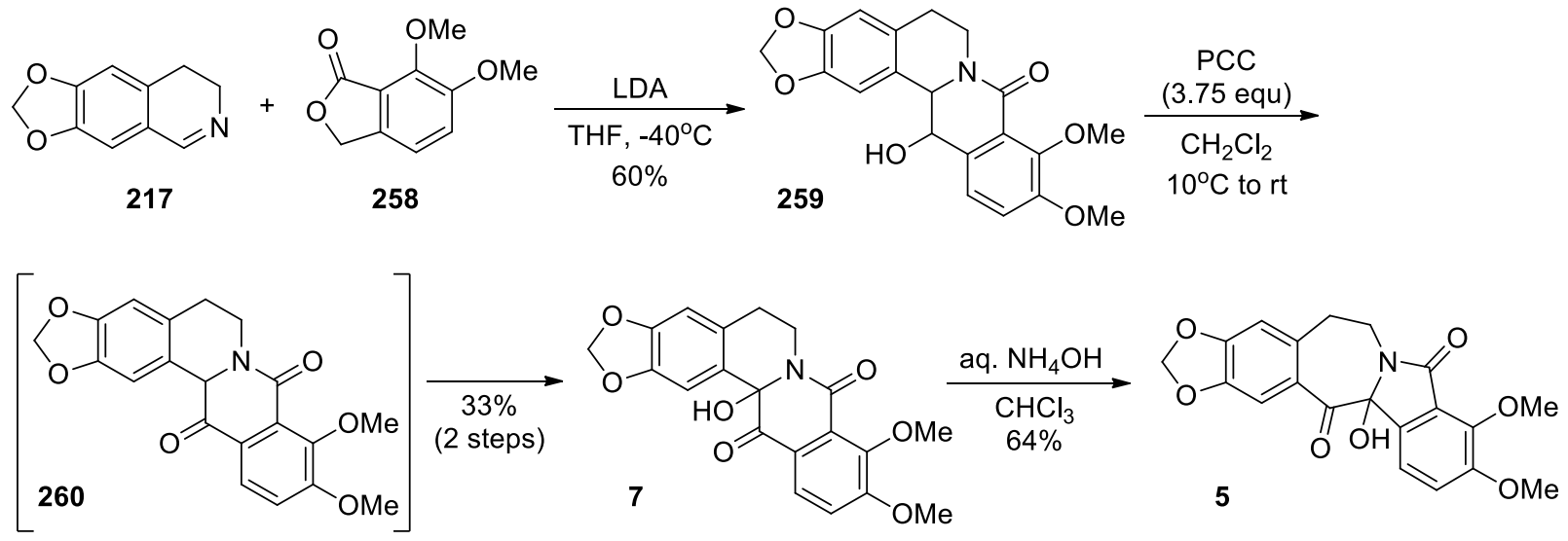

Scheme 80. Synthesis of chilenine using controlled oxygenation and carbinol-carbonyl transposition.

In another example of building the core from simple substrates, Castedo and co-workers built the unsubstituted aporhoeadane core using a novel transannular cyclization of an azamacrocycle $\left(\mathbf{2 6 5}\right.$, Scheme 81). ${ }^{66}$ Condensation of $o$-bromophenethylamine (261) and $o$ iodobenzoylchloride (262) yielded amide 263, which underwent Sonogashira coupling with trimethylsilylacetylene. While desilylation and radical cyclization was an option, it was lower yielding than direct radical cyclization of the silylated acetylene (264). The vinylsilane thus formed (265) underwent transannular cyclization at the $\beta$-position in base to yield the isoindolobenzazepinone $\mathbf{2 6 6}$ as the syn diastereomer. Subsequent desilylation yielded the aporhoeadane core (267).

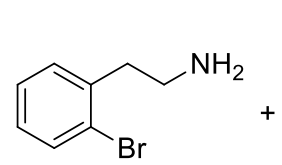

261<smiles>O=C(Cl)c1ccccc1I</smiles>

262

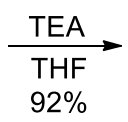

$92 \%$

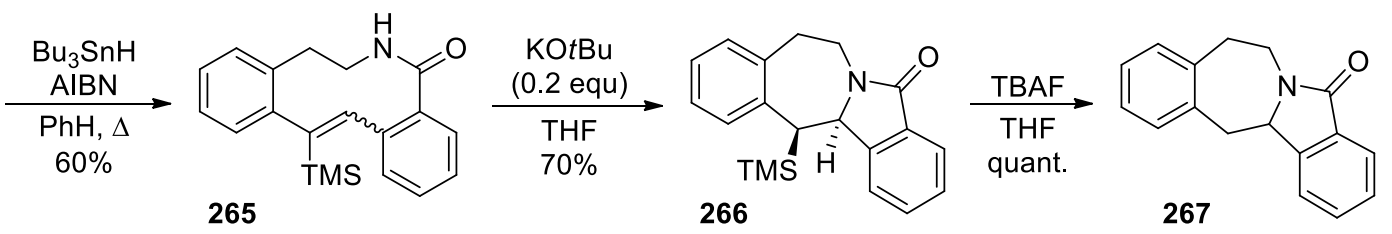

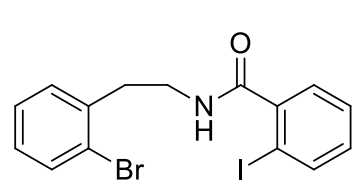

263

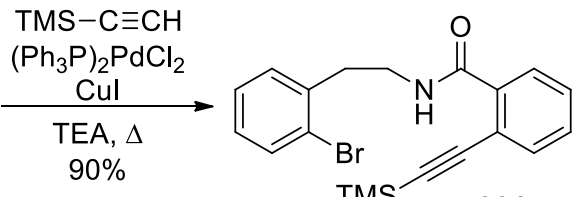

264

Scheme 81. Synthesis of the aporhoeadane core via transannular cyclization.

On the other hand, epoxidation of the vinylsilane followed by acidic workup led instead to the berberine architecture, presumably through rearrangement of the $\alpha$-epoxysilane to a ketone that underwent transannular cyclization with the lactam.

These same investigators (Castedo, Domínguez, and co-workers) utilized the vinylsilane methodology in a synthesis of lennoxamine. ${ }^{67}$ To construct the cyclization precursor, two 
fragments were needed. The phenethylamine fragment (96) was prepared from piperonal (268) through Henry reaction, reduction of the nitro group, and bromination (Scheme 82).

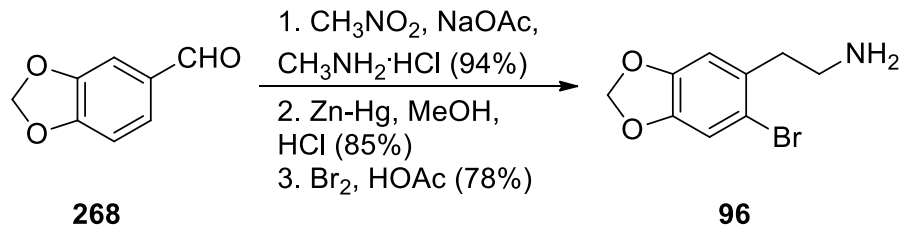

Scheme 82. Synthesis of the phenethylamine fragment.

2,3-Dimethoxybenzoic acid (186) provided the acid chloride fragment (269) after iodination and treatment with thionyl chloride (Scheme 83).

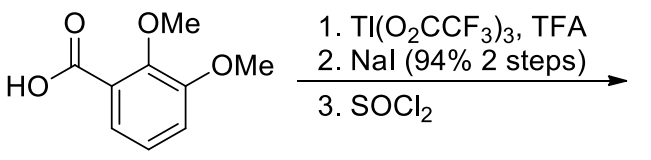

186<smiles>COc1ccc(I)c(C(=O)Cl)c1OC</smiles>

269

Scheme 83. Synthesis of the acid chloride fragment.

The fragments were smoothly united (Scheme 84), and then trimethylsilylacetylene was chemoselectively coupled to the benzamide (270), yielding the critical cyclization precursor (271) that would actually be used in two distinct routes to lennoxamine.

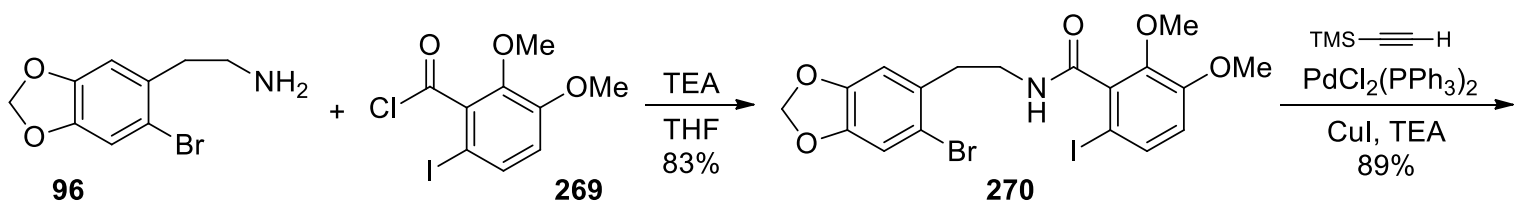

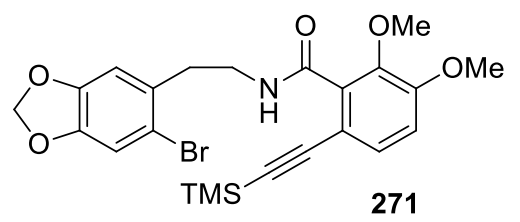

Scheme 84. Synthesis of the radical cyclization precursor.

First, macrocycle formation (272) occurred through intramolecular radical addition to the alkyne (Scheme 85). A single geometric isomer was isolated but its configuration was unknown and irrelevant for the remainder of the synthesis. Transannular base-induced cyclization created the aporhoeadane core (273), which was readily desilylated to provide lennoxamine (11). 


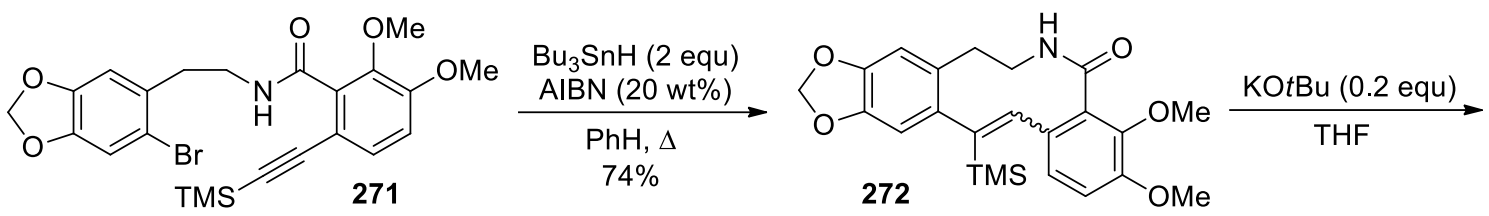<smiles>COc1ccc2c(c1OC)C(=O)N1CCc3cc4c(cc3CC21)OCO4</smiles>

Scheme 85. Macrocycle formation and transannular cyclization to form lennoxamine.

Alternatively, the same critical intermediate $\mathbf{2 7 1}$ readily underwent desilylation and cyclization in base (Scheme 86). The methylenephthalimide thus formed (99) was also a viable radical cyclization precursor yielding lennoxamine (11) upon closure of the benzazepine ring through formation of the C14-C14a bond instead.
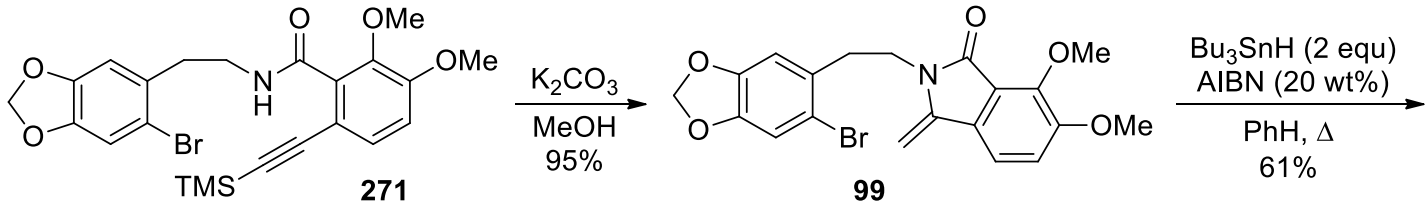<smiles>COc1ccc2c(c1OC)C(=O)N1CCc3cc4c(cc3CC21)OCO4</smiles>

Scheme 86. Alternative use of the radical cyclization precursor to yield lennoxamine via a different strategy.

This same research group (Domínguez, Saá, and co-workers) later reported that vinylsilanes 274 and 275 could be cyclized in one of two ways to yield protoberberines or aporhoeadanes (Scheme 87). ${ }^{68}$ Treatment of vinylsilane 274 or 275 with a moderate excess of hydroiodic acid in benzene at $50{ }^{\circ} \mathrm{C}$ yielded the tetrahydroprotoberberines 276 or 277 , respectively, in nearly quantitative yield. It appears that these reactions proceed via protonation $\beta$ to the vinylsilane and transannular attack of the amide nitrogen on the $\alpha$ carbocation. However, treatment of the same vinylsilanes with TBAF buffered with acetic acid yielded the isoindolobenzazepinones 216 or 278 instead. This reversal of regioselectivity is attributed to fluoride promoted transannular attack of the amide nitrogen on the $\beta$-position of the vinylsilane. 
<smiles>COc1cc2c(cc1OC)C(C)(C)C1(C)Cc3ccccc3C(=O)N1CC2</smiles><smiles>CC(C=O)C(C)(C)c1ccccc1</smiles><smiles>COc1cc2c(cc1OC)-c1ccccc1CC1(S)c3ccccc3CCN1C2=O</smiles><smiles>[Z10]c1cc(OC)c(OC)cc1C(C)=Cc1ccccc1C(=O)NCCc1cc(OC)ccc1CC(C(F)(F)F)C(F)(F)F</smiles><smiles></smiles>
216

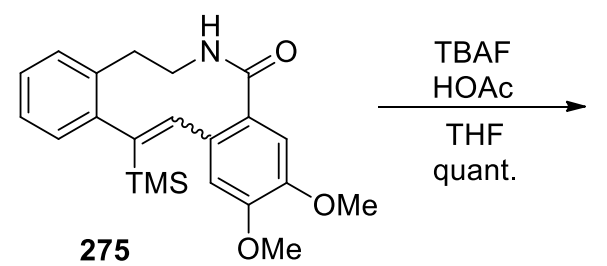<smiles>COc1cc2c(cc1OC)C1Cc3ccccc3CCN1C2=O</smiles>

Scheme 87. Formation of protoberberines or aporhoeadanes from macrocyclic vinylsilanes.

In another example, homoveratrylamine and ninhydrin can be condensed in acidic media in a process involving tandem Pictet-Spengler reaction and rearrangement of the spirocyclic adduct to ultimately provide oxyprotoberberine 279 (Scheme 88). Cupric acetate-mediated oxidation provides the methoxy ketone $\mathbf{2 8 0},{ }^{69}$ and conversion to the hydroxyl ketone (281) proceeds smoothly in aqueous acid. Base-induced carbinol-carbonyl transposition ${ }^{6,61}$ converts the homoannular $\alpha$-keto carbinolamide to the heteroannular $\alpha$-keto carbinolamide 207, which is the same chilenine analogue made by Mazzocchi and co-workers (see Scheme 64). This method consists of 4 steps and provides $11 \%$ overall yield (17.5\% based on recovered starting material in the final step). ${ }^{70}$
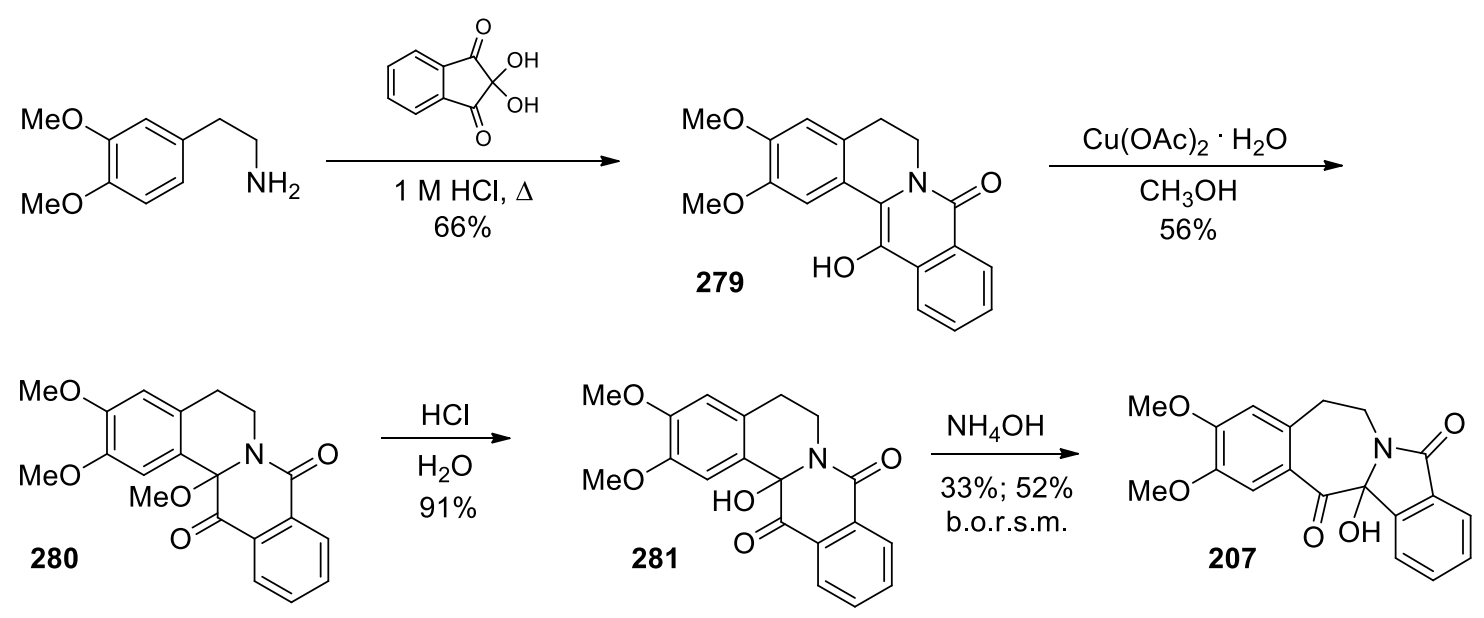

Scheme 88. Synthesis of a chilenine analogue from 3,4-dimethoxyphenethylamine and ninhydrin. 


\subsection{Formation of the N7-C13 and C13-C14 bonds}

Ruchirawat and co-workers reported a one-pot method for the construction of the aporhoeadane skeleton from dihydroisoquinolines and 2-chloromethylbenzoyl chloride (Scheme 89). ${ }^{71}$ This method was based on the preliminary observation that dihydroisoquinoline 211 and 2-chloromethylbenzoyl chloride (282) reacted in the presence of base so as to provide a somewhat unstable pseudobase $\mathbf{2 8 3}$ and aldehyde $\mathbf{2 8 4}$, both of which could subsequently be converted to enelactam 100 in methanolic sodium hydroxide.

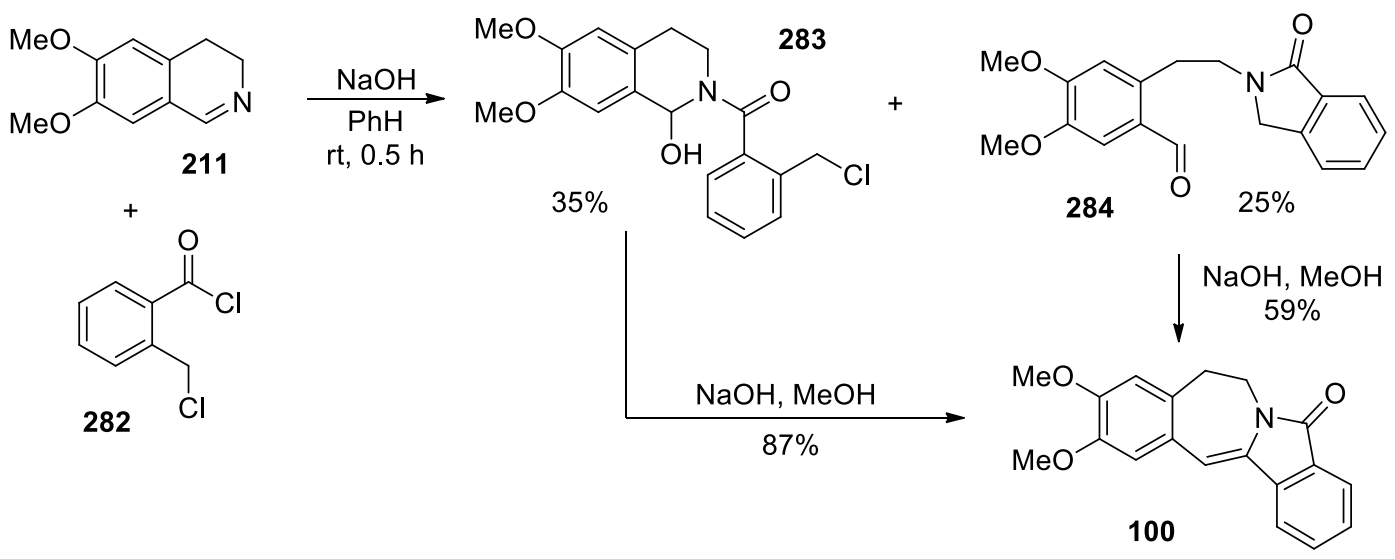

Scheme 89. Formation of enelactam 100 from a dihydroisoquinoline and 2-chloromethylbenzoyl chloride.

It was also observed that condensation of the dihydroisoquinoline and 2-chloromethylbenzoyl chloride followed by recrystallization from an alcoholic solvent simply provided the addition products $\mathbf{2 8 5}$ or $\mathbf{2 8 6}$ (Scheme 90).

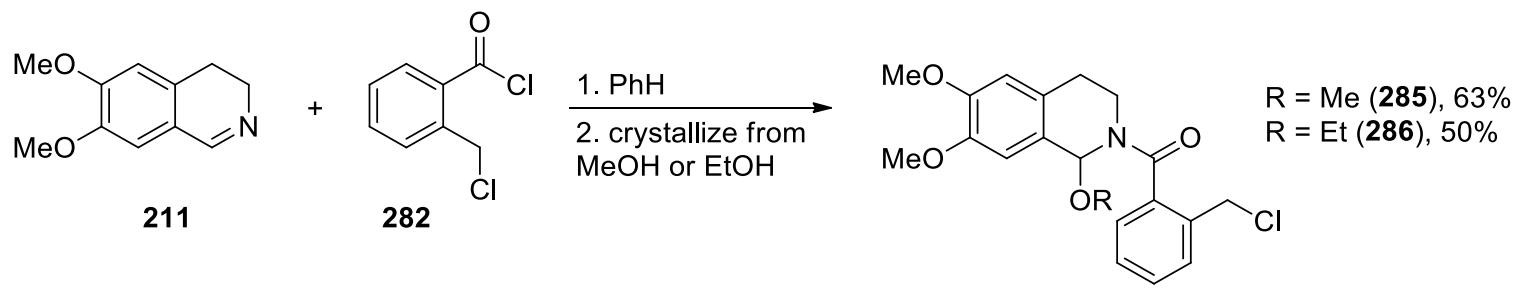

Scheme 90. Condensation of a dihydroisoquinoline and 2-chloromethylbenzoyl chloride followed by recrystallization.

These observations enabled the formulation of a one-pot approach to enelactams that included intial exposure of a dihydroisoquinoline and 2-chloromethylbenzoyl chloride (282) to sodium hydroxide in benzene, followed by removal of the solvent and addition of methanol (Scheme 91). This one-pot procedure was amenable to varying substitution on the dihydroisoquinoline (e.g. 211, 287, or 217). The identity of the hydroxide counterion was 
deemed critical. ${ }^{73}$ Furthermore, an alkoxy group at the 6 position was necessary, presumably to facilitate fragmentation to the aldehyde and amide ion needed for cyclization to form the lactam ring of $\mathbf{1 0 0 ,} \mathbf{2 8 8}$, or 289 . $^{72}$
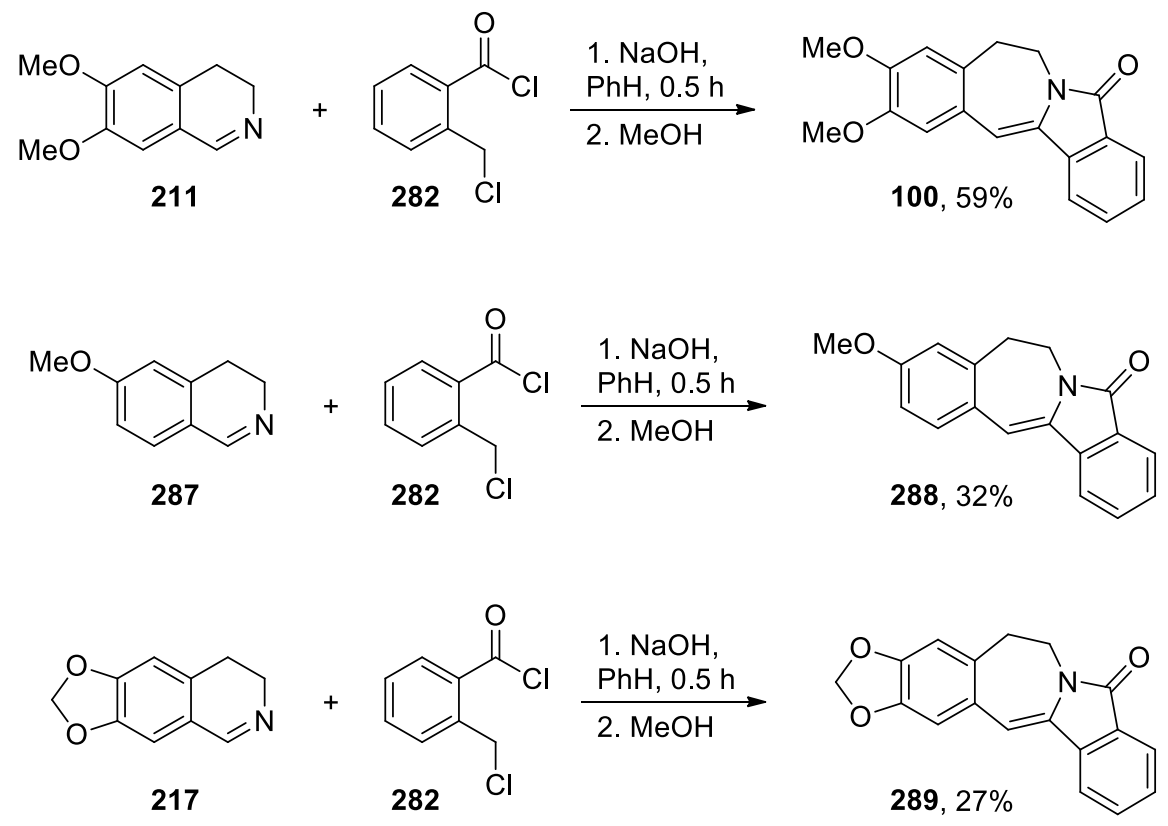

Scheme 91. One-pot approach to the aporhoeadane core.

\subsection{Formation of the N7-C8 and C13-C14 bonds}

The Ruchiwarat group revised its approach ${ }^{73}$ due to two principal challenges associated with the original route: the need for halomethylbenzoyl chlorides that are not readily accessible and the disappointing yield provided by 6,7-methylenedioxy-3,4-dihydroisoquinoline (217) in reaction with chloromethylbenzoyl chloride (282, refer to Scheme 91). This second-generation approach (Scheme 92) constructed the lactam ring through intramolecular attack of an amine on ester, as opposed to the intramolecular attack of an amide on a benzyl chloride used in the original approach. It was expected that the enhanced nucleophilicity of the amine would render the cyclization more facile in the second-generation approach. 6,7-Methylenedioxy-3,4-dihydroisoquinoline (217) was alkylated with the more easily obtained ethyl 6-chloromethyl-2,3dimethoxybenzoate (290) to yield an iminium ion (291) that was not isolated but was instead treated directly with potassium or sodium hydroxide. Dehydrolennoxamine (dehydro-11) was obtained directly without isolation of the putative pseudobase and aldehyde intermediates, deoxo-219 and 292 respectively. The 15\% lower yield obtained when using sodium hydroxide reinforces the earlier observation about the significance of the counterion. Finally, hydrogenation smoothly provided lennoxamine (11). 

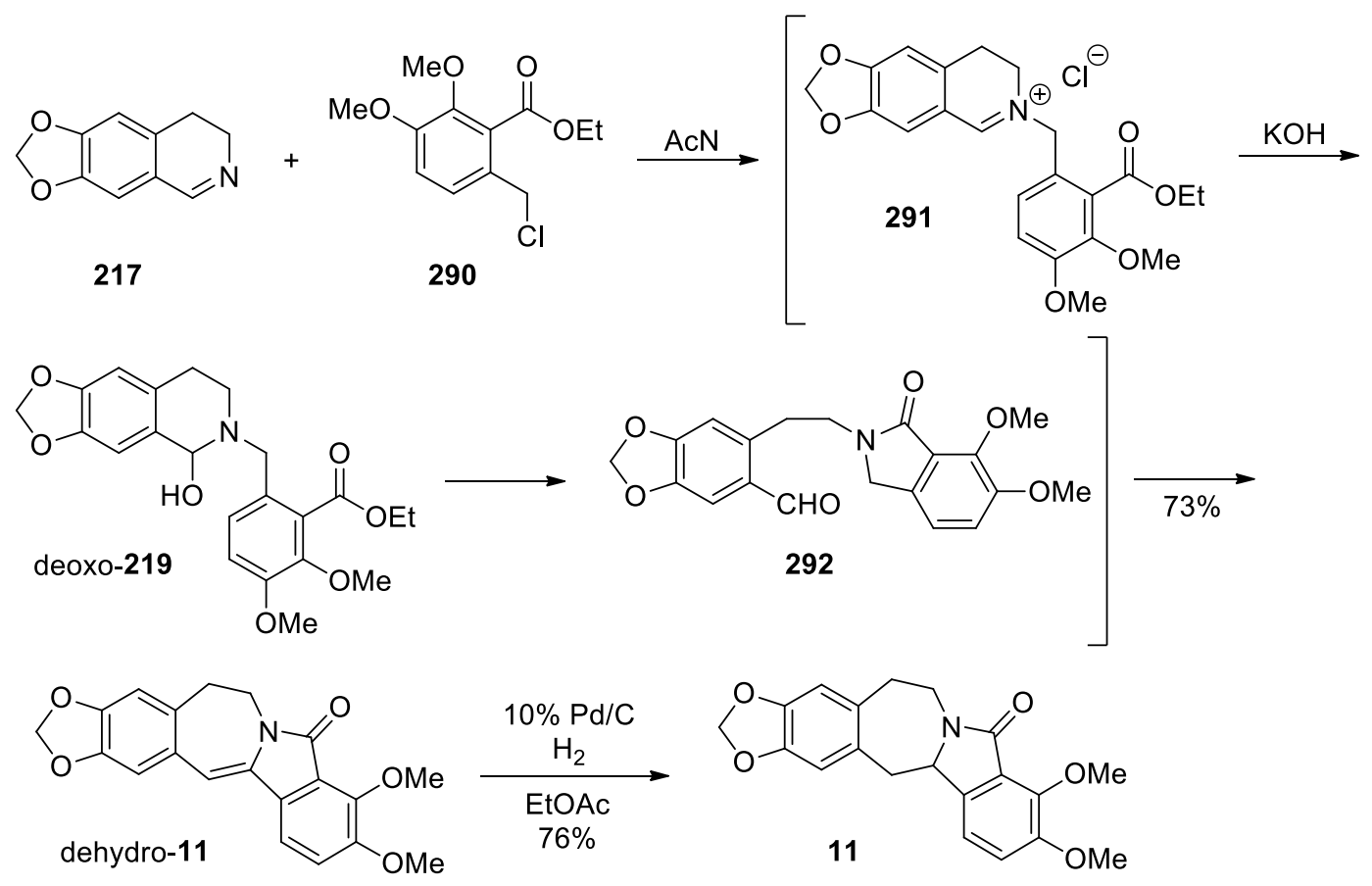

Scheme 92. Second-generation approach to the one-pot synthesis of aporhoeadanes.

In this approach, a methoxy group ortho to the ethyl ester is essential, presumably to enhance the leaving group ability. ${ }^{72}$

Given the critical nature of the pattern of oxygenation on both the dihydroisoquinoline and benzoate fragments, Sahakitpichan and Ruchirawat sought a method that would be efficient regardless of the substituent pattern. This third-generation approach ${ }^{72}$ (Scheme 93) sequentially prepares the five-membered ring, forming an isolable intermediate, before making the sevenmembered ring; however, it is included in this section for continuity. The seven-membered ring formation relies upon the use of an aldehyde isoindolone prepared in two steps from a phenethylamine of type $\mathbf{2 9 3}$ and a chloromethylbenzoate ester of type 294. An alkylationacylation sequence provides the isoindolone $\mathbf{2 9 5}$, while subsequent formylation with dichloromethyl methyl ether and titanium tetrachloride yields the aldehyde isoindolone $\mathbf{2 9 6}$.
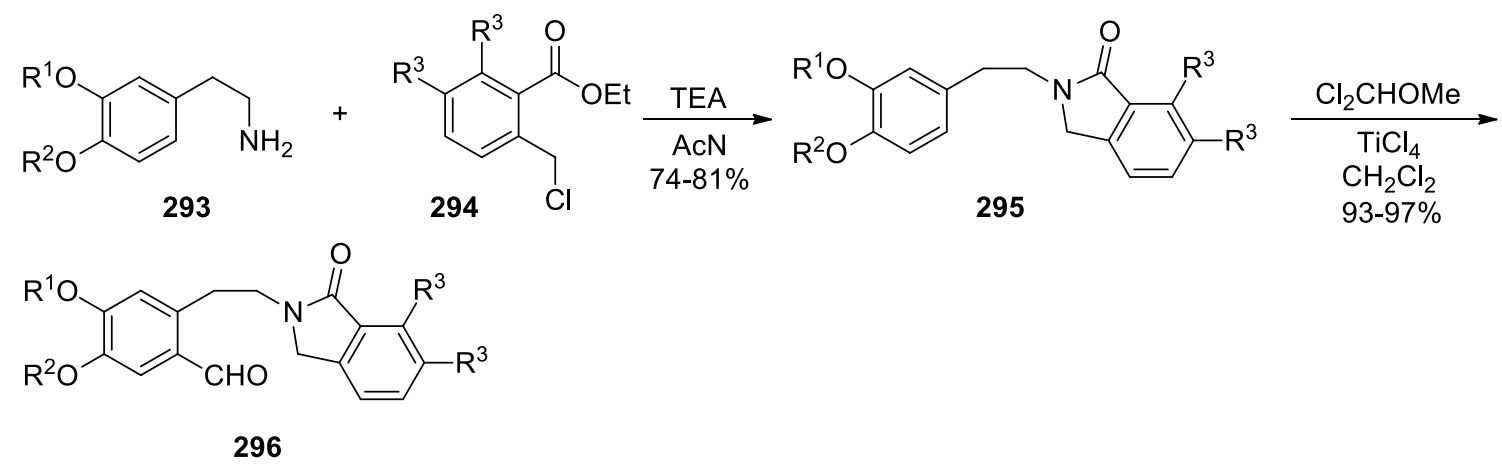

Scheme 93. Preparation of aldehyde isoindolones. 
Yields were good for both steps regardless of whether a 3,4-methylenedioxy $\left(\mathrm{R}^{1}=\mathrm{R}^{2}=\right.$ $\left.\mathrm{CH}_{2}\right)$ or 3,4-dimethoxyphenethylamine $\left(\mathrm{R}^{1}=\mathrm{R}^{2}=\mathrm{Me}\right)$ was used. Additionally, the presence of either methoxy groups $\left(\mathrm{R}^{3}=\mathrm{OMe}\right)$ or hydrogens $\left(\mathrm{R}^{3}=\mathrm{H}\right)$ on the chloromethylbenzoate ring had little impact on yield. The cyclization of the aldehyde isoindolone (296) in methanolic potassium hydroxide also proceeded smoothly in all cases with little, if any, noticeable impact of the substitution pattern on yield (Scheme 94). Finally, hydrogenation of the enelactam yielded lennoxamine or its analogues (298).
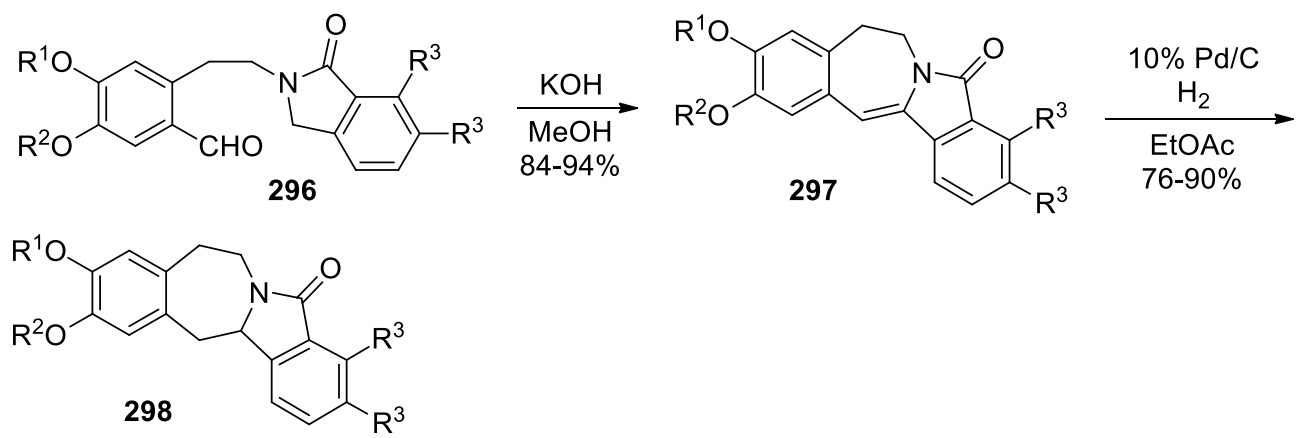

Scheme 94. Cyclization and hydrogenation of the aldehyde isoindolone.

\subsection{Formation of the N7-C8, N7-C13, and C13-C14 bonds}

Chiefari, Janowski, and Prager utilized decarboxylation of phthalidecarboxylic acids (299) in the presence of imine electrophiles to devise a strikingly concise synthesis of the aporhoeadane core (Scheme 95). ${ }^{74}$ When the imine was a dihydroisoquinoline (e.g. 211), the product of the condensation was an isoindolobenzazepinone (e.g. 100 or 300). The product is likely formed by initial decarboxylation and attack on the imine to give $\mathbf{3 0 1}$ followed by lactamization (302), ketone formation (303), and transannular cyclization. While the yields are modest, the brevity of the synthesis is a distinct advantage.

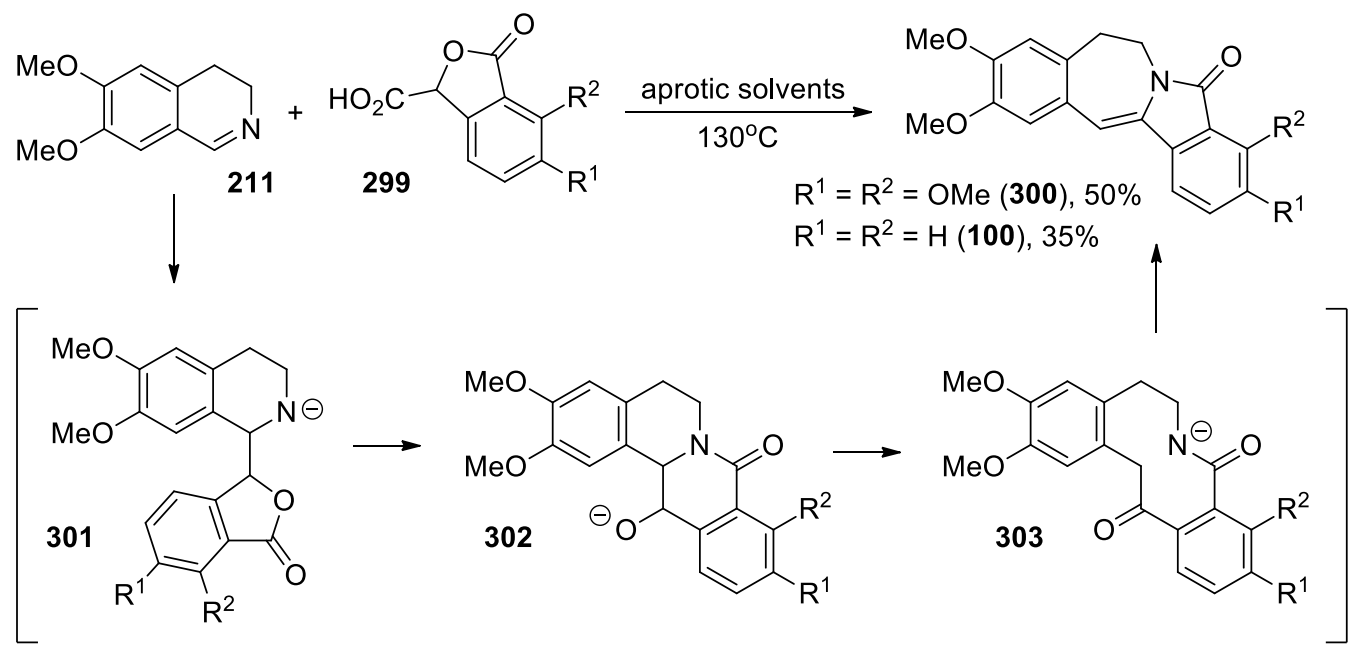

Scheme 95. Synthesis of the aporhoeadane core based on the decaroxylation of phthalidecarboxylic acids. 


\subsection{Formation of the C14a-C14 bond}

Nagasaka and co-workers reported a unique ring expansion of an isoindoloisoquinolone, which ultimately afforded both lennoxamine and chilenine. ${ }^{75,76}$ Their approach began with the $o$ ethynylbenzamide 304 (Scheme 96), which was prepared according to the previously reported protocol. ${ }^{47}$ Intramolecular cyclization proceeded in the presence of catalytic LiHMDS to yield methylideneisoindolone 305. On treatment with excess dimethyldioxirane in methanol and acetone, the methoxylactam $\mathbf{3 0 6}$ was formed. This methoxylactam underwent cyclization to the isoindoloisoquinolone $\mathbf{3 0 7}$ upon exposure to boron trifluoride diethyl etherate.
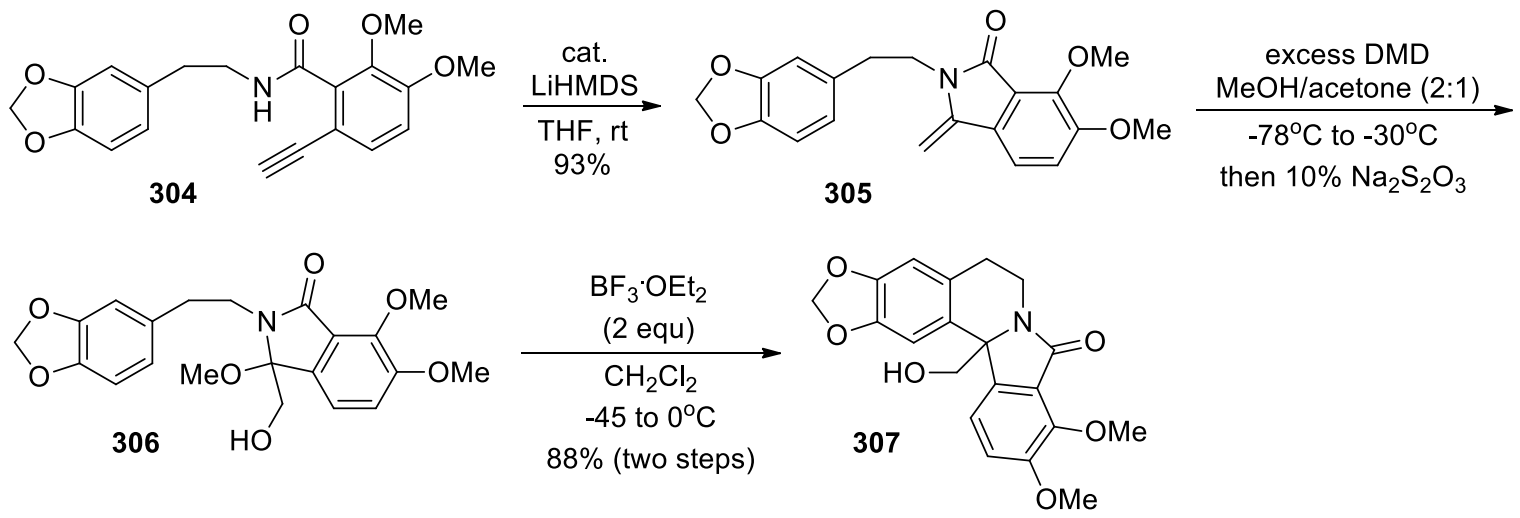

Scheme 96. Synthesis of the isoindoloisoquinolone ring expansion substrate.

Ring expansion occurred under two sets of conditions yielding related enelactams dehydro$\mathbf{1 1}$ or $\mathbf{3 0 8}$ in nearly identical yield (Scheme 97).

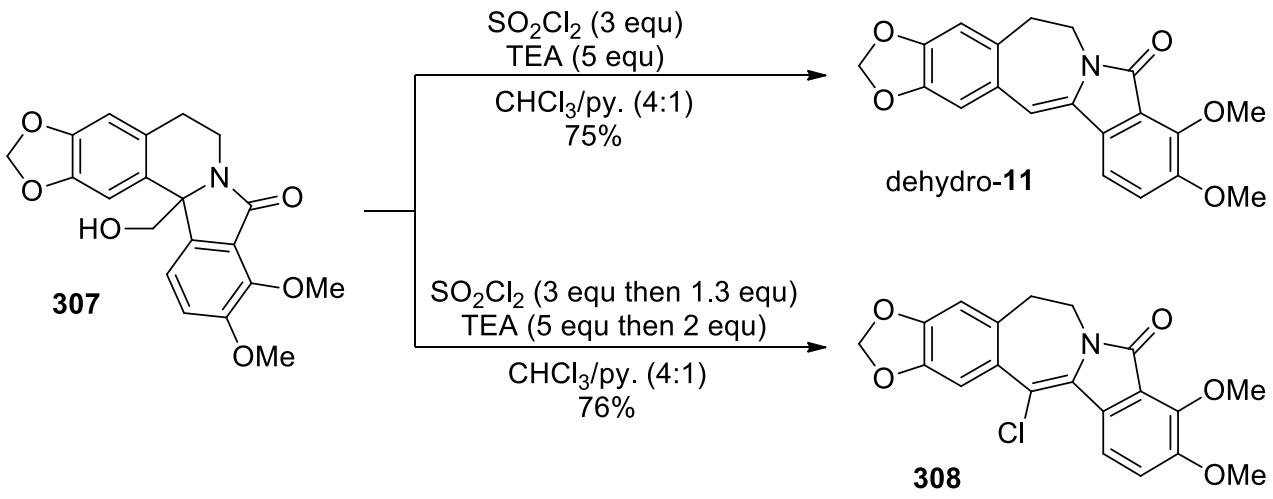

Scheme 97. Ring expansion of the isoindoloisoquinoline.

Chloroenelactam (308) could be reduced to lennoxamine (11, Scheme 98) in much higher yield $(96 \%)$ than that which resulted from the reduction of dehydrolennoxamine (dehydro-11, $38-51 \%)$. 


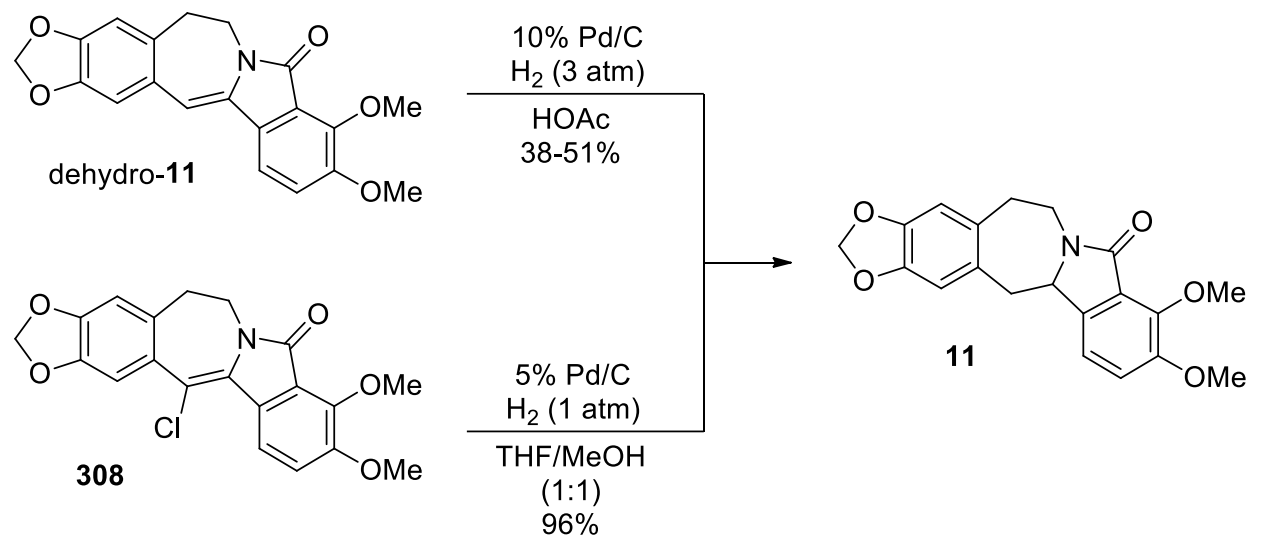

Scheme 98. Reduction to form lennoxamine.

Enelactams dehydro-11 and $\mathbf{3 0 8}$ were both converted to chilenine (5) in 38 and $42 \%$ yield, respectively, using the method of Fang and Danishefsky (Scheme 99). ${ }^{54}$

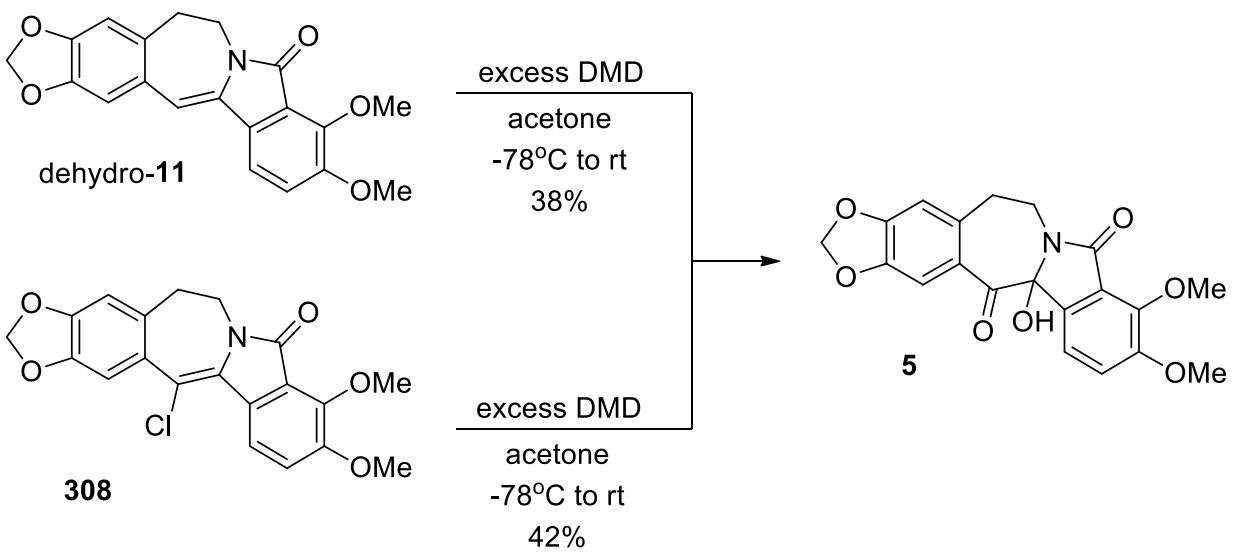

Scheme 99. Conversion to chilenine.

\subsection{Formation of the C12a-C13 and C14-C14a bonds}

Ishibashi and co-workers presented a concise synthesis of lennoxamine that relies upon a radical cascade involving aryl radical-induced 7-endo cyclization followed by homolytic aromatic substitution (Scheme 100). ${ }^{77}$ Phenethylamine 85 was condensed with acetaldehyde, and the imine thus formed (309) was immediately acylated to yield enamide 310. Radical initiation, using conditions carefully selected to suppress hydrogen abstraction by the intermediate radicals, yielded lennoxamine (11) via benzazepine radical $\mathbf{3 1 1}$ in a total of three steps and 22\% overall yield. 

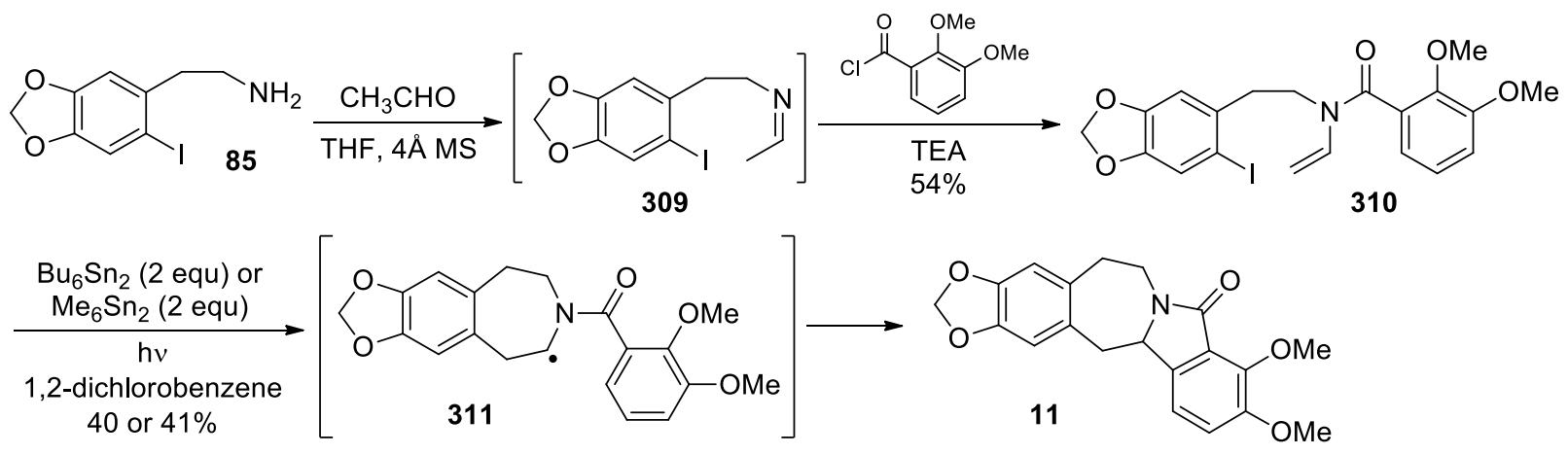

Scheme 100. Radical cascade synthesis of lennoxamine.

\subsection{Formation of the N7-C13, C12a-C13, and C14-C14a bonds}

Kim and co-workers devised another stunningly concise synthesis of chilenine that employed oxalyl chloride as a two-carbon synthetic equivalent for $\mathrm{C} 13$ and $\mathrm{C} 14$ of the natural product (Scheme 101). ${ }^{78}$ Their synthesis began with the straightforward coupling of phenethylamine $\mathbf{6 4}$ and benzoic acid 186. With amide 312 in hand, the chilenine synthesis was expected to proceed via sequential: Friedel-Crafts acylation to form the C14-C14a bond; cyclization of the amide nitrogen onto the remaining acid chloride to form the benzazepine through installation of the N7$\mathrm{C} 13$ bond; and Friedel-Crafts type reaction to close the isoindolone through the formation of C12a-C13.

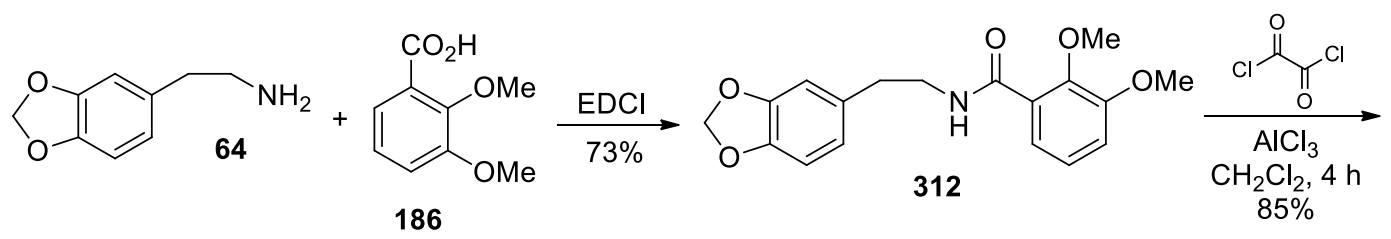<smiles>COc1ccc2c(c1OC)C(=O)N1CCc3cc4c(cc3C(=O)C21O)OCO4</smiles>

Scheme 101. Two-step synthesis of chilenine using oxalyl chloride as a synthetic equivalent.

This two-step synthesis of chilenine (5) provides $62 \%$ overall yield. Some evidence for the proposed mechanism of the one-pot procedure was obtained by premature quenching of the reaction with methanol and triethylamine (Scheme 102). This yielded keto ester 313, which provides support for initial Friedel-Crafts acylation to form the C14-C14a bond. 


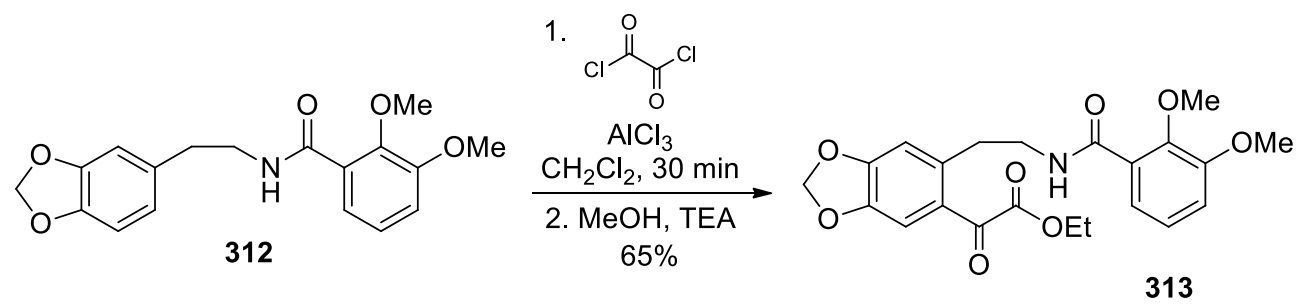

Scheme 102. Evidence for initial Friedel-Crafts acylation to form the C14-C14a bond.

\section{Reactions of Aporhoeadanes}

\subsection{Reactions in base}

Shamma and co-workers have extensively studied the reactions of aporhoeadanes including chilenine. Some of the earliest observations included comparisons to the reactivity of its homoannular $\alpha$-ketocarbinolamide counterpart prechilenine (7). For instance, the heteroannular $\alpha$-ketocarbinolamide chilenine is more stable to base than its homoannular counterpart. ${ }^{61}$ Treatment of the homoannular $\alpha$-ketocarbinolamide (7) with aqueous sodium hydroxide readily yields noroxyhydrastine (314) as the major product, along with Perkin's anhydroberberilic acid (315, Scheme 103). ${ }^{6}$

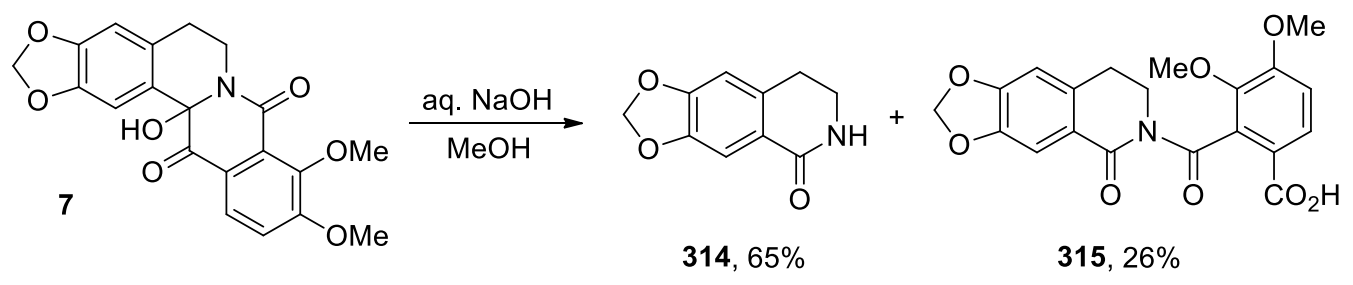

Scheme 103. Oxidative cleavage of the homoannular $\alpha$-ketocarbinolamide prechilenine.

However, alkaline hydrolysis of the heteroannular $\alpha$-ketocarbinolamide chilenine (5) requires prolonged warming, ultimately leading to cleavage of the $\mathrm{C} 13$ to $\mathrm{C} 14$ bond to form imidol 316 (Scheme 104). ${ }^{1}$ This process is akin to Haller-Bauer reaction of the ketone of chilenine.
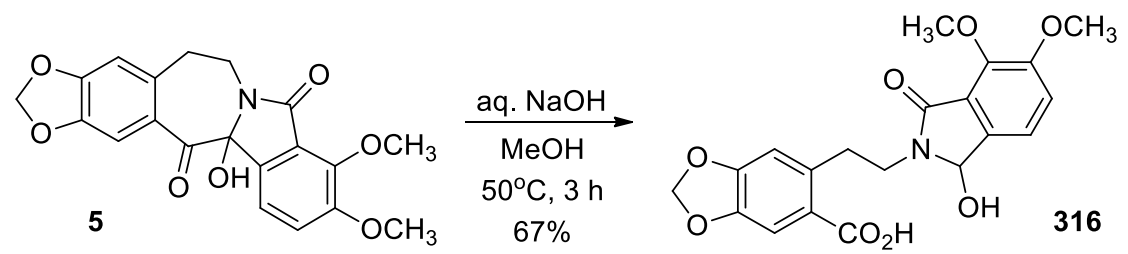

Scheme 104. Alkaline hydrolysis of chilenine. 
This reaction was an important part of the synthesis of nuevamine $(\mathbf{8})$, which occurred five years before it was isolated. ${ }^{1}$ Basic cleavage of the azepine ring was followed by treatment with trifluoroacetic acid, which initially formed iminium ion 317 (Scheme 105). Intramolecular Friedel-Crafts alkylation (318) preceded extrusion of carbon dioxide to provide nuevamine.

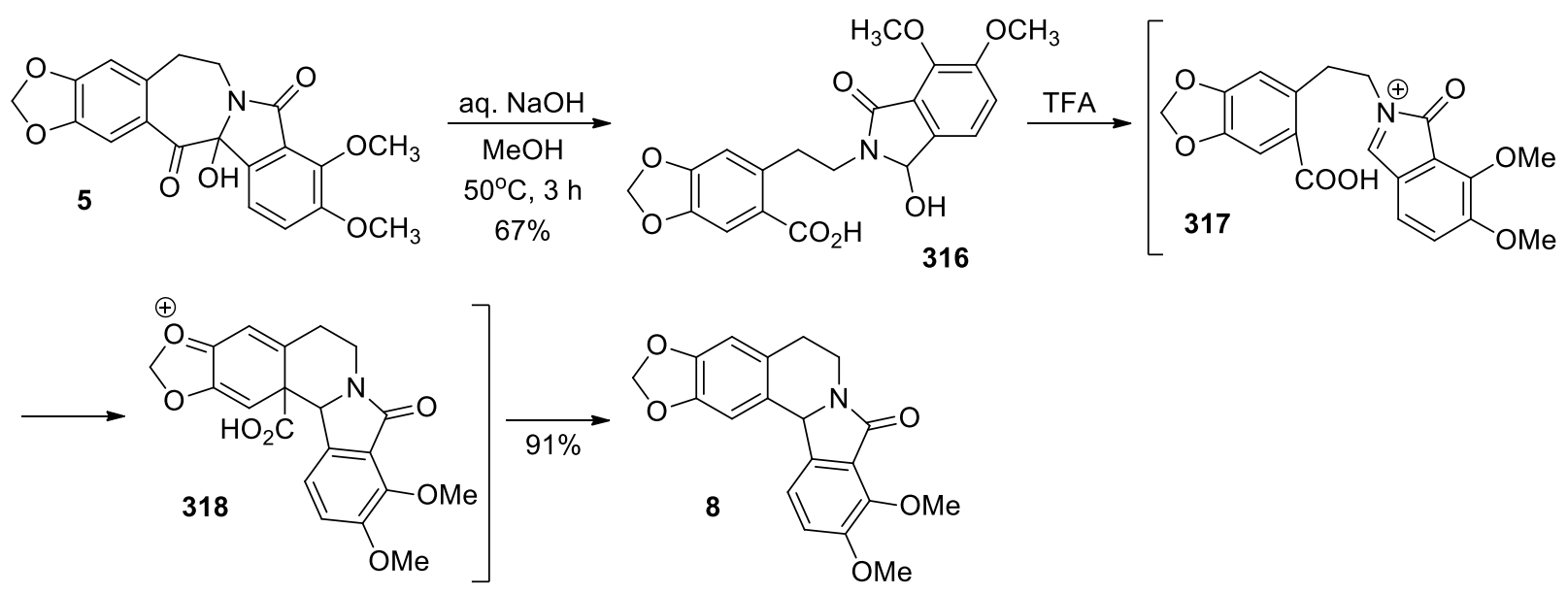

Scheme 105. Conversion of chilenine to nuevamine.

\subsection{Reactions in acid}

On the other hand, treatment of chilenine with strong acid at elevated temperatures leads to ring contraction and amide bond scission (Scheme 106). ${ }^{1}$ When chilenine (5) is heated at reflux in $35 \%$ sulfuric acid, the reaction is understood to proceed through initial formation of the homoannular $\alpha$-ketocarbinolamide 7. As an aside, this is significant because treatment of the homoannular $\alpha$-ketocarbinolamide with ammonium hydroxide incites the reverse reaction. ${ }^{6,61}$ The hydroxyl group is lost to give the violet iminium salt 319, and the lactam is subsequently cleaved. Sodium borohydride was then used to reduce the $\alpha$-ketoiminium ion (320) to the corresponding amino alcohol, which spontaneously lactonized. Finally, methylation with excess methyl iodide yielded $\beta$-hydrastine methiodide (321).

Chilenine is, however, amenable to nucleophilic exchange much like its homoannular counterpart. Treatment with methanol in $>28 \%$ sulfuric acid induces the exchange. ${ }^{61}$ Alternatively, treatment with $10 \%$ methanolic hydrogen chloride accomplishes the same result (Scheme 107). ${ }^{6}$ The drastic color change that occurs during the reaction suggests the intermediacy of iminium ion $\mathbf{1 7}$, which is blue-black in color. 

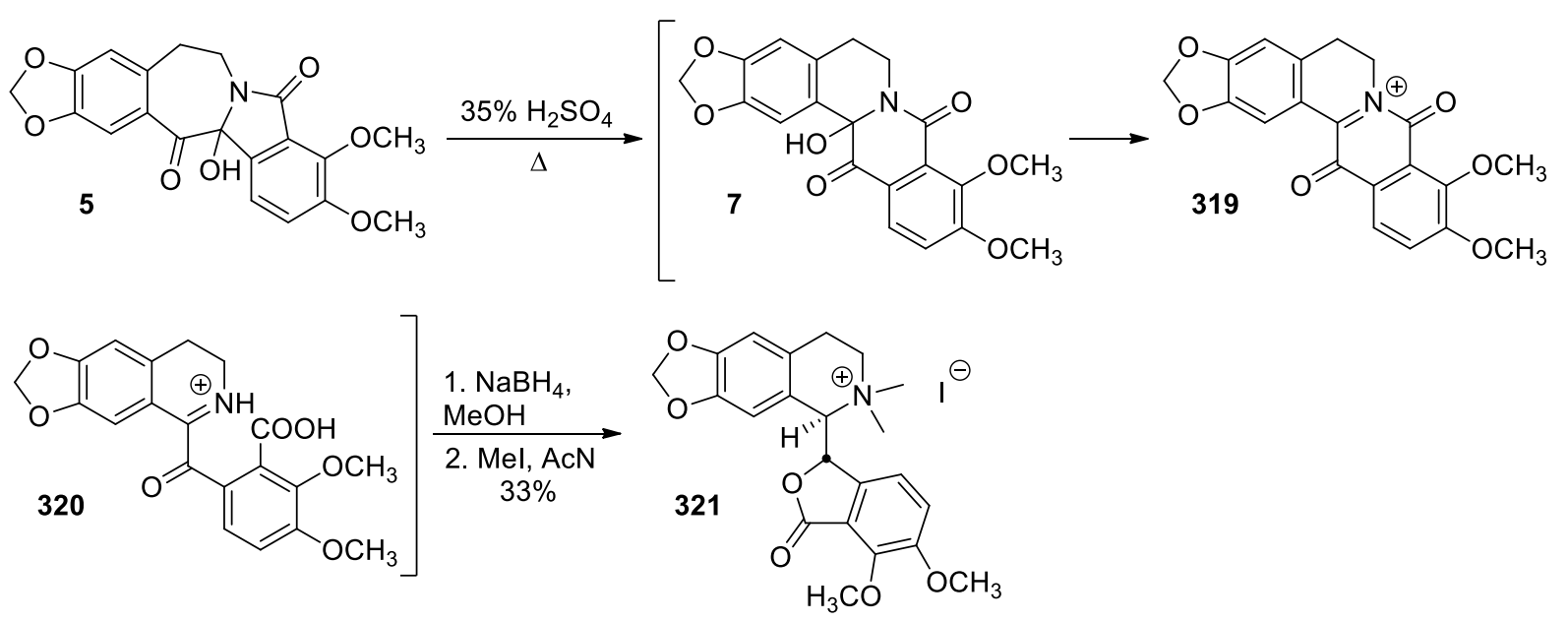

Scheme 106. Ring contraction and amide bond scission of chilenine.<smiles>COc1ccc2c(c1OC)C(=O)N1CCc3cc4c(cc3C(=O)C21O)OCO4</smiles>

Scheme 107. Nucleophilic exchange with methanol.

Nucleophilic exchange also happens readily in acetic anhydride and pyridine upon standing at room temperature (Scheme 108). Given the mild reaction conditions and the tertiary nature of the hydroxyl group, it is presumed that the same iminium ion (17) is an intermediate and that it adds acetate to yield $\mathbf{3 2 3}$. $^{1}$

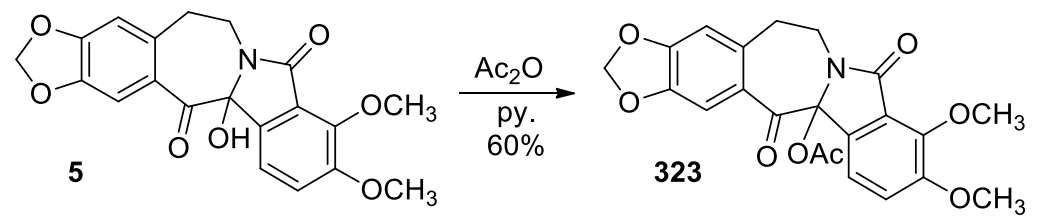

Scheme 108. Nucleophilic exchange with acetic anhydride.

\subsection{Reactions with reducing agents}

Mild reducing conditions convert the ketone of chilenine or its C13 methoxy analogue to the cis or trans-diol or $\alpha$-hydroxyether, respectively. Conditions that preclude intramolecular participation lead to the cis products, while those that allow intramolecular participation result in trans products. ${ }^{1}$ For instance, when chilenine is treated with sodium borohydride in methanol the trans-diol (324) is the predominant product (Scheme 109). It is probable that the C13 hydroxyl 
group of chilenine complexes with borohydride and that intramolecular addition of hydride to the carbonyl then necessarily occurs from the same side as the hydroxyl group affording the trans product. Acidification of the aqueous layers during workup provides the cis-diol 226 as the minor product. The necessity of acidification to isolate the cis-diol suggests that it was present as the cyclic borate ester.

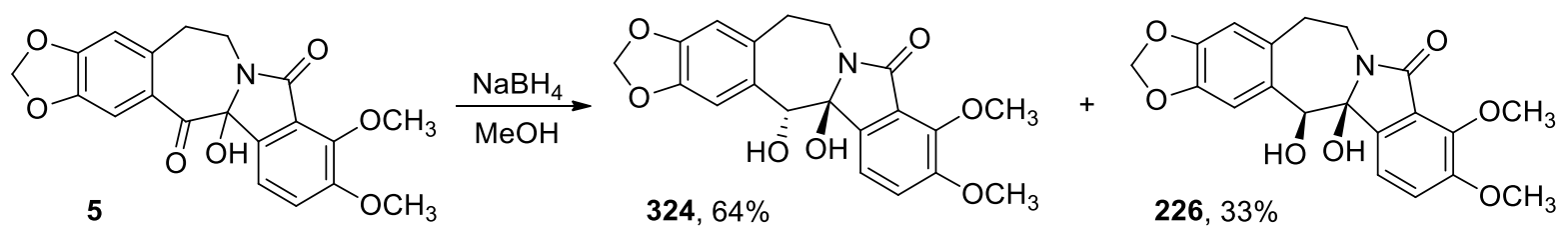

Scheme 109. Sodium borohydride reduction of chilenine.

On the other hand, the C13 methoxy analogue of chilenine (322) undergoes reduction in the same conditions to provide the cis-hydroxyether $\mathbf{3 2 5}$ as the major product (Scheme 110). In this case, intramolecular participation is precluded, so attack of hydride simply occurs from the less hindered face, opposite the methoxy group. A comparatively small amount of the transhydroxyether (326) was isolated as a minor product.

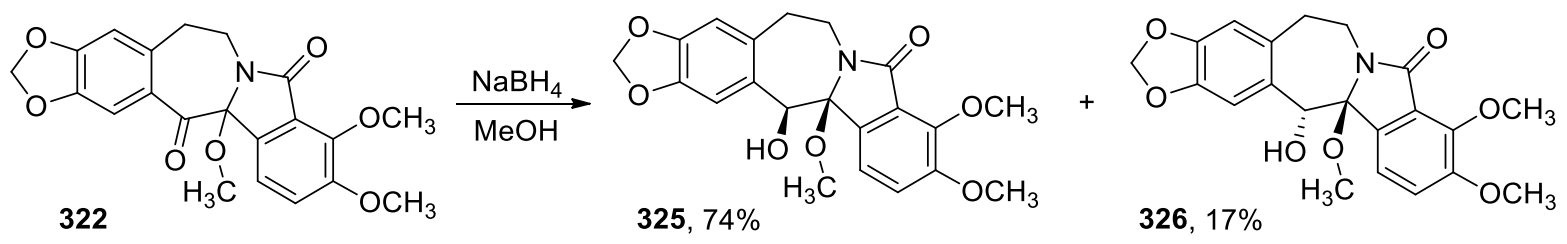

Scheme 110. Sodium borohydride reduction of the C13 methoxy analogue of chilenine.

If mild reduction is followed immediately by acetylation, elimination of the angular hydroxyl group is observed, and the product is acetoxyenamide 227, which happens to be highly fluorescent (Scheme 111). ${ }^{61}$

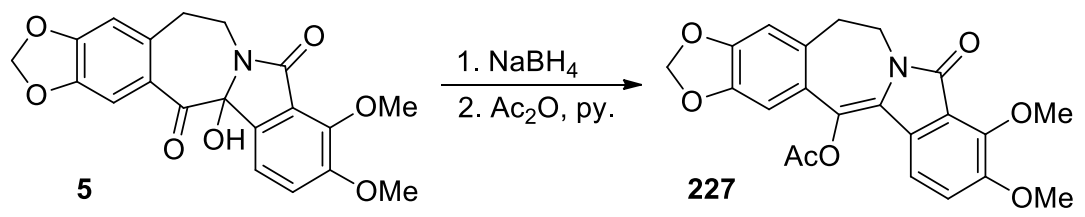

Scheme 111. Conversion of chilenine to an acetoxyenamide.

If the intermediate trans and cis-diols are first isolated and subjected separately to acetic anhydride in pyridine, the cis-diol 226 undergoes acetylation and elimination much more readily (i.e. without heating) due to the trans orientation of the angular hydroxyl group and the 
neighboring hydrogen. The trans-diol $\mathbf{3 2 4}$ requires stronger conditions to undergo this transformation (i.e. heating at $60{ }^{\circ} \mathrm{C}$ for $18 \mathrm{~h}$ ). ${ }^{1}$

Dissolving metal reduction of chilenine (5) in strong acid results in the loss of the C13 and C14 oxygenation yielding lennoxamine (11) as the major product along with a small amount of enaminol 327 (Scheme 112). ${ }^{1,61}$<smiles>COc1ccc2c(c1OC)C(=O)N1CCc3cc4c(cc3C(=O)[C@@]21C)OCO4</smiles>

Scheme 112. Dissolving metal reduction of chilenine.

\subsection{Hofmann elimination}

When chilenamine (15), also known as Schöpf's base VI, was quaternized with methyl bromide, the resultant methobromide (328) could be subjected to Hofmann elimination to yield a mixture of styrene $\mathbf{3 2 9}$ and the tetrahydrobenzazecine $\mathbf{3 3 0}$ (Scheme 113). ${ }^{79}$
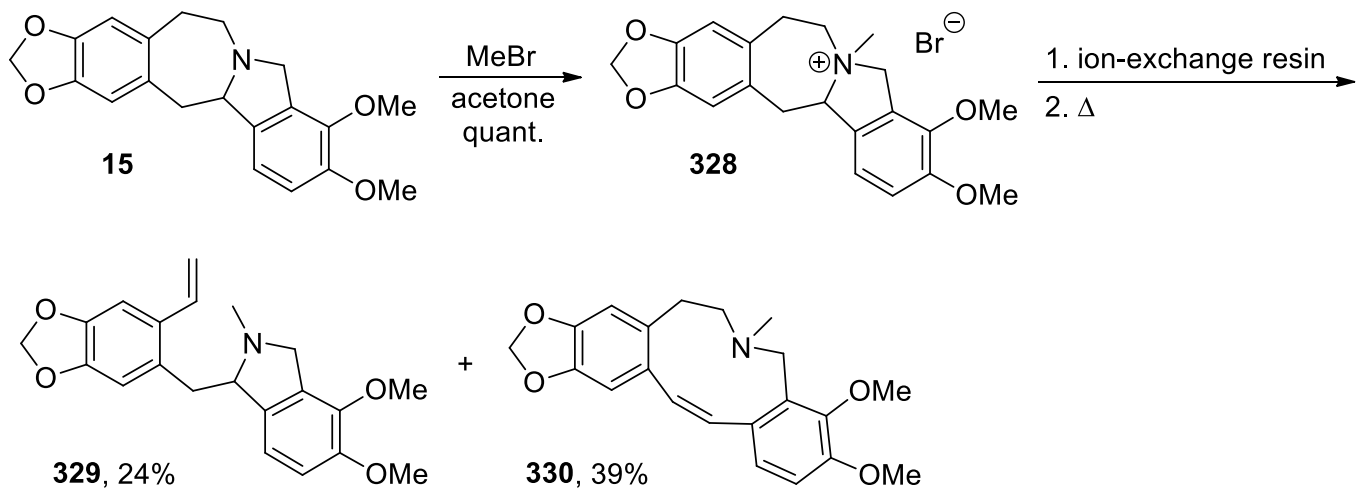

Scheme 113. Hofmann degradation of chilenamine.

\section{Conclusions}

Over a period of nearly 50 years, the aporhoeadanes have continually spurred advances in synthetic heterocyclic chemistry. Despite a relative lack of biological activity, these small, sometimes densely functionalized, alkaloids have prompted a myriad of strategically unique synthetic approaches. Given the close relationship of the aporhoeadanes to a variety of other alkaloids, it is likely that these syntheses will continue to be useful, especially as new methods to interconvert these and other heterocycles are unveiled. 


\section{References}

1 Moniot, J. L.; Hindenlang, D. M.; Shamma, M. J. Org. Chem. 1979, 44, 4347-4351.

2. Walterová, D.; Šantavý, F. Collect. Czech. Chem. Commun. 1968, 33, 1623-1625.

3. Fajardo, V.; Elango, V.; Cassels, B.; Shamma, M. Tetrahedron Lett. 1982, 23, 39-42.

4. Maung, T.-W. U.S. Pat. Appl. 20070298132 A1. 2007.

5. Valencia, E., Weiss, I.; Firdous, S.; Freyer, A. J.; Shamma, M. Tetrahedron 1984, 40, 39573962.

6. Moniot, J. L.; Hindenlang, D. M.; Shamma, M. J. Org. Chem. 1979, 44, 4343-4346.

7. Valencia, E.; Freyer, A. J.; Shamma, M.; Fajardo, V. Tetrahedron Lett. 1984, 25, 599-602.

8. Fajardo, V.; Elango, V.; Chattopadhgay, S.; Jackman, L.; Shamma, M.; Tetrahedron Lett. 1983, 24, 155-158.

9. Okunade, A. L.; Hufford, C. D.; Richardson, M. D.; Peterson, J. R.; Clark, A. M. J. Pharm. Sci. 1994, 83, 404-406.

10. Valencia, E.; Fajardo, V.; Freyer, A. J.; Shamma, M. Tetrahedron Lett. 1985, 26, 993-996.

11. Hocquemiller, R.; Cavé, A.; Fournet, A. J. Nat. Prod. 1984, 47, 539-540.

12. Slavík, J. Chem. Listy 1958, 52, 1957-1964.

13. Slavík, J. Collect. Czech. Chem. Commun. 1959, 24, 2506-2515.

14. Pfeifer, S.; Mann, I. Pharmazie 1965, 20, 643-649.

15. Summarized in Shamma, M. The Isoquinoline Alkaloids: Chemistry and Pharmacology; Academic Press: New York, 1972.

16. Klötzer, W.; Teitel, S.; Brossi, A. Monatsh. Chem. 1972, 103, 1210-1212.

17. Klötzer, W.; Teitel, S.; Blount, J. F.; Brossi, A. J. Am. Chem. Soc. 1971, 93, 4321-4323.

18. Klötzer, W.; Teitel, S., Brossi, A. Helv. Chim. Acta 1971, 54, 2057-2059.

19. Teitel, S.; Klötzer, W.; Borgese, J.; Brossi, A. Can. J. Chem. 1972, 50, 2022-2024.

20. Moody, C. J.; Warrellow, G. J. Tetrahedron Lett. 1987, 28, 6089-6092.

21. Moody, C. J.; Warrellow, G. J. J. Chem. Soc., Perkin Trans. I 1990, 2929-2936.

22. Yasuda, S.; Sugimoto, Y.; Mukai, C.; Hanaoka, M. Heterocycles 1990, 30, 335-337.

23. Fuchs, J. R.; Funk, R. L. Org. Lett. 2001, 3, 3923-3925.

24. Honda, T.; Sakamaki, Y. Tetrahedron Lett. 2005, 46, 6823-6825.

25. Zhao, Y.-F.; Xi, S.-K.; Song, A.-T.; Ji, G.-J. J. Org. Chem. 1984, 49, 4549-4551.

26. Fuwa, H.; Sasaki, M. Org. Biomol. Chem. 2007, 5, 1849-1853.

27. Fuwa, H.; Sasaki, M. Heterocycles 2008, 76, 521-539.

28. Kim, G.; Lee, K. Y.; Yoo, C.-H. Synth. Commun. 2008, 38, 3251-3259.

29. Onozaki, Y.; Kurono, N.; Senboku, H.; Tokuda, M.; Orito, K. J. Org. Chem. 2009, 74, 54865495.

30. Scartoni, V.; Marsili, A. Tetrahedron Lett. 1969, 10, 887-890.

31. Marsili, A.; Scartoni, V. Tetrahedron Lett. 1968, 9, 2511-2516.

32. Bernhard, H.; Snieckus, V. Tetrahedron Lett. 1971, 12, 4867-4870.

33. Bernhard, H.; Reed, J. N.; Snieckus, V. J. Org. Chem. 1977, 42, 1093-1095. 
34. Ishibasji, H.; Kawanami, H.; Iriyama, H.; Ikeda, M. Tetrahedron Lett. 1995, 36, 6733-6734.

35. Ishibashi, H.; Kawanami, H.; Ikeda, M. J. Chem. Soc., Perkin Trans. I 1997, 817-821.

36. Montaño, R. G.; Zhu, J. Chem. Commun. 2002, 20, 2448-2449.

37. Kim, G.; Kim, J. H.; Kim, W.; Kim, Y. A. Tetrahedron Lett. 2003, 44, 8207-8209.

38. Trojanek, J.; Koblicova, Z.; Vesley, Z.; Suchan, V.; Holubek, J. Coll. Czech. Chem. Commun. 1975, 40, 681.

39. Crabb, T. A.; Newton, R. F.; Jackson, D. Chem. Rev. 1971, 71, 109.

40. Comins, D. L.; Schilling, S.; Zhang, Y. Org. Lett. 2005, 7, 95-98.

41. Kametani, T.; Honda, T.; Inoue, H.; Fukumoto, K. J. Chem. Soc., Perkin Trans. I 1976, 1221.

42. Suzuki, T.; Takabe, K.; Yoda, H. Synlett 2006, 20, 3407-3410.

43. Scartoni, V.; Fiaschi, R.; Catalano, S.; Morelli, I.; Marsili, A. J. Chem. Soc., Perkin Trans. I 1979, 1547-1551.

44. King, C. R. The Synthesis of Aporhoeadane Alkaloid Analogs. Ph.D. Thesis, University of Maryland, College Park, MD. 1986.

45. Barili, P. L.; Fiaschi, R.; Napolitano, E.; Pistelli, L.; Scartoni, V.; Marsili, A. J. Chem. Soc., Perkin Trans. I 1981, 1654-1658.

46. Napolitano, E.; Spinelli, G.; Fiaschi, R.; Marsili, A. J. Chem. Soc., Perkin Trans. I 1986, 785-787.

47. Koseki, Y.; Nagasaka, T. Chem. Pharm. Bull. 1995, 43, 1604-1606.

48. Couture, A.; Deniau, E.; Grandclaudon, P.; Hoarau, C. Tetrahedron 2000, 56, 1491-1499.

49. Couty, S.; Meyer, C.; Cossy, J. Tetrahedron Lett. 2006, 47, 767-769.

50. Couty, S.; Liegault, B.; Meyer, C.; Cossy, J. Tetrahedron 2006, 62, 3882-3895.

51. Mazzocchi, P. H.; King, C. R.; Ammon, H. L. Tetrahedron Lett. 1987, 28, 2473-2476.

52. Kessar, S. V.; Singh, T.; Vohra, R. Tetrahedron Lett. 1987, 28, 5323-5326.

53. Kessar, S. V.; Singh, T.; Vohra, R. Indian J. Chem. Sect. B 1991, 30B, 999-1005.

54. Fang, F. G.; Danishefsky, S. J. Tetrahedron Lett. 1989, 30, 2747-2750.

55. Padwa, A.; Beall, L. S.; Eidell, C. K.; Worsencroft, K. J. J. Org. Chem. 2001, 66, 24142421.

56. Yoda, H.; Nakahama, A.; Koketsu, T.; Takabe, K. Tetrahedron Lett. 2002, 43, 4667-4669.

57. Yoda, H.; Inoue, K.; Ujihara, Y.; Mase, N.; Takabe, K. Tetrahedron Lett. 2003, 44, $9057-$ 9060.

58. Schöpf, C.; Schweikert, M. Chem. Ber. 1965, 98, 2566-2571.

59. Shamma, M. The Isoquinoline Alkaloids: Chemistry and Pharmacology; Academic Press: New York. 1972.

60. Leonard, N. J.; Fuller, G.; Dryden, Jr., H. L. J. Am. Chem. Soc. 1953, 75, 3727-3730 and references cited therein.

61. Shamma, M.; Moniot, J. L.; Hindenlang, D. M. Tetrahedron Lett. 1977, 18, 4273-4276.

62. Elango, V.; Shamma, M. J. Org. Chem. 1983, 48, 4879-4881.

63. Kessar, S. V.; Singh, T.; Vohra, R. Indian J. Chem. Sect. B 1991, 30B, 299-301. 
64. Marsden, R.; MacLean, D. B. Can. J. Chem. 1984, 62, 1392-1399.

65. Edwards, G. A.; Perkin, W. H.; Stoyle, F. W. J. Chem. Soc., Trans. 1925, 127, 195-199.

66. Lamas, C.; Saá, C.; Castedo, L.; Domínguez, D. Tetrahedron Lett. 1992, 33, 5653-5654.

67. Rodríguez, G.; Cid, M. M.; Saá, C.; Castedo, L.; Domínguez, D. J. Org. Chem. 1996, 61, 2780-2782.

68. Rodríguez, G.; Castedo, L.; Domínguez, D.; Saá, C. Tetrahedron Lett. 1998, 39, 6551-6554.

69. Tomasevich, L. L.; Kennedy, N. M.; Zitelli, S. M.; Hull, II, R. T.; Gillen, C. R.; Lam, S. K.; Baker, N. J.; Rohanna, J. C.; Conley, J. M.; Guerra, M. L.; Starr, M. L.; Sever, J. B.; Carroll, P. J.; Leonard, M. S. Tetrahedron Lett. 2007, 48, 599-602.

70. Piko, B. E.; Keegan, A. L.; Leonard, M. S. Tetrahedron Lett. 2011, 52, 1981-1982.

71. Ruchirawat, S.; Lertwanawatana, W.; Thianpatanagul, S.; Cashaw, J. L.; Davis, V. E. Tetrahedron Lett. 1984, 25, 3485-3488.

72. Sahakitpichan, P.; Ruchirawat, S. Tetrahedron. 2004, 60, 4169-4172.

73. Ruchirawat, S.; Sahakitpichan, P. Tetrahedron Lett. 2000, 41, 8007-8010.

74. Chiefari, J.; Janowski, W.; Prager, R. Tetrahedron Lett. 1986, 27, 6119-6122.

75. Koseki, Y.; Kusano, S.; Sakata, H.; Nagasaka, T. Tetrahedron Lett. 1999, 40, 2169-2172.

76. Koseki, Y.; Katsura, S.; Kusano, S.; Sakata, H.; Sato, H.; Monzene, Y.; Nagasaka, T. Heterocycles 2003, 59, 527-540.

77. Taniguchi, T.; Iwasaki, K.; Uchiyama, M.; Tamura, O.; Ishibashi, H. Org. Lett. 2005, 7, 4389-4390.

78. Kim, G.; Jung, P.; Tuan, L. A. Tetrahedron Lett. 2008, 49, 2391-2392.

79. Teitel, S.; Borgese, J.; Brossi, A. Helv. Chim. Acta 1973, 56, 553-557.

\section{Author's Biography}

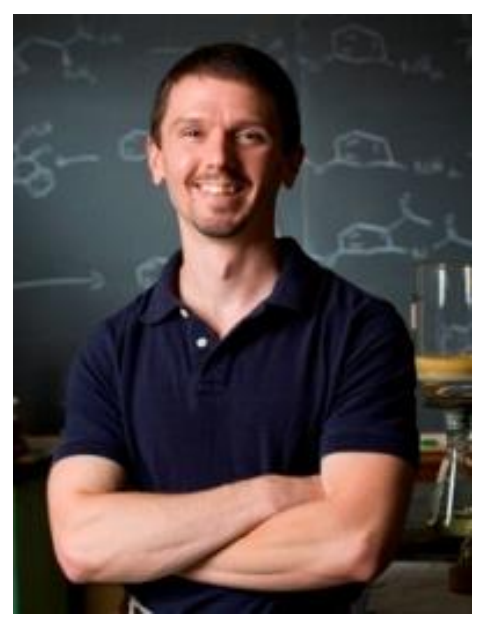

Michael Leonard earned his B.A. in Chemistry from Goucher College (Baltimore, MD) in 1998 under the direction of Professor David E. Horn with whom he conducted research on the "Synthesis of symmetrically substituted 1,4-bis[(aminoalkyl)amino]-5,8-dimethylanthracene- 
9,10-diones" (published in this journal). Upon graduating from Goucher, he transitioned to the University of Pennsylvania for his doctoral studies in the laboratory of Professor Madeleine M. Joullié. His thesis focused on "I. Total Synthesis and Application of Fluorophore-Labeled Didemnin and Tamandarin Analogues; II. Synthetic Approaches to Pondaplin and Analogues; III. Yohimbanones: Formation and Reaction via Novel Rearrangements." After obtaining his Ph.D. in 2003, he joined the faculty of Washington \& Jefferson College, where is currently Associate Professor and Chair of Chemistry. 